\title{
Italian guidelines for primary headaches: 2012 revised version
}

\author{
Paola Sarchielli Franco Granella $\cdot$ Maria Pia Prudenzano $\cdot$ Luigi Alberto Pini - Vincenzo Guidetti • \\ Giorgio Bono · Lorenzo Pinessi - Massimo Alessandri · Fabio Antonaci - Marcello Fanciullacci • \\ Anna Ferrari • Mario Guazzelli · Giuseppe Nappi - Grazia Sances • Giorgio Sandrini · Lidia Savi • \\ Cristina Tassorelli · Giorgio Zanchin
}

(C) The Author(s) 2012. This article is published with open access at Springerlink.com

\begin{abstract}
The first edition of the Italian diagnostic and therapeutic guidelines for primary headaches in adults was published in J Headache Pain 2(Suppl. 1):105-190 (2001). Ten years later, the guideline committee of the Italian Society for the Study of Headaches (SISC) decided it was time to update therapeutic guidelines. A literature search was carried out on Medline database, and all articles on
\end{abstract}

On behalf of the Ad Hoc Committee of the Italian Society for the Study of Headaches for the Guidelines of Primary Headaches in adults.

M. Guazzelli: Deceased.

P. Sarchielli $(\bowtie)$

Headache Centre, Neurologic Clinic, University of Perugia,

Perugia, Italy

e-mail: paola.sarchielli@gmail.com

F. Granella

Neurologic Clinic, University of Parma, Parma, Italy

\section{P. Prudenzano}

Headache Centre, Neurologic Clinic "L. Amaducci",

University of Bari, Bari, Italy

L. A. Pini - A. Ferrari

Headache Centre, University of Reggio Emilia and Modena, Modena, Italy

V. Guidetti

Department of Child and Adolescent Neurology,

Psychiatry and Rehabilitation, "Sapienza",

University of Rome, Rome, Italy

\section{G. Bono}

Neurology Unit, Ospedale di Circolo e Fondazione Macchi, University of Insubria, Varese, Italy

L. Pinessi - L. Savi

Neurologia II, Department of Neurology, Headache Centre, University of Turin, Turin, Italy primary headache treatments in English, German, French and Italian published from February 2001 to December 2011 were taken into account. Only randomized controlled trials (RCT) and meta-analyses were analysed for each drug. If RCT were lacking, open studies and case series were also examined. According to the previous edition, four levels of recommendation were defined on the basis of levels of evidence, scientific strength of evidence and clinical effectiveness. Recommendations for symptomatic and prophylactic treatment of migraine and cluster headache were therefore revised with respect to previous 2001 guidelines

\section{Alessandri}

Headache Centre, Department of Internal Medicine,

Misericordia Hospital, Grosseto, Italy

F. Antonaci · G. Nappi · G. Sances · G. Sandrini · C. Tassorelli Headache Science Centre, C. Mondino National Institute of Neurology Foundation IRCCS, Pavia, Italy

F. Antonaci - G. Sandrini - C. Tassorelli

Department of Public Health, Neuroscience,

Experimental and Forensic Medicine,

University of Pavia, Pavia, Italy

M. Fanciullacci

Florence, Italy

M. Guazzelli

Department of Psychiatry, Neurobiology,

Pharmacology and Biotechnologies,

University of Pisa, Pisa, Italy

G. Zanchin

Department of Neurosciences, Headache Centre,

University of Padua, Padua, Italy 
and a section was dedicated to non-pharmacological treatment. This article reports a summary of the revised version published in extenso in an Italian version.

Keywords Guidelines · Primary headaches . Symptomatic and prophylactic treatment - Pharmacological and non pharmacological

\section{Introduction and methodology}

Ten years after the first edition (2001), the Italian Society for the Study of Headaches (SISC) decided to update the diagnostic and therapeutic guidelines for primary headaches in adults, not only including migraine, but also tension-type headache, trigeminal-autonomic cephalgias (TACs) and other primary headaches.

This concise version synthetically reports only treatment aspects (including non-pharmacological treatments and interventions), referring to the International Headache Society classification (ICHD-II, 2004) and its Appendix for diagnostic criteria. Therapeutic approach to other primary headaches has already been published by the members of

Table 1 Levels of evidence

Level A: Two or more clinically controlled, randomize, doubleblind studies carried out according to good clinical practice (GCP) versus placebo or versus an active drug for which there is proven evidence of efficacy

Level B: One clinically controlled study according to GCP or more than one controlled case-control study/ies or Cohort study/ ies

Level C: Favourable judgement of two-thirds of the Ad Hoc Committee, historical controls, non-randomized studies, case reports

Table 2 Scientific strength of evidence

\begin{tabular}{c}
\hline$++\quad$ The difference in the parameters of efficacy registered in \\
studies compared with placebo or another active drug has a \\
high level of significance $(p<0.01 ; p<0.001 ;$ \\
$p<0.0001)$. Adverse events are rare or occasional and not \\
severe \\
$++\quad$ The difference in the parameters of efficacy registered in \\
studies reaches the minimum level of significance \\
$(p<0.05)$ or the minimum clinically significant level \\
(difference in the parameters $<15 \%)^{\text {a }}$ \\
The difference in the efficacy parameters between the study \\
drug and placebo or another active drug is not statistically \\
significant \\
The drug is not efficacious or is characterized by severe \\
adverse events
\end{tabular}

${ }^{a}$ Even drugs for which the difference in the efficacy parameters compared with placebo or another active drug is higher than the minimum level of statistical significance, but have frequent, yet no severe adverse events are included in this group
Other Primary Headaches Subcommittee and therefore is not included in this updated version of Italian Primary Headaches Guidelines [2-5].

A literature search was performed on Medline database, considering all the articles on primary headache diagnosis and treatment published in English, German, French and Italian from February 2001 to December 2011. Only randomized controlled trials (RCT) and meta-analyses were analysed for each drug, if available. Lacking RCT, open studies and case series were also examined.

Four levels of recommendation were defined on the basis of the levels of evidence, the scientific strength of evidence and clinical effectiveness (Tables 1, 2, 3, 4).

Following the tradition, the management of primary headaches is divided into acute/symptomatic (to relieve headache attack) and preventive (to reduce frequency and intensity of headache attacks) treatment.

\section{Migraine}

Symptomatic treatment of migraine attacks alone is recommended when attacks are non-disabling or, if disabling, they occur $<4$ days per month. Vice versa, a preventive treatment is recommended when disabling migraine attacks are $\geq 4$ per

Table 3 Assessment of the clinical effectiveness of treatments

\begin{tabular}{|c|c|}
\hline \multicolumn{2}{|c|}{ Symptomatic drugs } \\
\hline+++ & $\begin{array}{l}\text { The majority }(\geq 60 \%) \text { of the patients had partial or total } \\
\text { relief of headache. More than } 30 \% \text { of them were pain } \\
\text { free }\end{array}$ \\
\hline++ & $\begin{array}{c}\text { Many patients (from } \geq 40 \text { to }<60 \% \text { ) had partial or total relief } \\
\text { of headache, or } 20-29 \% \text { of the patients were pain free }\end{array}$ \\
\hline+ & $\begin{array}{l}\text { Some of the patients (from } 20 \text { to }<40 \% \text { ) had partial or total } \\
\text { relief of headache. Up to } 20 \% \text { were pain free }\end{array}$ \\
\hline 0 & $\begin{array}{l}\text { Less than } 20 \% \text { of the treated patients received a clinical } \\
\text { benefit }\end{array}$ \\
\hline$?$ & $\begin{array}{l}\text { The members of the Ad Hoc Committee were unable to } \\
\text { express any judgement on effectiveness based on their } \\
\text { personal clinical impressions }\end{array}$ \\
\hline \multicolumn{2}{|c|}{ Preventive drugs } \\
\hline+++ & $\begin{array}{l}\text { The majority ( } \geq 50 \%) \text { of the patients experienced a } \\
\text { reduction, of at least } 50 \% \text {, in the frequency (and } \\
\text { intensity) of attacks }\end{array}$ \\
\hline++ & $\begin{array}{l}\text { Many patients (from } \geq 30 \text { to }<50 \% \text { ) experienced a } \\
\text { reduction, of at least } 50 \% \text {, in the frequency (and } \\
\text { intensity) of attacks }\end{array}$ \\
\hline+ & $\begin{array}{l}\text { Some of the patients (from } \geq 20 \text { to }<30 \% \text { ) experienced a } \\
\text { reduction, of at least } 50 \% \text {, in the frequency (and } \\
\text { intensity) of attacks }\end{array}$ \\
\hline 0 & $\begin{array}{l}\text { Less than } 20 \% \text { of the treated patients received a clinical } \\
\text { benefit }\end{array}$ \\
\hline$?$ & $\begin{array}{l}\text { The members of the Ad Hoc Committee were unable to } \\
\text { express any judgement on effectiveness based on their } \\
\text { personal clinical impressions }\end{array}$ \\
\hline
\end{tabular}


Table 4 Levels of recommendation for the pharmacological treatment of primary headaches

\section{Level I Drugs with high efficacy supported by statistically significant data (evidence of at least two controlled, randomized studies versus placebo or versus active drugs of proven efficacy) or very high clinical benefit for patients (clinical effectiveness +++ ) and with no severe adverse events}

Level II Drugs whose value of efficacy is statistically of lower significance compared to drugs of group I and with a less significant clinical benefit for patients (clinical effectiveness ++ ) and no severe adverse events

Level III Drugs showing efficacy from a statistical point of view but not from a clinical point of view (contrasting results or evidence is not conclusive). The drugs belonging to this group were further subdivided into two subgroups:

(a) Drugs with no severe adverse events

(b) Unsafe drugs or with complex indications for use (e.g. special diets) or important pharmacological interactions

Level IV Drugs of proven efficacy but with frequent and severe adverse events or drugs whose efficacy has not been proven from a clinical or statistical point of view (no difference with respect to placebo). Drugs with unknown clinical patient benefit or statistical significance of efficacy (data unavailable or insufficient)

month or, if $<4$ per month, in the case of poor response to symptomatic treatment. As in other primary headaches, a headache diary is a fundamental tool for monitoring attack frequency, duration and severity [6]. It is required when deciding the best treatment to suggest and for monitoring the effectiveness of symptomatic and prophylactic prescribed treatment.

Acute attack treatment

1. A stratified approach, consisting in a different choice of initial treatment based on the severity of the attack (migraine-specific drugs, i.e. triptans, for moderate/ severe attacks and non-specific drugs like analgesics and non-steroidal anti-inflammatory drugs (NSAIDs) for mild/moderate attacks) is recommended [7].

2. The most appropriate drug should be taken at the lowest useful dosage as early as possible after the attack begins.

3. As a rule, preparations with only one active principle should be preferred.

4. It is convenient to provide some alternatives for attacks of different severity.

5. Rescue drugs should be provided in case of first-choice medication failure.

Symptomatic drugs

Drugs for migraine attacks include triptans, analgesics (NSAIDs), ergot derivatives and antiemetics.
Triptans

Indications They are indicated for the treatment of moderate or severe attacks (level of recommendation I). Efficacy RCT have demonstrated the efficacy of triptans, not only for headache but also for accompanying symptoms and functional disability [8-19] (Table 2). The consistency of efficacy of triptans in the treatment of multiple attacks and in long-term treatment (no development of tachyphylaxis) has also been shown [8, 9, 20]. They were also effective in menstrual-related migraine attacks [21]. Headto-head studies did not establish the superiority of one triptan over the others [22]. Preference trials suggest that no ideal triptan exists for all patients, but the treatment must be tailored taking into account the characteristics of each patient and of the attacks [23-26]. Headache recurrence occurs in about 25-40\% of patients [8, 27, 28]. Observations When a triptan is administered early at the beginning of attack, it has a greater efficacy [29-31]. About 25-35\% of patients do not respond to a particular triptan, in which case other triptans can be tried [32-37]. In the case of an unsatisfactory response to a triptan or headache recurrence, a NSAID can be used [38]. Sumatriptan is available in all formulations (subcutaneous, tablet, nasal spray, suppository); subcutaneous sumatriptan is the most effective drug in the class [39-41]. Rizatriptan and zolmitriptan are available in rapid-dissolving formulations (RPD) which have an effectiveness similar to that of tablet formulations of the same drugs at the same dosages [42, 43]. Pharmacokinetics findings do not show higher blood levels reached at shorter times for RPD formulations. The latter can, however, be useful because they are easier to use without need of water, particularly when moderate or severe nausea is present. Naratriptan is not available in Italy. In some studies oral triptans at lower dosages have not demonstrated to be superior to some NSAIDs, simple or combination analgesics [21]. Oral triptan formulations are superior to oral ergotamine which has a low bioavailability $(<1 \%)$. Ergotamine and dihydroergotamine have an efficacy similar to that of triptans but induce more frequent adverse events [44-47]. The excessive use of triptans ( $\geq 10$ days a month) exposes the patient to the risk of migraine chronification and should be avoided [48]. The concurrent use of triptans and NSAIDs seems to have a greater efficacy compared with that of triptans alone and is associated to lower headache recurrence [41-52]. Side effects are mostly mild-to-moderate, of short duration (10-15 $\mathrm{min}$ ) and include triptan syndrome (chest and neck tightness, chest pain) in $4-5 \%$ in patients treated with s.c. sumatriptan and 2-4\% with the oral formulation, fatigue, somnolence, dizziness and facial flush [6, 204-207]. Cardio- and cerebrovascular severe adverse events (myocardial infarction, ictus), without an established cause-effect 
relationship, were rarely reported. ECG modifications are also rarely reported [53]. Dystonic crises, akathisia, euphoria, can also rarely occur. Contraindications to triptans are uncontrolled blood hypertension, coronary artery disease, history of ischemic stroke, pheripheral artery disease, pregnancy and lactation and age $>65$ years.

\section{Warnings}

Pregnancy and breastfeeding From findings obtained by pregnancy registries, a greater number of preterm newborns or newborns with low birth-weight due to the use of sumatriptan during pregnancy have been described. In the case of repeated administration of sumatriptan in the first trimester there is no increased risk of newborn malformations but the sumatriptan use in the second and third trimester is associated with atonic uterus and bleeding $>500 \mathrm{ml}$ at delivery. Information on the safety of triptans during breastfeeding is limited but reassuring, because the minimal quantities secreted with milk are insufficient to induce adverse events to the child [54]. According to Italian Health Ministry Regulatory Agency the use of triptans is not recommended under 18 years of age with the exception of sumatriptan nasal spray $10 \mathrm{mg}$ and zolmitriptan nasal spray $2.5 \mathrm{mg}$, which may be used in patients over 12 years of age [55, 56]. Also, according to this Agency, the use of triptans after 65 years of age is not recommended. They can be used only with a therapeutic plan approved by an Ethical Committee and with informed consent [57].

\section{Pharmacological interactions}

Ergot derivates A triptan can be used at least $24 \mathrm{~h}$ after ergot derivate administration. After taking a triptan it is necessary to wait at least $6 \mathrm{~h}$ before taking an ergot derivate.

SSRI antidepressants A serotoninergic syndrome can occur in the case of contemporary use of triptans and consists in motor incoordination, marked asthenia and hyperreflexia. MAO-A inhibitors They should be suspended at least 2 weeks before starting triptan treatment. Propranolol increases the concentration of rizatriptan. In the case of concomitant administration of propranolol, rizatriptan should be used at the dosage of $5 \mathrm{mg}$ for the single attack, at the maximum daily dosage of $10 \mathrm{mg}$. After taking propranolol, it is necessary to wait at least $2 \mathrm{~h}$ before taking rizatriptan. Drugs which are metabolized via CYP450 Eletriptan, rizatriptan and zolmitriptan may interact with drugs metabolized via CYP450 such as oral contraceptives and antimicotics. The clinical relevance of these observations needs to be clarified [58].

\section{NSAIDs and analgesics}

Indications They are indicated for the treatment of mild or moderate attacks or when triptans are contraindicated or ineffective [59, 60]. Efficacy The most consistent evidence of efficacy is available for paracetamol, acetylsalicylic acid (ASA), lysine acetylsalicylate, naproxen sodium, ibuprofen, diclofenac sodium and potassium, metamizole and ketorolac, whereas the evidence of efficacy for other NSAIDs is more limited [61-65]. Head-to-head studies have not shown a clearcut superiority of a NSAID over another. Few studies have evaluated the efficacy of analgesics and NSAIDs on associated symptoms and functional disability. There is evidence only for ASA, salicylates, ibuprofen and diclofenac sodium. There are no studies supporting the consistency of efficacy and recurrence rates for the majority of analgesics/NSAIDs. The efficacy of ASA and other NSAIDs on migraine aura has never been tested.

Observations ASA is recommended in patients with cardio- and cerebrovascular comorbidities. Paracetamol is firstchoice drug for migraine attacks during pregnancy. The excessive use of NSAIDs ( $\geq 15$ days a month) should be avoided for the risk of migraine chronification. There is evidence of the use of ketorolac i.v. in the emergency department (ED), supporting its efficacy in the treatment of migraine attacks even if the results are less favourable than those obtained with prochlorperazine [66, 67]. In the same setting, ketorolac has been demonstrated to be more effective than sumatriptan nasal spray [68]. Metamizole, both by oral and intravenous route, has been demonstrated to be effective in the treatment of migraine attacks, but the risk of agranulocytosis and hypotension as relevant side effects should be considered [6]. Side effects consist mainly in gastrointestinal adverse events (from gastric pain to gastric or duodenal ulcer). The percentage of adverse events found in clinical trials concerning the use of NSAIDs for migraine attack are lower than those detected in studies regarding their daily use. These adverse events, occasional in migraine patients using sometimes NSAIDs, can occur with higher frequency in the case of daily or almost daily use by chronic migraine patients. Contraindications include severe renal and hepatic failure, hemorrhagic risk, gastric or duodenal ulcer.

Warnings Few NSAIDs can be used in patients under 14 years of age (ibuprofen, ketoprofen, morniflumate). NSAIDs should be administered with caution in elderly patients.

Pharmacological interactions Cumarol derivates or heparin (with the exception of those with low molecular weight): more risk of bleeding in the case of contemporary use with analgesics or NSAIDs. Alcohol should be avoided by concomitant use of analgesics or NSAIDs. Digoxin, barbiturates, lithium: NSAIDs increase their plasma concentration. Aldosterone, antagonists and potassium saving diuretics and antihypertensive drugs: NSAIDs reduce their efficacy.

\section{Ergot derivatives}

Indications Their use should be restricted to low frequency, severe attacks unresponsive to other drugs for their 
potential risk of abuse [69]. Efficacy Ergotamine tartrate with or without caffeine and dihydroergotamine have been demonstrated to be effective versus placebo or versus an active drug in reducing migraine headache [70, 71]. Ergotamine tartrate is not effective on nausea or vomiting; rather, because of the interaction with dopaminergic receptors, it may itself induce or increase nausea or vomiting accompanying the migraine attack [72]. Studies are lacking for its use for migraine aura. Ergotamine tartrate administration is associated with low incidence of recurrence $(<30 \%)$ [70]. Oral ergotamine is inferior to sumatriptan and eletriptan $[44,45]$.

Observations Dihydroergotamine, the drug of the class with the best risk-benefit ratio, is not available in Italy. Because nausea and vomiting may worsen due to the administration of ergot derivates, the contemporary administration of an antiemetic is generally indicated [72]. Caffeine doubles the rate of absorption of ergotamine and increases its peak blood concentration. This explains the development of combination formulations.

Patients who overuse ergotamine derivatives may develop rebound headaches. The abuse of ergot derivatives may induce an increase in the frequency of attacks and develop into a chronic headache. Therefore, these drugs are recommended for sporadic attacks and cannot be used for more than 10 days/month [48].

Major side effects Nausea, vomiting, diarrhoea and ergotism [73]. Ergotamine has a teratogenic effect [74]. Contraindications Cardiovascular and cerebrovascular diseases, uncontrolled blood hypertension, Raynaud disease, renal failure, pregnancy and lactation. Pharmacological interactions Triptans: an ergot derivate should not be administered within $6 \mathrm{~h}$ after the administration of a triptan. Beta-blockers: an increase in the risk of peripheral vasoconstriction has been observed in patients who also used beta-blockers. The majority of patients are able to tolerate such association; caution is necessary for particularly sensitive patients [58].

\section{Combination analgesics}

Indications They have the same indications of simple analgesics and NSAIDs. Few studies have been performed on these combination drugs [75]. Efficacy has been demonstrated only for the association with acetylsalicylic acid, paracetamol and caffeine. Recent trials have demonstrated a significant efficacy on migraine attacks of moderate intensity and moderate disability [76]. This association has been demonstrated to be effective in migraine attacks related to the menstrual cycle [76]. Recent data suggest that the effectiveness of the association of indomethacin + caffeine + prochlorperazine is similar to that of triptans, even though supporting studies are needed [77, 78].
Combination analgesics available in Italy include acetylsalicylic acid + acethaminophen + propyhenazone, acetylsalicylic acid + acethaminophen + indomethacin (with/ without caffeine), and acetaminophen + propyphenazone and acetaminophen + codeine. Dosages of active substances in the combinations are different from those tested for migraine attacks. The efficacy of acetylsalicylic acid + acethaminophen + propyphenazone and butalbital + propyphenazone + caffeine has never been investigated in RCT for migraine.

Observations To avoid the risk of abuse, the use of combination analgesics should be limited to $\leq 10$ days/ month; abuse can lead to headache chronification [79-81]. Side effects and contraindications in combination analgesics are the same as those for each component. Caffeine may induce anxiety and insomnia.

\section{Antiemetics}

Indications Antiemetics are to be considered adjuvants, especially when nausea and vomiting are prominent [82]. Efficacy Most studies have concerned the association of antiemetics with analgesics and NSAIDs (naproxen, paracetamol, tolfenamic acid) or dihydroergotamine [72]. These associations have been proposed to improve the absorption of the symptomatic drugs and to act as adjuvants in reducing nausea or vomiting associated with the attacks. No RCT, however, clearly demonstrated a superiority of this association over NSAIDs alone. There is some evidence that suggests that the use of an antiemetic may improve the efficacy of a triptan [83]. Metoclopramide, prochlorperazine and chlorpromazine have also shown a modest antimigraine effect, besides a clear antiemetic effect $[84,85]$.

A modest antimigraine effect has been demonstrated for metoclopramide administered intramuscularly or intravenously [86].

Prochlorperazine or chlorpromazine administered intramuscularly or intravenously have been shown to be modestly effective in studies carried out in the ED. Oral prochlorperazine has also shown some partial efficacy [87, 88].

Dated findings on a limited number of patients support some efficacy of domperidone in preventing migraine attacks or reducing head pain intensity [326-328].

Intramuscular or intravenous formulations can be used in the treatment of attacks of severe intensity in which nausea and vomiting are prevailing and in the case in which other symptomatic drugs are contraindicated or sedation is needed. They can be considered as single drugs for the treatment of migraine in particular clinical settings (i.e. emergency department).

Side effects Metoclopramide may rarely induce dystonia, tardive dyskinesia and akathisia. The more frequent 
adverse events are somnolence and sedation. Rare adverse events are acute dystonic crises or akathisia and postural hypotension, particularly when an antihypertensive drug is coadministered.

The occurrence of adverse events due to phenothiazines is facilitated by alcohol or propranolol, which raises their plasma levels. Metoclopramide, prochlorperazine and chlorpromazine should not be coadministered with narcotics, sedatives, hypnotics and tranquilizers due to the synergic effects on the central nervous system. Prochlorperazine and chlorpromazine may lower the seizure threshold; they should be used with caution in patients with epilepsy. Contraindications Metoclopramide is contraindicated in patients affected by pheochromocytoma, epilepsy and in combination with neuroleptics such as phenothiazines, butyrophenones, MAOIs.

Antiemetics are not recommended in patients with prolactinoma. The use of metoclopramide, chlorpromazine and prochlorperazine must be limited only to cases of extreme necessity in pregnancy and during breast feeding [89].

Pharmacological interactions Anticholinergic drugs and antiacids may antagonize the effects of metoclopramide and domperidone on gastric motility.

\section{Other drugs}

Simple or combination opioid analgesics Controlled studies have demonstrated the association of paracetamol with codeine, doxilamine or buclizine to be no more effective than paracetamol alone [90]. In a more recent study the combination of paracetamol + codeine has been shown to be more efficacious than ASA [91]. The association of ASA with dextropropoxyphen and phenazone was not more effective than ergotamine [92].

Also, butorphanol (not available in Italy) by intramuscular route has not shown to be more effective than dihydroergotamine administered intravenously in association with metoclopramide.

There are no studies comparing butorphanol nasal spray with other non-opioid symptomatic antimigraine drugs [93, 94]. A double-blind study comparing the efficacy of ketorolac $(60 \mathrm{mg})$ and meperidine $(75 \mathrm{mg}) /$ promethazine ( $25 \mathrm{mg}$ ), both administered by intramuscular route, did not show a statistically significant difference between the two drugs [95].

More recently, tramadol administered by intravenous route alone or in combination with paracetamol has been demonstrated effective in the acute treatment of migraine [96-98].

The Ad Hoc Committee has unanimously decided that this class of drugs does not represent a valid option for the symptomatic treatment of migraine attacks. This is due to the lack of data demonstrating their effectiveness compared with other symptomatic drugs and because of the potential risk of abuse and developing a chronic headache [99].

\section{Other drugs}

\section{Barbiturates}

There is no data supporting the efficacy of this class of drugs in the treatment of migraine crises [100]. Barbiturates may induce intoxication, addiction and dependence. High dosages may induce withdrawal syndrome after discontinuation. Their use should be avoided for the potential risk of abuse, rebound headache and chronification of migraine.

\section{Lidocaine}

Limited evidence is available suggesting the effectiveness of this drug administered intravenously for the treatment of migraine attacks and in the chronic, refractory migraine unresponsive to other treatments, with or without symptomatic drug overuse [101].

Results of randomized, double-blind studies indicate a modest, but significant efficacy although with frequent and early recurrence $[102,103]$.

\section{Steroids}

Available findings are conflicting and do not allow definitive conclusions to be drawn on their effectiveness in the treatment of migraine attacks, particularly in the case of refractory attacks and in reducing headache recurrence [104-108]. Steriods are indicated for the treatment of status migrainosus.

The group of experts recommends dexamethasone administered by intravenous route at a dosage of $10 \mathrm{mg}$ or prednisone administered by oral route at a dosage of $50-100 \mathrm{mg}$ in the treatment of status migrainosus, even though there are no consistent results from controlled trials versus placebo.

Limited findings are available for metilprednisolone [109, 110]. One study demonstrated the superiority of the association of dexamethasone and a triptan compared with triptan alone in the treatment of menstrual migraine attacks [111].

\section{Valproic acid}

The drug administered by intravenous route at the dosage of $300-800 \mathrm{mg}$ has been demonstrated to be effective in the treatment of migraine attacks. The promising results obtained need to be confirmed in double-blind, placebocontrolled studies involving a larger sample of patients [112]. 
Gepants

They have been developed in recent years, and preclinical and clinical data suggest a role for calcitonin gene-related peptide (CGRP) in determining migraine attacks.

They include telcagepant (formerly MK-0974) whose efficacy has been shown in a study involving 500 migraine patients with good tolerability profile. The compound BI 44370 in a phase II study has shown its superiority compared with placebo at a dosage of $400 \mathrm{mg}$; phase III studies are still on going [113].

Further CGRP antagonists are currently being developed and a considerable expansion in this particular therapeutic area is expected. Currently these drugs are not available in the market and it is still too early to anticipate when they will be available for use in a clinical setting.

Levels of recommendation

Table 5 shows symptomatic antimigraine drugs with levels of recommendation I and II.

Table 6 includes symptomatic drugs with levels of recommendations III and IV.

Preventive treatment

1. A good response to prophylactic treatment is obtained if there is at least a $50 \%$ reduction in the frequency and severity of migraine attacks and a significant improvement in the quality of life is reached.

2. To minimize side effects and improve patient's compliance, the most appropriate drug should be taken at the lowest dosage, preferentially as a monotherapy. Doses can be slowly increased until therapeutic goals are achieved without side effects.

3. Prophylactic treatment should be maintained for at least 3 months. Clinical benefit may take some time to be obtained.

4. Prophylactic drugs should be chosen based on patient's comorbidities.

5. Particular attention should be devoted to drug-drug and drug-food interactions.

6. Most preventive drugs may have a teratogenic effect. Women should use a safe contraception.

7. Prophylactic treatment during pregnancy should be limited to special situations, and in these cases drugs with lowest risk for the foetus should be preferred.

Preventive drugs

Preventive drugs include beta-blockers, calcium channel blockers, 5HT antagonists, antidepressants, antiepileptic drugs, angiotensin inhibitors, dihydroergotamine, botulinum toxin A and supplements [114, 115].

\section{Beta-blockers}

These drugs are to be preferred in the case of hypertension or tachycardia [116, 117].

Their efficacy as preventive drugs for migraine has been fortuitously demonstrated in migraine patients with concurrent hypertension. The efficacy of atenolol, nadolol, timolol, bisoprolol and nebivolol is supported by few controlled studies [118-124]. Even though prophylactic treatment is generally not advisable in pregnancy, propranolol may be used with relative safety [125]. The abrupt suspension of these drugs can induce an increase in the frequency of migraine attacks and an increase of blood pressure.

Adverse events include fatigue, depression exacerbation and nightmares, which are the most frequent, while asthma, orthostatic hypotension, impotence, hallucinations and weight gain occur less frequently.

Contraindications include congestive heart failure, atrio-ventricular block, peripheral artheriopathy, Raynaud syndrome, asthma, diabetes and depression.

Calcium channel antagonists are particularly recommended for patients with anxiety and insomnia [126].

Efficacy Flunarizine is the most used drug. Cinnarizine has a good antimigraine action although few studies have been carried out to investigate its efficacy in migraine [127, 128]. There are insufficient data supporting the efficacy of nimodipine and ciclandelate in migraine [129]. Therapeutic effects become evident only after some months of treatment. Cinnarizine induces the CNS side effects and accumulation phenomena less frequently.

Side effects of flunarizine are somnolence, asthenia, weight gain, depression and extrapyramidal symptoms in the long-term treatment and occur more frequently in elderly patients; cinnarizine can induce somnolence and epigastric pain which can be avoided by taking the drug on a full stomach, weight gain, extrapyramidal symptoms in the long-term treatment and occur more frequently in elderly patients [130-132].

Contraindications include Parkinson's disease or extrapyramidal disturbances, obesity, pregnancy and breast feeding.

Antidepressants: tricyclics

Among tricyclics, there are only two double-blind studies versus placebo supporting the efficacy of amitryptiline [133-135]. 
Table 5 Drugs for the symptomatic treatment of migraine with a level of recommendation I and II

\begin{tabular}{|c|c|c|c|}
\hline Drug & Dosage (mg) & $\begin{array}{l}\text { Level of } \\
\text { recommendation }\end{array}$ & Comments \\
\hline \multicolumn{4}{|l|}{$5 \mathrm{HT}_{1 \mathrm{~B} / 1 \mathrm{D}}$ agonists } \\
\hline \multicolumn{4}{|l|}{ Sumatriptan } \\
\hline Subcutaneous & 6 & & $\begin{array}{l}\text { Rapid onset of action compared to the other } \\
\text { formulations }\end{array}$ \\
\hline Tablet & $50-100$ & I & \\
\hline Suppository & 25 & & $\begin{array}{l}\text { Useful when oral route is not possible due to } \\
\text { nausea }\end{array}$ \\
\hline Nasal spray & 20 & & $\begin{array}{l}\text { Useful when oral route is not possible due to } \\
\text { nausea }\end{array}$ \\
\hline Zolmitriptan & & & Rapid onset of action \\
\hline Tablet & 2.5 & & \\
\hline Oral disintegrating tablet & 2.5 & I & \\
\hline Nasal spray & $2.5-5$ & & \\
\hline Rizatriptan & & & Rapid onset of action. The optimal dosage is \\
\hline Tablet & $5-10$ & I & $10 \mathrm{mg}$ \\
\hline Oral disintegrating tablet & 10 & & $\begin{array}{l}\text { Recommended dosage is } 5 \mathrm{mg} \text { in patients } \\
\text { treated with propranolol which increases the } \\
\text { plasma concentration of rizatriptan }\end{array}$ \\
\hline \multicolumn{4}{|l|}{ Eletriptan } \\
\hline Tablet & 20,40 & I & $\begin{array}{l}\text { The optimal dosage is } 40 \mathrm{mg} \\
\text { (best efficacy/tolerability ratio) }\end{array}$ \\
\hline & & & $\begin{array}{l}\text { The dosage of } 20 \mathrm{mg} \text { is recommended in the } \\
\text { case of renal or liver failure }\end{array}$ \\
\hline \multicolumn{4}{|l|}{ Almotriptan } \\
\hline Tablet & 12.5 & I & Good tolerability profile \\
\hline \multicolumn{4}{|l|}{ Frovatriptan } \\
\hline Tablet & 2.5 & I & Long half-life, good tolerability profile \\
\hline \multicolumn{4}{|l|}{ Ergot derivatives } \\
\hline Ergotamine oral, rectal, subcutaneous & $1-2$ & II & $\begin{array}{l}\text { Indicated in the case of infrequent migraine } \\
\text { attacks. Risk of abuse and headache chronification. } \\
\text { An excessive use may cause ergotism }\end{array}$ \\
\hline \multicolumn{4}{|l|}{ NSAIDs } \\
\hline Acetylsalicylic acid (ASA) oral & $500-1,000$ & I & $\begin{array}{l}\text { Good efficacy/tolerability profile } \\
\text { Gastrointestinal adverse events }\end{array}$ \\
\hline Lisine acetylsalicylate oral & $500-1,000$ & I & $\begin{array}{l}\text { Good efficacy/tolerability profile } \\
\text { Gastrointestinal adverse events }\end{array}$ \\
\hline Lisine acetylsalycilate i.v. & 1,000 & I & To be used in a hospital setting. Risk of bleeding \\
\hline Diclofenac-K+ oral & 100 & II & $\begin{array}{l}\text { In the case of frequent migraine attacks risk of } \\
\text { abuse and headache chronification }\end{array}$ \\
\hline Diclofenac-Na+ i.m. & 75 & II & \\
\hline Flurbiprofen oral & $100-300$ & II & \\
\hline Ibuprofen oral & $400-1,200$ & I & \\
\hline Ibuprofen oral & 200 & II & \\
\hline Ketoprofen i.m. & 100 & II & \\
\hline Ketorolac i.m. or i.v. & $30-60$ & II & $\begin{array}{l}\text { Clinical trials have been performed in particular } \\
\text { settings (emergency departments) }\end{array}$ \\
\hline Metamizole (dipirone) i.v. or oral & 1,000 & II & $\begin{array}{l}\text { Potential risk of agranulocytosis }>0.1 \% \text { and } \\
\text { hypotension (i.v. formulation) }\end{array}$ \\
\hline
\end{tabular}


Table 5 continued

\begin{tabular}{|c|c|c|c|}
\hline Drug & Dosage (mg) & $\begin{array}{l}\text { Level of } \\
\text { recommendation }\end{array}$ & Comments \\
\hline Naproxen oral & $500-1,500$ & I & \\
\hline $\mathrm{Na}+$ Naproxen oral & $550-1,500$ & I & \\
\hline Mefenamic acid per os & 500 & II & Effective in menstrual migraine attacks \\
\hline \multicolumn{4}{|l|}{ Combination analgesics } \\
\hline $\begin{array}{l}\text { Paracetamol }+ \text { acetyl salicylic } \\
+ \text { caffeine suppository }\end{array}$ & $500+500+130$ & & $\begin{array}{l}\text { To be used for attacks of moderate intensity. } \\
\text { Effective also in the treatment of menstrual } \\
\text { migraine. In the case of frequent migraine } \\
\text { attacks, risk of abuse and headache chronification }\end{array}$ \\
\hline $\begin{array}{l}\text { Indomethacin }+ \text { prochlorperazine } \\
+ \text { caffeine oral }\end{array}$ & $25+2+75$ & I & $\begin{array}{l}\text { In the case of frequent migraine attacks, risk of } \\
\text { abuse and headache chronification }\end{array}$ \\
\hline $\begin{array}{l}\text { Indomethacin }+ \text { prochlorperazine } \\
+ \text { caffeine suppository }\end{array}$ & $25-50+4-8+75-150$ & II & See above \\
\hline Paracetamol + codeine per os & $400-650+6-25$ & II & See above \\
\hline \multicolumn{4}{|l|}{ Antiemetics } \\
\hline Metoclopramide i.v. & $0.1 / \mathrm{kg} 1-3$ times & II & To be used in a hospital setting \\
\hline
\end{tabular}

Amitryptiline is the first-choice drug particularly in patients with comorbid anxiety and depression or with concomitant tension-type headache.

Prophylactic effectiveness is obtained with doses lower than those used for depression (10-20 mg/day) [135].

The most frequent adverse events are antimuscarinic effects such as dry mouth, constipation and sedation. Often an increase in appetite (craving) with a consequent weight gain, or occasionally orthostatic hypotension and impotence, may occur [134].

Contraindications include cardiac arrhythmias, prostatic hypertrophy, glaucoma and epilepsy.

Serotonin norepinephrine reuptake inhibitors (SNRIs), selective serotonin reuptake inhibitors (SSRIs) and noradrenergic and specific serotonergic antidepressants (NaSSAs)

Promising data have been obtained for venlafaxine but RCT have some methodological limitations [136-138]. Although paroxetine, escitalopram, fluvoxamine and sertraline are sometimes used for migraine prophylaxis due to their good tolerability profile, available data are limited and contrasting [139-143]. There are no data available for mirtazapine. There is also some positive evidence for fluoxetine [144, 145].

Venlafaxine can be useful in patients with depression and concomitant anxiety. Fluoxetine can induce insomnia, fatigue, tremor and epigastric pain. SSRI can interfere with $5 \mathrm{HT}_{1}$ agonists.

\section{Antiepileptic drugs}

Sodium valproate and topiramate are first-choice drugs in the treatment of high-frequency migraine attacks, chronic migraine, with and without symptomatic drug overuse and in the case of comorbid epilepsy [146, 147].

Sodium valproate and topiramate are effective in both migraine with and without aura and in chronic forms. Their long-term efficacy has been shown [148-153]. The dosages useful for the prophylactic treatment of migraine are lower than those used for epilepsy. Gabapentin has a good tolerability profile [154]. In open studies, lamotrigine (50-200 mg/ day) has been shown to be effective in the treatment of highfrequency migraine attack with aura [155-157]. It is ineffective in migraine without aura [158]. Promising data have been obtained for zonisamide, levetiracetam, pregabalin and need to be confirmed.

Contraindications are hepatitis, pancreatitis, thrombocytemia for sodium valproate; liver and kidney insufficiency, kidney stones, glaucoma for topiramate; hypersensitivity to the drug for gabapentin and lamotrigine. All antiepileptics are contraindicated during pregnancy due to their teratogenic effect [159].

Adverse events caused by sodium valproate include asthenia, dizziness, tremor, alopecia, weight gain, menstrual disorders, hepatopathy and pancreatitis; for topiramate, asthenia, memory problems, anomia, weight loss, paresthesia, dysgeusia and depression; rare adverse events include metabolic acidosis, kidney stones, psychosis and narrow-angle glaucoma; for gabapentin asthenia, somnolence, ataxia, diplopia and constipation; for lamotrigine: skin rashes (which may be warning signs of Stevens-Johnson syndrome; to reduce this risk a slow titration is recommended), somnolence, gastroenteric disturbances and ataxia [160].

\section{HT-antagonists}

5HT-antagonists are the oldest drugs available for migraine prophylaxis and include methysergide, a semisynthetic 


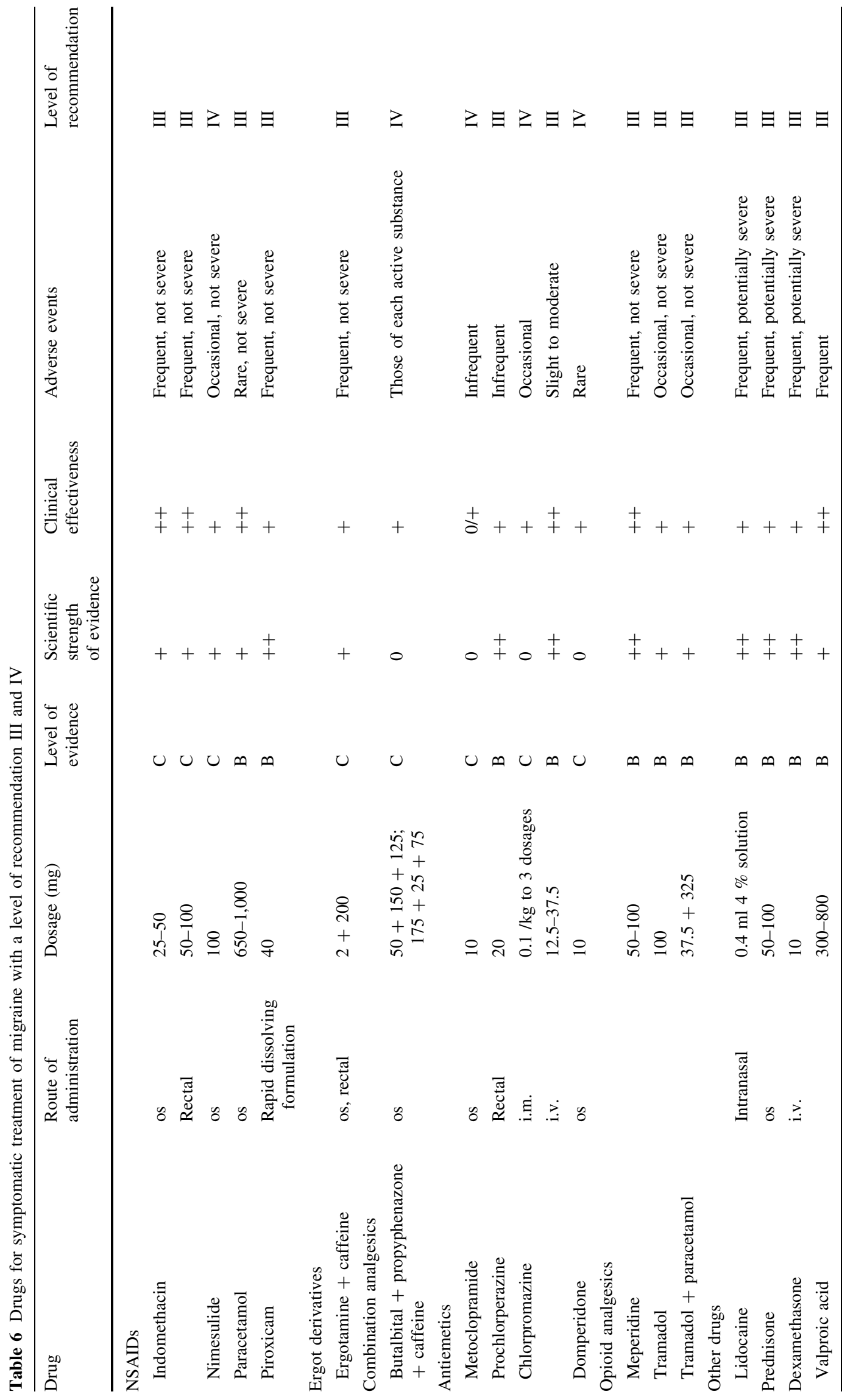


derivative of ergometrine, which is not available in Italy and pizotifen, a serotonin antagonist with modest antihistaminic and cholinergic effects, which is a second-choice drug due to its side effects [161].

There are a few dated clinical studies supporting the efficacy of pizotifen [162-165]. This drug has a long halflife (about $23 \mathrm{~h}$ ) and can be used in a unique dose $(0.5-1.5 \mathrm{mg})$, for cycles of 3 months.

Contraindications include glaucoma, arrhythmias, urinary retention and obesity.

The most frequent side effects are somnolence, increase in appetite, weight gain, xerosthomia and constipation [166].

\section{Angiotensin inhibitors}

Indications Lisinopril and candesartan are second-choice drugs to be considered for patients with a concomitant hypertension [167-169]. There is only one positive RCT for both drugs [170, 171].

Contraindications are angioedema, bilateral stenosis of renal artery for lisinopril; hypersensitivity to sulphonamides, hypokaliemia, hypercalcemia, liver and kidney insufficiency and gout for candesartan.

Adverse events for lisinopril are asthenia, hypotension, dry cough, hyperkalemia, gastrointestinal disturbances and impotence; for candesartan asthenia, dizziness, tachycardia and hyperuricemy.

Other drugs Two ergot derivatives, controlled release dihydroergotamine $10 \mathrm{mg} / \mathrm{day}$ and dihydroergocryptine $20 \mathrm{mg} /$ day (not available in Italy), can be taken into account as second-line treatments $[172,173]$. Riboflavin at high doses $(400 \mathrm{mg})$ showed a certain efficacy in preventing migraine, with few side effects (moderate abdominal pain, diarrhoea), in one RCT [174]. This drug is available as a galenic preparation in Italy. Among herbal remedies, butterbur root extract (Petasites hybridus), at the dosage of $150 \mathrm{mg} /$ day, proved to be effective in two RCTs, while another herbal drug, Tanacetum parthenium, studied in several RCTs, gave more conflicting results $[175,176]$.

One controlled study versus placebo demonstrated the efficacy of Coenzyme Q10 (100 mg $\times 3$ per day) [177]. The superiority of tiotic acid, a drug which also increases brain energetic metabolism, has also been shown compared with placebo [178]. Conflicting findings have been obtained for pidolate magnesium (400-600 mg/day) [179, 180]. The use of non-chelated formulations determines diarrhoea at clinically efficacious doses. It can be used in women with menstrual migraine and premenstrual syndrome, but a precise administration schedule has not been established (646-648). OnabotulinumtoxinA showed some efficacy in various open studies in migraine patients, but contradictory results emerged in double-blind controlled studies versus placebo concerning patients with episodic migraine [181]. These studies used different protocols, individualized or standardized, different inoculation sites and groups with different frequency of attacks (see chronic migraine).

Menstrual migraine In pure menstrual migraine or menstrually related migraine, a short-term prophylactic therapy around menses can be tried if menstrual cycles are regular and migraine attacks are predictable [182]. Two different strategies may be followed: (1) administration of symptomatic drugs, in particular triptans, on a regular basis instead of on demand; (2) administration of estrogens, to avoid the premenstrual oestrogen fall that is thought to be a main cause of menstrual migraine. In the first case, frovatriptan $(5 \mathrm{mg} /$ day $)$ or zolmitriptan $(5-7.5 \mathrm{mg} /$ day $)$ may be administered [183-185]. Positive results have also been obtained in one RCT for sumatriptan $100 \mathrm{mg}$ and for naproxen sodium (1,100 mg/day) [186]. The administration should be limited to the period $-2+4 / 5$ days from menstrual onset. If the second option is chosen, estradiol gel $(1.5 \mathrm{mg} /$ day $)$ or transdermal estradiol patch $(100 \mu \mathrm{g})$ are probably the best choices $[187,188]$.

Chronic migraine Only recently some RCTs have been carried out in patients affected by the most disabling form of migraine, i.e. chronic migraine. Two drugs have so far showed some evidence of efficacy: topiramate and onabotulinumtoxinA. Topiramate $(100 \mathrm{mg} / \mathrm{day})$ has been partially effective also in patients with medication overuse; onabotulinumtoxinA (injection every 12 weeks) has given a statistically significant clinical benefit [189-191].

Data supporting a significant efficacy of onabotulinumtoxinA have been obtained in patients with chronic migraine with or without symptomatic drug overuse [192-194].

\section{Levels of recommendation}

Table 7 shows prophylactic drugs with levels of recommendation I and II. Table 8 includes preventive drugs with levels of recommendation III and IV.

\section{Tension-type headache (TTH)}

Acute attack treatment

Just like in migraine, the treatment of the acute episode is necessary. Patients should record attack frequency, duration and severity in a headache diary to monitor the disease course and the effectiveness of therapy.

\section{General considerations}

1. The most appropriate drug should be taken at the first symptoms and at the lowest dosage useful to obtain a complete resolution of the crises and as early as possible. 
Table 7 Drugs for the preventive treatment of migraine with a level of recommendation I and II

\begin{tabular}{llll}
\hline Drug (by oral route) & $\begin{array}{l}\text { Daily } \\
\text { dosage } \\
(\mathrm{mg})\end{array}$ & $\begin{array}{l}\text { Level of } \\
\text { recommendation }\end{array}$ & Comments \\
\end{tabular}

Beta-blockers

Propranolol

$80-240 \quad$ I

$\begin{array}{lll}\text { Metoprolol } & 50-200 & \text { I } \\ \text { Atenolol } & 100 & \text { I } \\ \text { Bisoprolol } & 5-10 & \text { II } \\ \text { Nadolol } & 40-240 & \text { II }\end{array}$

Calcium channel blockers

Flunarizine

$5-10$

I

Cinnarizine 75-150 II

Antidepressants tricyclic

Amitriptyline $\quad 10-75 \quad$ I

Antiepileptic drugs

Sodium valproate

500-1,500

Topiramate

50-100

Gabapentin

Pizotifen

$900-2,400$

II

Other drugs

Dihydroergotamine

$1.5 \quad$ II

$10 \quad$ II

Dihydroergocriptine

Onabotulinum toxin

type A

$20 \quad$ II

155-195 U $\mathrm{U}^{\mathrm{a}}$ IV (episodic migraine)

I (chronic migraine)
Useful in patients with hypertension, anxiety and panic disorders. It can exacerbate depression. Do not use with ergotamine. Increase doses gradually. Particularly useful in patients with essential tremor. Most frequent adverse events are fatigue, mood disorders, nightmares. Other side effects are bradicardia, orthostatic hypotension, impotence, hallucinations, weight gain

Same indications and side effects as for propranolol, excluding essential tremor

Same indications and side effects as for propranolol, excluding essential tremor

Same indications and side effects as for propranolol, excluding essential tremor

Use administration schedules with periodic suspensions (i.e. 5 days/week or 3 weeks/ month), to avoid the accumulation of the drug

Most frequent side effects are weight gain, sedation and depression. Extrapyramidal symptoms may be observed in elderly patients. The recommended dose to reduce adverse events is $5 \mathrm{mg}$

Most frequent side effects are weight gain and drowsiness

Dosages tested in clinical trials, the majority of them dated, are in general higher than those usually used in clinical practice for prophylactic treatment of migraine

A progressive increase in doses is recommended until maintenance doses are reached in order to reduce adverse events

Most frequent side effects are drowsiness, weight gain and anticholinergic symptoms. Particularly useful in patients with depression, concurrent migraine and tension-type headache. Higher doses should be used in patients with comorbid depression

Controlled release formulations are available with a better tolerability profile. Recommended for patients with prolonged or atypical migraine aura. Not recommended in patients with liver disease and haemorrhagic diathesis. A progressive increase in doses is recommended. Frequent adverse events include nausea, asthenia, somnolence. Other side effects include weight gain, hair loss and tremor. Teratogenic potential

Gradual increase of dosage is recommended. Frequent, not serious adverse events include paresthesiae, memory and concentration disturbances, nausea, weight loss and drowsiness. Rare serious adverse events include kidney stones, narrow-angle glaucoma

Recommended for elderly patients. Well tolerated

Frequent adverse events include weight gain and somnolence

Do not use within $6 \mathrm{~h}$ after triptan administration. Useful for intermittent or short-term prophylaxis. Withdrawal could be associated with rebound headache

Mild side effects. Withdrawal could be associated with rebound headache

The majority of controlled studies have not provided conclusive results in episodic migraine

It is effective in chronic migraine. Costs are comparable to topiramate $100 \mathrm{mg}$ for a period of treatment of 3 months and lower than topiramate for a period of 4 months

${ }^{a}$ Dosage referred to each inoculation 
Table 8 Drugs for the preventive treatment of migraine with a level of recommendation III and IV

\begin{tabular}{|c|c|c|c|c|c|c|c|}
\hline Drug & $\begin{array}{l}\text { Route of } \\
\text { administration }\end{array}$ & $\begin{array}{l}\text { Daily } \\
\text { dosage } \\
(\mathrm{mg})\end{array}$ & $\begin{array}{l}\text { Level of } \\
\text { evidence }\end{array}$ & $\begin{array}{l}\text { Scientific } \\
\text { strength of } \\
\text { evidence }\end{array}$ & $\begin{array}{l}\text { Clinical } \\
\text { effectiveness }\end{array}$ & $\begin{array}{l}\text { Adverse } \\
\text { events }\end{array}$ & $\begin{array}{l}\text { Level of } \\
\text { recommendation }\end{array}$ \\
\hline \multicolumn{8}{|l|}{ SNRI and SSRI } \\
\hline Fluoxetine & os & $10-40$ & $\mathrm{~B}$ & + & + & $\begin{array}{l}\text { Frequent, not } \\
\text { severe }\end{array}$ & III \\
\hline Venlafaxine & os & $75-150$ & $\mathrm{~B}$ & + & + & $\begin{array}{l}\text { Occasional, not } \\
\text { severe }\end{array}$ & III \\
\hline \multicolumn{8}{|l|}{ Angiotensin inhibitors } \\
\hline Lisinopril & os & $5-20$ & $\mathrm{~B}$ & + & + & $\begin{array}{l}\text { Occasional, not } \\
\text { severe }\end{array}$ & III \\
\hline Candesartan & & 16 & $\mathrm{~B}$ & ++ & + & Rare, not severe & III \\
\hline \multicolumn{8}{|l|}{ Antiepileptic drugs } \\
\hline Lamotrigin & os & $50-200$ & $\mathrm{~B}$ & ++ & $\begin{array}{c}+++ \text { (only } \\
\text { migraine } \\
\text { with aura) }\end{array}$ & $\begin{array}{l}\text { Occasional, not } \\
\text { severe }\end{array}$ & III \\
\hline \multicolumn{8}{|l|}{$5 \mathrm{HT}_{1}$ antagonists } \\
\hline Methysergide & & $2-8$ & A & +++ & ++ & Potentially severe & III $^{\mathrm{a}}$ \\
\hline \multicolumn{8}{|l|}{ Other drugs } \\
\hline Ribloflavin & & 400 & B & ++ & + & Rare, not severe & III $^{\mathrm{b}}$ \\
\hline Magnesium & & $400-600$ & B & ++ & + & Rare, not severe & III $^{\mathrm{b}}$ \\
\hline Petasites hybridus & & $100-150$ & B & ++ & + & Rare, not severe & $\mathrm{III}^{\mathrm{c}}$ \\
\hline Tanacetum parthenium & & 18.75 & $\mathrm{~B}$ & + & $0 /+$ & Rare, not severe & $\mathrm{III}^{\mathrm{c}}$ \\
\hline Thiotic acid & & 600 & $\mathrm{~B}$ & + & $?$ & Rare, not severe & $\mathrm{III}^{\mathrm{c}}$ \\
\hline
\end{tabular}

${ }^{a}$ Not available in Italy

b Not available in Italy at the recommended dosages

c Available in Italy as a herbal product or as an over-the-counter product

2. Formulations containing solely one active drug should be preferred.

3. The patient should fill in a headache diary to evaluate headache recurrence, treatment efficacy and potential side effects.

4. The choice of the symptomatic drug/s should be based on the careful and critical consideration of clinical data, the mechanism of action and side effects of the drugs.

Symptomatic drugs

Drugs for TTH attacks include NSAIDs, simple analgesics, antiemetics and other drugs.

\section{NSAIDs}

Scientific evidence supports the efficacy of acetylsalicylic acid (ASA), diclofenac, ibuprofen, ketoprofen, metamizol (dipyrone) and naproxen [195-205].
ASA, ketoprofen and naproxen are first-choice drugs. ASA is especially useful in the case of comorbid cerebrovascular or cardiovascular disease, but is to be avoided in patients with gastric disease. Low doses of NSAIDs are usually sufficient to obtain a therapeutic result. Ibuprofen is reported to have minor gastric adverse effects. Comparative studies were not able to demonstrate the superiority of one drug because the comparisons were not based upon equivalent doses of the different molecules [196, 198-201, $204,205]$. The assumption of NSAIDs or simple analgesics for 15 days or more per month, for $>3$ months, can induce a chronification of headache and a chronic medicationoveruse headache.

For contraindications, drug interactions and side effects, see the paragraph on migraine.

\section{Simple analgesics}

Paracetamol has been tested in TTH patients showing good efficacy and tolerability [196, 200, 204]. It is a first-choice 
drug both in pregnancy and in patients with gastric disease but it should be used with caution in subjects with liver disease.

Combination analgesics with caffeine, codeine and butalbital share indications with simple analgesics and are more effective than the latter. The combination drugs with caffeine (paracetamol + caffeine, paracetamol + ASA + caffeine and ibuprofen + caffeine) are classified at recommendation level I [206-210]. Also, the association of indometacin + prochlorperazine + caffeine was demonstrated to be effective in one study [207].

An excessive and frequent use of combination analgesics (for 10 days a month or more) should be avoided because of the high risk of drug abuse, headache chronification and druginduced headache. Paracetamol + codeine $(500+30 \mathrm{mg})$ and butalbital + propyphenazone + caffeine (50-150+ $125-175+25-75 \mathrm{mg}$ ) are recommended at the level III because of the addiction potential [211,212]. Patients taking opiates or barbiturates should be informed about the risks deriving from an abrupt discontinuation and undergo a hospitalized drug discontinuation schedule. Combination analgesics share the same contraindications, drug interactions and side effects of the single components (for details see "Migraine").

Antiemetics are generally not necessary in the usual management of TTH acute therapy. Intravenous metoclopramide, however, was found to be effective in the emergency treatment of TTH episodes [213]. Also, intravenous administration of chlorpromazine was effective in the ER TTH management [214].

Complementary or alternative drugs Promising results have been obtained with a topical preparation of peppermint oil $10 \mathrm{~g}$ and ethanol $(90 \%)$ to 100 [215, 216]. Tiger balm has also shown to have a modest but significant effect in inducing headache relief [217].

\section{Preventive treatment}

\section{General considerations}

1. A preventive therapy is recommended in the case of headache-related disability for $\geq 4$ days/month or poor response to symptomatic treatment even if the headache frequency is lower.

2. Treatment is considered effective if it reduces attack frequency and/or severity by at least $50 \%$.

3. The identification of trigger factors and their elimination, when possible, contribute to reduce attack frequency [218].

4. Comorbid diseases play a main role in the choice of therapy (e.g., the use of amitriptyline is contraindicated in prostatic hypertrophy and glaucoma).
5. Particular attention should be devoted to drug interactions.

6. Preventive therapy should always be based on a single drug which should be titrated to the lowest effective and well tolerated dose.

7. No recommendations are available concerning the best duration of treatment.

8. Patients should be involved in the choice of treatment and it is advisable to use a limited number of administrations (compliance is in fact inversely proportional to the number of administrations).

9. Patients should also be informed on how and when drugs should be taken, on their potential side effects and their efficacy. Patients should be advised to record their attacks in the headache diary to verify frequency and duration of headache, functional impairment, number of symptomatic drugs taken, efficacy of prevention treatment and possible side effects.

\section{Preventive drugs}

Drugs for prevention therapy of TTH include antidepressants (tricyclics, SSRI, other antidepressants), muscle relaxants, benzodiazepines and other drugs.

\section{Antidepressants}

Among tricyclics amitriptyline is a first-choice drug. It is also recommended in case of comorbidity with anxiety, insomnia, depression or migraine [219, 220]. Amitriptyline is utilized at much lower dose for TTH than that necessary to obtain an antidepressive effect. A slow titration of the drug is recommended to increase its tolerability and avoid adverse events.

Contraindications include cardiac arrhythmias, prostatic hypertrophy, glaucoma and epilepsy. It should be used with caution in the elderly because of its anticholinergic action. For side effects see paragraph on migraine. Also, clomipramine $(150 \mathrm{mg} / \mathrm{die})$ and desipramine $(75 \mathrm{mg} / \mathrm{die})$ may be useful [221, 222].

SSRI are less effective than amitriptyline but better tolerated [223, 224]. Fluvoxamine was the most studied molecule in this class. Also fluoxetin and paroxetin showed some evidence of efficacy.

\section{Other antidepressants}

Mirtazapine, a specific noradrenergic and serotoninergic antidepressant, is another first-choice drug which is especially indicated in the case of comorbid anxiety, insomnia and depression [225, 226]. It should be taken at low initial doses because it can induce sedation and sleepiness. 
Table 9 Drugs for the symptomatic treatment of tension-type headache with a level of recommendation I and II

\begin{tabular}{|c|c|c|c|}
\hline Drug & Dosage (mg) & $\begin{array}{l}\text { Level of } \\
\text { recommendation }\end{array}$ & Comments \\
\hline \multicolumn{4}{|l|}{ Analgesics and NSAIDs } \\
\hline Acetylsalicylic acid oral & $500-1,000$ & I & $\begin{array}{l}\text { Good efficacy and tolerability profile. Not } \\
\text { recommended in pregnancy and in gastric } \\
\text { disease }\end{array}$ \\
\hline Diclofenac-K + oral & $12.5-50$ & II & \\
\hline Ibuprofen oral & $400-800$ & II & Reduced gastric damage \\
\hline Ketoprofen oral & $50-100$ & II & \\
\hline Lumiracoxib & $200-400$ & II & \\
\hline Metamizol (dipyrone) oral & $500-1,000$ & II & $\begin{array}{l}\text { Potential risk of agranulocytosis }>0.1 \% \\
\text { and of hypotension }\end{array}$ \\
\hline Metamizol (dipyrone) intravenous & 1,000 & II & $\begin{array}{l}\text { Tested to treat TTH in the emergency room. } \\
\text { Potential risk of agranulocytosis }>0.1 \% \\
\text { and of hypotension }\end{array}$ \\
\hline Naproxen oral & $275-550$ & I & \\
\hline Paracetamol oral & $500-1,000$ & I & $\begin{array}{l}\text { Use with caution in patients with epatic } \\
\text { failure }\end{array}$ \\
\hline \multicolumn{4}{|l|}{ Combination analgesics } \\
\hline Ibuprofen + caffeine oral & $400+200$ & II & $\begin{array}{l}\text { Risk of abuse and headache chronification } \\
\text { with frequent use }\end{array}$ \\
\hline $\begin{array}{l}\text { Indometacin }+ \text { prochlorperazine } \\
+ \text { caffeine oral }\end{array}$ & $25+2+75$ & II & See above \\
\hline Paracetamol + caffeine oral & $500-1,000+30-130$ & I & See above \\
\hline $\begin{array}{l}\text { Paracetamol }+ \text { acetyilsalicylic acid } \\
+ \text { caffeine oral }\end{array}$ & $200-1,000+500+30-50$ & I & See above \\
\hline
\end{tabular}

Promising results come from venlafaxin, a noradrenalin and serotonin selective reuptake inhibitor (SNRI), which is able to reduce headache frequency independently of the association with anxiety or depression [227, 228]. Maprotiline and mianserine are other antidepressants that have shown to be effective in TTH preventive therapy [229, 230]. The latter was compared to both clomipramine and fluvoxamine with similar efficacy [221]. No conclusive results have been obtained for nefazodone [231] and ritanserine [232, 233], not available in Italy; sulpiride has been used at the dosage of $30 \mathrm{mg} /$ day and has been shown to be more effective than paroxetine [234].

\section{Muscle relaxants}

One RCT supports the use of tizanidine in chronic headache including TTH. The drug was slowly titrated over 4 weeks to $24 \mathrm{mg}$ or the maximum tolerated dose showing moderate adverse effects (somnolence, dizziness, dry mouth, asthenia) [235, 236]. In one study cyclobenzaprine has demonstrated to be effective in the improvement or complete relief of headache in half of $20 \mathrm{TTH}$ patients, whereas only partial relief was obtained in one-third of patients treated with placebo [237].

\section{Benzodiazepines}

In dated studies diazepam ( $5 \mathrm{mg} /$ day) seemed to be more effective than placebo in reducing headache frequency [238, 239]. It can be useful in the case of comorbid anxiety. Also, alprazolam ( $0.75 \mathrm{mg} / \mathrm{day})$ has been demonstrated to be effective in TTH preventive therapy with a lower level of rating (level of recommendation III) [240].

\section{Other drugs}

Positive results have been obtained with topiramate (25-100 mg/die), which was tested at the initial dose of $25 \mathrm{mg} /$ die titrated to $100 \mathrm{mg} /$ die in chronic TTH patients in a recent open study [241]. Buspirone, a non-benzodiazepine anxyolitic drug, has been compared to amitriptyline, showing moderate results in a small sample of patients [220]. Further investigation is needed (level of recommendation III). L-5-hydroxytryptophan at the daily dose of $300 \mathrm{mg}$ showed mild efficacy in the prophylaxis of chronic TTH in one RCT (level of recommendation III) [242]. Conflicting results have been found with onabotulinumtoxinA which may be attributed, at least in part, to variability of doses, study protocols, inoculation sites and 
headache frequency of enrolled patients. Further studies are needed (level of recommendation IV) [243, 244].

Levels of recommendation

Table 9 shows symptomatic drugs for TTH with levels of recommendation I and II. Table 10 includes symptomatic drugs with level of recommendation III.

In Table 11 preventive drugs for TTH with levels of recommendation I and II are listed. Table 12 reports preventive drugs with level of recommendation III.

\section{Cluster headache (CH)}

Treatment of $\mathrm{CH}$ is a difficult challenge and needs the active participation of the patients, who should be reassured on the benign nature of his/her headache. They should be informed on the drugs available for preventing or interrupting attacks and that at present there are no treatments able to prevent active periods and modify the natural history of the disease. $\mathrm{CH}$ patients should be advised on factors that may precipitate attacks during an active phase, in particular, alcoholic beverages that should therefore be avoided.

\section{Acute attack treatment}

Treatment of $\mathrm{CH}$ attack should not be delayed. Drugs should be promptly bioavailable and this can be attained if they are administered by parenteral or subcutaneous route [245, 246].

The objectives of a correct and effective symptomatic treatment are (1) to treat the attack when it starts; (2) to obtain pain relief as soon as possible (possibly within 15 min from the administration of the drug); (3) to limit to a minimum the adverse events [247].

Symptomatic drugs

\section{Sumatriptan}

Its efficacy has been demonstrated for the subcutaneous (s.c.) and intranasal formulations. Sumatriptan s.c. (6 mg) has been shown to be effective both on pain and associated symptoms [248-250]. When administered for long periods, it maintains its efficacy without tachyphylaxis and with a good safety profile [251, 252]. The efficacy of sumatriptan nasal spray (20 mg in a nostril) has been shown within 30 min after administration in a double-blind randomized study [253]. The greater latency of action suggests its use for attacks lasting at least $45 \mathrm{~min}$. Sumatriptan nasal spray does not have the indication for cluster headache in Italy.
The most common adverse events are reactions in the site of injection, dizziness, paraesthesia, sensation of cold or warm and irritation of the nostril for the intranasal formulation. In $90 \%$ of cases they are mild or moderate [254].

\section{Zolmitriptan}

Its efficacy has been demonstrated for the oral and intranasal formulations. Oral formulation (5 and $10 \mathrm{mg}$ ) has been demonstrated to be effective at $30 \mathrm{~min}$ (reduction of 2 points of pain intensity in a 5-point scale) in one RCT [255]. In Italy the only dosage available is $5 \mathrm{mg}$ (to be reached only once within $24 \mathrm{~h}$ if needed). Zolmitriptan nasal spray ( 5 and $10 \mathrm{mg}$ ) has also been shown to induce $\mathrm{CH}$ relief in two RCTs, with a higher efficacy for the 10-mg formulation and with few adverse events for both dosages [256-258].

A Cochrane analysis of six randomized studies, controlled versus placebo, demonstrated that sumatriptan and zolmitriptan are superior to placebo [254]. Adverse events of triptans include paraesthesia, asthenia, nausea, dizziness and irritation of the nostril for the intranasal formulation.

\section{Oxygen by inhalation}

The efficacy of oxygen inhalation at the flow of $71 / \mathrm{min}$ for 15 min has been shown in dated open studies and in a more recent controlled crossover study versus room air [259]. In a further randomized study using an oxygen mask and oxygen flow of $12 \mathrm{l} / \mathrm{min}$ a complete remission of cluster headache attacks both in the episodic and chronic forms was obtained within $15 \mathrm{~min}$ in $78 \%$ of cases versus $20 \%$ for room air [260]. In the case of no response to usual recommended flow it may be increased to $14-151 / \mathrm{min}$ [261].

\section{Ergotamine derivatives}

Dated studies have shown the efficacy of ergotamine tartrate $250 \mu \mathrm{g}$ i.m. (only 1 study vs. placebo), ergotamine tartrate $(1 \mathrm{mg})$ plus caffeine $(100$ or $200 \mathrm{mg}$ ) tablets (in a study also in association with bellafoline $100 \mathrm{mg}$ ) and ergotamine tartrate (2 mg) plus caffeine (100 mg) and dihydroergotamine nasal spray for the acute treatment both in patients with episodic and chronic forms [262-266].

\section{Anaesthetics}

Contrasting results have been obtained for lidocaine intranasal $(4 \%)$ in open studies [101, 267, 268]. Better 
Table 10 Drugs for the symptomatic treatment of tension-type headache with a level of recommendation III

\begin{tabular}{|c|c|c|c|c|c|}
\hline Drug & Dosage $(\mathrm{mg})$ & $\begin{array}{l}\text { Level of } \\
\text { evidence }\end{array}$ & $\begin{array}{l}\text { Scientific strength } \\
\text { of evidence }\end{array}$ & $\begin{array}{l}\text { Clinical } \\
\text { effectiveness }\end{array}$ & $\begin{array}{l}\text { Adverse } \\
\text { events }\end{array}$ \\
\hline \multicolumn{6}{|l|}{ Combination analgesics } \\
\hline Paracetamol + codeine oral & $500+30$ & B & ++ & ++ & Occasional, not severe \\
\hline $\begin{array}{l}\text { Butalbital + propyphenazone } \\
+ \text { caffeine oral }\end{array}$ & $50-150+125-175+25-75$ & $\mathrm{~B}$ & ++ & ++ & Occasional, not severe \\
\hline \multicolumn{6}{|l|}{ Antiemetics } \\
\hline Metoclopramide intravenous & 10 & $\mathrm{~B}$ & + & + & Moderate, not severe \\
\hline Chlorpromazine intravenous & 10 & B & ++ & ++ & Frequent \\
\hline \multicolumn{6}{|l|}{ Complementary alternative drugs } \\
\hline Peppermint with ethanol (90\%) to 100 topic & 10 & B & ++ & ++ & Not recorded \\
\hline Tiger balm topic & Not defined & B & ++ & + & Not recorded \\
\hline
\end{tabular}

Table 11 Drugs for the preventive treatment of tension-type headache with a level of recommendation I and II

\begin{tabular}{|c|c|c|c|c|c|c|c|}
\hline Drug & $\begin{array}{l}\text { Dosage } \\
(\mathrm{mg})\end{array}$ & $\begin{array}{l}\text { Level of } \\
\text { evidence }\end{array}$ & $\begin{array}{l}\text { Scientific } \\
\text { strength of } \\
\text { evidence }\end{array}$ & $\begin{array}{l}\text { Clinical } \\
\text { effectiveness }\end{array}$ & Adverse events & $\begin{array}{l}\text { Level of } \\
\text { recommendation }\end{array}$ & Comments \\
\hline \multicolumn{8}{|l|}{ Antidepressants } \\
\hline Amitriptyline & $25-75$ & A & +++ & +++ & Frequent, not severe & I & $\begin{array}{l}\text { Useful in patients with } \\
\text { comorbid anxiety, } \\
\text { depression, insomnia. } \\
\text { Contraindicated in the } \\
\text { case of glaucoma and } \\
\text { prostatic hypertrophy }\end{array}$ \\
\hline Clomipramine & $10-150$ & $\mathrm{~B}$ & ++ & ++ & Frequent, not severe & II & \\
\hline Fluvoxamine & $50-100$ & B & ++ & ++ & Frequent, not severe & II & \\
\hline Maprotilin & 75 & B & +++ & ++ & Frequent, not severe & II & \\
\hline Mianserin & $30-60$ & A & ++ & + & Frequent, not severe & II & \\
\hline Mirtazapine & $15-30$ & A & +++ & +++ & Frequent, not severe & I & $\begin{array}{l}\text { Particularly indicated in } \\
\text { patients with anxiety, } \\
\text { depression, insomnia. It } \\
\text { may induce somnolence }\end{array}$ \\
\hline Venlafaxine & $75-150$ & B & ++ & ++ & Frequent, not severe & II & \\
\hline \multicolumn{8}{|l|}{ Muscle relaxants } \\
\hline $\begin{array}{l}\text { Tizanidine } \\
\text { oral }\end{array}$ & $3-12$ & B & +++ & +++ & Frequent, not severe & II & $\begin{array}{l}\text { Especially useful in the } \\
\text { case of pericranial muscle } \\
\text { tenderness }\end{array}$ \\
\hline \multicolumn{8}{|l|}{ Benzodiazepines } \\
\hline Diazepam & 5 & B & ++ & ++ & Occasional, not severe & II & \\
\hline \multicolumn{8}{|l|}{ Other drugs } \\
\hline $\begin{array}{l}\text { Topiramate } \\
\text { oral }\end{array}$ & $25-100$ & $\mathrm{C}$ & +++ & +++ & $\begin{array}{l}\text { Frequent, not severe. } \\
\text { Rarely severe }\end{array}$ & II & \\
\hline
\end{tabular}

results were achieved in a study using $10 \%$ lidocaine solution with respect to saline [269].

The application of a solution of cocaine $10 \%$ in both nostrils has been shown to block the attack in a controlled study versus placebo (saline solution) in patients with episodic and chronic cluster headache [269, 270]. No significant adverse events were recorded with the exception of a mild state of arousal in a patient who had abused the drug. Cocaine is not available in Italy as medication.

\section{Somatostatin and somatostatin analogues}

Two randomized controlled trials are available, one for somatostatin i.v. (25 $\mathrm{gg}$ in $50 \mathrm{ml}$ saline) and one for 
Table 12 Drugs for the preventive treatment of tension-type headache with a level of recommendation III

\begin{tabular}{|c|c|c|c|c|c|}
\hline Drug & $\begin{array}{l}\text { Dosage } \\
(\mathrm{mg})\end{array}$ & $\begin{array}{l}\text { Level of } \\
\text { evidence }\end{array}$ & $\begin{array}{l}\text { Scientific strength } \\
\text { of evidence }\end{array}$ & $\begin{array}{l}\text { Clinical } \\
\text { effectiveness }\end{array}$ & Adverse events \\
\hline \multicolumn{6}{|l|}{ Antidepressants } \\
\hline Desipramine & 75 & $\mathrm{C}$ & + & ++ & Frequent, not severe \\
\hline Fluoxetine & 20 & $\mathrm{C}$ & + & ++ & Frequent, not severe \\
\hline Paroxetine & $20-30$ & $\mathrm{~B}$ & + & + & Frequent, not severe \\
\hline Nefazodone & $100-450$ & $\mathrm{C}$ & ++ & ++ & Frequent, not severe \\
\hline Ritanserin & 10 & $\mathrm{~B}$ & + & + & Frequent, not severe \\
\hline Sulpiride & 30 & $\mathrm{~B}$ & + & ++ & Frequent, not severe \\
\hline \multicolumn{6}{|l|}{ Muscle relaxants } \\
\hline Cyclobenzaprine oral & 10 & $\mathrm{~B}$ & ++ & ++ & Frequent, not severe \\
\hline \multicolumn{6}{|l|}{ Benzodiazepines } \\
\hline Alprazolam oral & 0.75 & $\mathrm{~B}$ & + & + & Occasional, not severe \\
\hline \multicolumn{6}{|l|}{ Other drugs } \\
\hline Buspirone & 30 & $\mathrm{C}$ & + & + & Frequent, not severe \\
\hline L-5-hydroxytryptophan oral & 300 & B & + & + & Occasional, not severe \\
\hline
\end{tabular}

None of the drugs evaluated by the group of experts were included at level of recommendation IV

octreotide i.v. (an analogue with longer half-life: $1.5 \mathrm{~h}$, $100 \mu \mathrm{g}$ in $1 \mathrm{ml}$ vehicle) demonstrating a significant reduction of pain in 20 and 30 min. respectively [271, 272]. Most common side effects are nausea, diarrhoea and meteorism.

\section{Preventive treatment}

Preventive treatment is a fundamental part of the management of active $\mathrm{CH}$, which cannot be obtained only with the acute treatment due to the high frequency, suddenness and shortness of the attacks. A symptomatic treatment alone should be limited, in the episodic form, to active phases of short duration (mini cluster). The objectives of the preventive treatment are (1) the rapid disappearance of attacks and the resolution of active periods; (2) the reduction of frequency, intensity and duration of attacks [245, 246, 273].

The effectiveness of preventive treatment can be evaluated with certainty only in the chronic form, because in the episodic form there is always the doubt that the active period runs out spontaneously and not because of the treatment.

1. Preventive treatment must start early in the active phase.

2. Treatment must continue for at least 2 weeks after disappearance of attacks.

3. Treatment must be suspended gradually.

4. If the attacks reappear, dosages must be increased to therapeutic levels.

5. Treatment must be re-started at the onset of a subsequent active period.

6. The choice of the drug depends on different factors: age and lifestyle of the patient (avoid alcohol intake during the cluster period); expected duration of the cluster period; type of $\mathrm{CH}$ (episodic or chronic); response to previous treatments; reported side effects; contraindications to recommended drugs; comorbid diseases.

7. Polytherapy, tested in a few trials, is indicated only in patients resistant to monotherapy or patients who do not tolerate recommended drugs at optimal dosage.

Preventive drugs

\section{Verapamil}

In a double-blind controlled study versus placebo this drug at the dosage of $120 \mathrm{mg} \times 3$ per day has demonstrated to be effective in patients with episodic $\mathrm{CH}$. In these patients it is indicated as first-choice drug [274]. In the chronic form, according to two open studies and one head-to-head study versus lithium carbonate, it was effective in 50-55\% of the patients [275-277]. Dosages used were higher than those used for the episodic form (up to 960-1,200 mg). In the comparison study verapamil was effective more rapidly with fewer side effects [276]. The most relevant adverse events include arrhythmia (19\% of cases) and bradycardia (36\%); ECG monitoring of patients is recommended to avoid an atrioventricular block and symptomatic bradycardia [274, 278, 279]. In Italy, verapamil is not indicated for cluster headache.

\section{Lithium salts}

Results are available from some dated open studies and two RCTs demonstrating the effectiveness of this drug in the 
preventive treatment of chronic $\mathrm{CH}$. In the two RCTs, dosages were $300 \mathrm{mg} \times 3$ per day and $800 \mathrm{mg} / \mathrm{day}$, respectively [277, 280, 281]. Blood lithium levels should range from 0.4 to $0.6 \mathrm{mmol} / \mathrm{l}$. The most frequent adverse events include tremor, gastrointestinal disturbances, dizziness and polyuria [281, 282].

\section{Steroids}

In a retrospective study, prednisone (10-80 mg/day) induced a significant reduction (72\% of cases) or a complete remission (58\% of cases) of attacks within 3-10 days in a small sample of $\mathrm{CH}$ patients with episodic or chronic form, with the best results obtained for dosages $\geq 40 \mathrm{mg}$ [283]. When dosage was gradually reduced, $(<20 \mathrm{mg})$ the attacks reappeared. The drug is recommended for short-term usage (i.e., at the start of other recommended preventive treatments).

Methylprednisolone i.v. (250 mg in $100 \mathrm{ml}$ saline) followed by prednisone per os $(10 \mathrm{mg} / \mathrm{day})$ induced a further benefit in patients treated with optimal doses of verapamil [284]. The i.v. administration of methylprednisolone ( $30 \mathrm{mg} /$ $\mathrm{kg}$ in $500 \mathrm{ml}$ of saline in $3 \mathrm{~h}$ ) induced the interruption of the cluster period for 2-3 days, with a subsequent prompt reappearance of attacks [285]. No significant side effects were observed for both drugs at the used dosages.

\section{Serotonin antagonists}

Methysergide has been tested only in dated open studies which demonstrated an efficacy in 76-77\% of cases [286, 287]. The recommended dose is $8 \mathrm{mg}$ (although the dosage of $16 \mathrm{mg}$ has also been tested). The drug should be started with the dose of $2 \mathrm{mg}$ and should be increased gradually every 3-7 days. Side effects occur in 20-45\% of patients. The most frequent include nausea, dizziness, stomach pain, restlessness, somnolence and cramps. The drug should not be used for more than 6 months due to the possible development of retroperitoneal and lung fibrosis [288]. It is not available in Italy. Pizotifen (1-4 mg/day), in a dated double-blind study, showed a certain efficacy in a limited number of patients with episodic $\mathrm{CH}$ (reduction $>50 \%$ of attack frequency in $36 \%$ of the cases and interruption of cluster period in $21 \%$ ) [289]. Lisuride has been administered at variable dosages from 0.075 to $0.400 \mathrm{mg} /$ day to patients with episodic and chronic cluster headache in an open study. In all patients the drug induced a benefit without relevant side effects [290]. Lisuride is available in Italy at the dosages of $0.2-0.5 \mathrm{mg}$ and does not have the indication for $\mathrm{CH}$.

\section{Antiepileptics}

A positive effect of sodium valproate (1-2 g/day) had been suggested by an open study but was not confirmed by a more recent RCT [291, 292]. In the latter study, drug/ placebo was administered for 2 weeks and $50 \%$ of responders were identified in the valproate group versus $62 \%$ of placebo group [292]. Two open studies showed an effect of topiramate at different dosages (50 and $125 \mathrm{mg} /$ day and $25-200 \mathrm{mg} /$ day, respectively) with a remission within about 3 weeks from the beginning and a reduction of duration of the cluster period; a RCT (50-250 mg/day) did not show a superiority of topiramate compared with placebo [293-295]. After obtaining promising results in a single case, gabapentin has been tested in three open trials involving a limited number of patients at doses ranging from 800 to $3,600 \mathrm{mg} / \mathrm{day}$. The drug, administered for 4-6 months, reduced significantly the frequency and intensity of attacks or interrupted the cluster period in at least $50 \%$ of cases and was well tolerated [296-299]. Most of the antiepileptics listed above do not have the indication for $\mathrm{CH}$ in Italy.

Ergotamine derivatives i.m. ergotamine has been tested in an open study involving a limited number of patients during the active phase at dosages ranging from 0.25 to $0.50 \mathrm{mg} /$ day to $0.25 \mathrm{mg}$ four times per day. It induced a complete disappearance of attacks in all the patients without a reduction of cluster period. Side effects were somnolence, anorexia, bad taste and daze [300]. Dihydroergotamine i.v. was evaluated in two retrospective studies involving hospitalized patients. In the first study dihydroergotamine at the dosage of $0.5 \mathrm{mg}$ three times per day interrupted the cluster period in patients with both episodic and chronic forms, refractory to other preventive treatments. In the second study dihydroergotamine i.v. $(0.5+1 \mathrm{mg})$ and dihydroergotamine nasal spray $1 \mathrm{mg}$ or dihydroergotamine s.c. at the dosage of $0.5-1 \mathrm{mg}$ induced the disappearance of attacks or a reduction $>50 \%$ of attacks in $88 \%$ of patients with episodic and $57 \%$ of patients with chronic $\mathrm{CH}[301,302]$. Side effects were mild and only a few patients had to discontinue the drug.

\section{Histamine}

After the first observations of Horton (838), one dated open study involving few patients demonstrated that histamine sulphate i.v. ( $2.75 \mathrm{mg}$ in $250 \mathrm{ml}$ the first day, followed by $11 \mathrm{mg}$ in $500 \mathrm{ml}$ saline in the subsequent 9 days) induced a reduction of 75-100\% in one-third of cases, of 10-49\% in an another one-third of cases and no effect in the remaining cases [303].

\section{Triptans}

They were proposed for the short-term prophylaxis at the beginning of the cluster period instead of steroids (defined also as transitional therapy) or for the short-term 
prophylaxis of mini cluster. A reduction of the attacks was observed for frovatriptan ( $5 \mathrm{mg}$ /day) in studies involving episodic $\mathrm{CH}$ patients treated with verapamil (retrospective study) and chronic $\mathrm{CH}$ patients resistant to preventive treatments (open study) [304]. In an open study eletriptan (40 mg two times per day for 6 days) induced $50 \%$ reduction of attacks in one-third of the cases [305]. Responders were all treated with verapamil, whereas nonresponders did not use preventive drugs. In a randomized double-blind versus placebo study sumatriptan $100 \mathrm{mg}$ administered three times per day for 7 days did not induce a significant reduction of attack frequency [306].

\section{Capsaicin}

A first study demonstrated that the bilateral application of $300 \mu \mathrm{g}$ per nostril, repeated to reach a complete desensitization, induced a significant reduction and disappearance of the attacks, while a second study demonstrated that the application in the ipsilateral nostril is equally efficacious, whereas the application in the contralateral nostril was ineffective [307, 308]. This effect was observed in the majority of patients with both episodic and chronic $\mathrm{CH}$ after 10 days of treatment. In the chronic patients after 25-40 days from the last application of capsaicin the attacks reappeared. Capsaicin is not available in Italy.

\section{Melatonin}

Its efficacy at the dosage of $10 \mathrm{mg}$ per os has been tested in a limited number of patients with episodic form demonstrating the ability of the drug to reduce significantly the attack frequency. In responders this effect was obtained in $3-5$ days $[309,310]$. These promising results were not confirmed in a further pilot study involving patients with episodic $\mathrm{CH}$ [311].

Levels of recommendation for symptomatic and preventive drugs are reported in Table 13.

\section{Other trigeminal autonomic cephalgias (TACs)}

Paroxysmal hemicrania

Due to the low prevalence of this form, few studies have been carried out regarding the treatment of paroxysmal hemicrania $(\mathrm{PH})$.

They are, in general, non-standardized, open, non-controlled studies and at times the studies lack relevant clinical information data, such as the effective duration of the treatment, the dosage of tested drugs and the patient follow-up.

$\mathrm{PH}$, by definition, is a headache responsive to indomethacin and therefore, the diagnosis should be reconsidered in patients not responding to this drug at effective dosages $(200 \mathrm{mg}$ ) [312-314].

Other drugs have been tested in PH patients who do not tolerate indomethacin. They include verapamil, COX-2 selective inhibitors (rofecoxib, colecoxib) and piroxicam [315-320].

\section{Short-lasting unilateral neuralgiform headache with conjunctival injection and tearing (SUNCT)}

This rare headache form is also included in the TACs group and is therefore difficult to carry out controlled randomized clinical studies on its treatment [246].

Available data for several drugs have been obtained from case reports with limited patient series and rarely from observational studies.

In particular, studies involving lidocaine i.v. have been carried out on a few patients, whereas only case reports are available using i.v. or oral steroids [321].

Studies with more conspicuous patient series concern antiepileptic drugs used for preventive treatment. They include carbamazepine, gabapentin, topiramate and lamotrigine [321]. The most studied antiepileptic drug is lamotrigine due to its good efficacy and discrete tolerability.

\section{Levels of recommendation}

It was impossible to define levels of recommendation for all drugs used for preventive treatment of PH and SUNCT because of the limited number of patients tested.

For both headache forms, levels of evidence, scientific strength of evidence, clinical effectiveness and side effects are reported in Tables 14 and 15.

\section{Primary headaches management in particular conditions}

Emergency Department

In the Emergency Department (ED) acute treatment must be simple, based on a few drugs with a clear evidence of efficacy, administrable through rapid absorption routes (rectal, intramuscular or endovenous) and rapidly effective [358].

\section{Migraine}

Among NSAIDs, ketorolac $60 \mathrm{mg}$, administered intramuscularly, followed by a subsequent dose of $30 \mathrm{mg}$ after $8 \mathrm{~h}$, has been shown to be more effective than intranasal sumatriptan, but less effective than phenotiazines in relieving migraine attacks in the $\mathrm{ED}[67,68,359]$. 


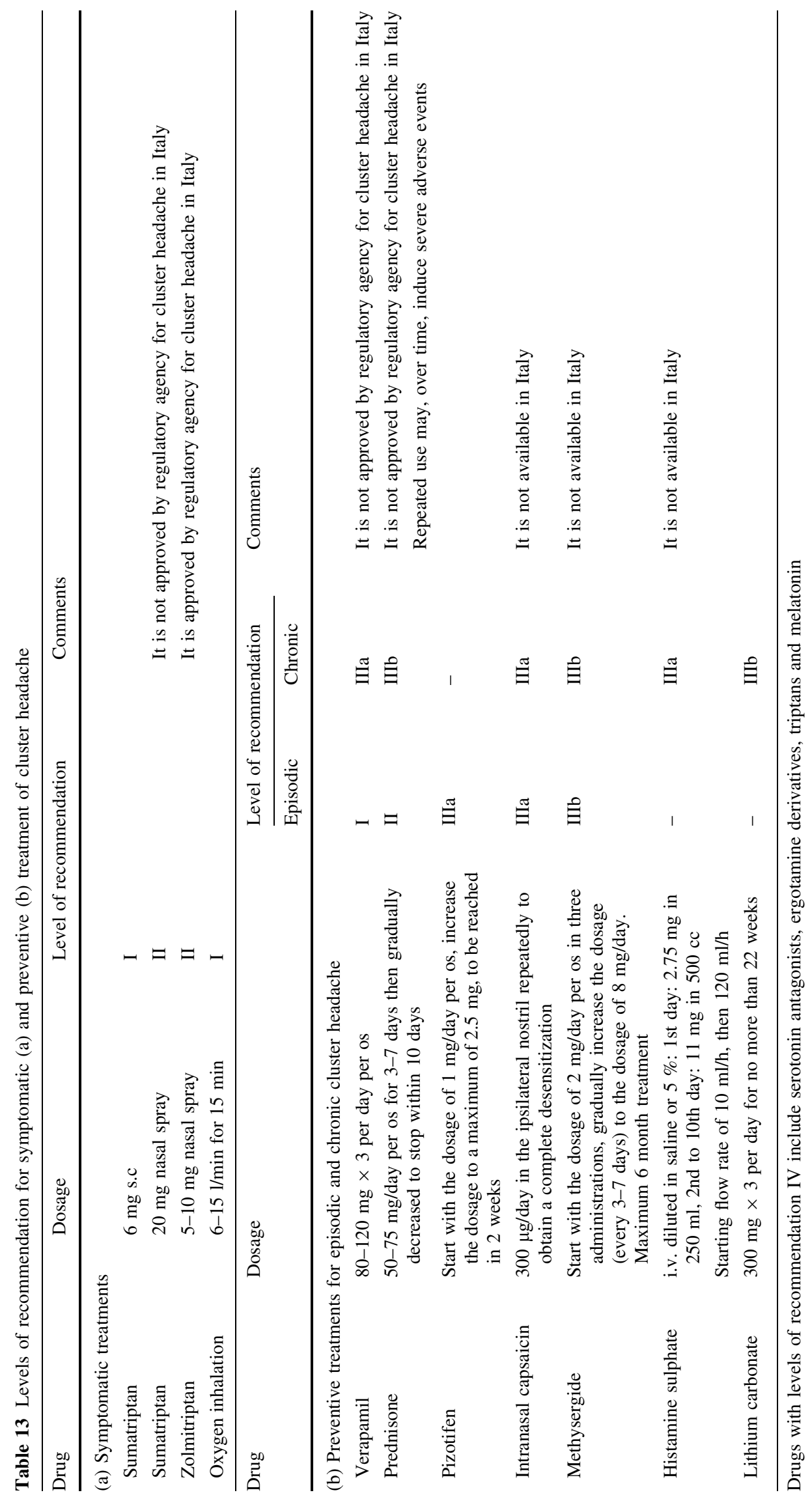


Table 14 Level of evidence, scientific strength of evidence, clinical effectiveness, adverse events of preventive drug for Paroxysmal Headache

\begin{tabular}{|c|c|c|c|c|c|c|c|}
\hline Drug & $\begin{array}{l}\text { Daily } \\
\text { dosage (mg) }\end{array}$ & $\begin{array}{l}\text { Level of } \\
\text { evidence }\end{array}$ & $\begin{array}{l}\text { Scientific strength } \\
\text { of evidence }{ }^{\mathrm{a}}\end{array}$ & $\begin{array}{l}\text { Clinical } \\
\text { effectiveness }\end{array}$ & Adverse events & $\begin{array}{l}\text { No. of } \\
\text { cases }\end{array}$ & References \\
\hline Indomethacin & $25-50$ & $\mathrm{C}$ & $0 /+$ & + & - & 1 & {$[322]$} \\
\hline Indomethacin & 75 & $\mathrm{C}$ & $0 /+$ & +++ & Occasional, not severe & 8 & [323-330] \\
\hline Indomethacin & 150 & $\mathrm{C}$ & $0 /+$ & +++ & - & 2 & {$[330,331]$} \\
\hline Indomethacin & $200-225$ & $\mathrm{C}$ & $0 /+$ & ++ & Occasional, not severe & 3 & {$[331,332]$} \\
\hline Verapamil & 480 & $\mathrm{C}$ & $0 /+$ & $?$ & - & 1 & [333] \\
\hline Piroxicam- $\beta$-cyclodextrine & $20-40$ & $\mathrm{C}$ & $0 /+$ & ++ & - & 6 & [334] \\
\hline Rofecoxib & 25 & $\mathrm{C}$ & $0 /+$ & +++ & - & 1 & [317] \\
\hline Rofecoxib & 50 & $\mathrm{C}$ & $0 /+$ & +++ & Occasional, not severe & 2 & {$[317,318]$} \\
\hline Celecoxib & 400 & $\mathrm{C}$ & $0 /+$ & +++ & - & 1 & [319] \\
\hline Verapamil & $240-320$ & $\mathrm{C}$ & $0 /+$ & ++ & - & 10 & [320] \\
\hline
\end{tabular}

${ }^{a}$ The scientific strength of evidence has been indicated as 0 (inefficacy)/+because there is no comparison with placebo or one active agent but sometimes the efficacy of the tested drug has been demonstrated

Table 15 Level of evidence, scientific strength of evidence, clinical effectiveness, adverse events of preventive drugs for SUNCT

\begin{tabular}{|c|c|c|c|c|c|c|c|}
\hline Drug & $\begin{array}{l}\text { Daily } \\
\text { dosage (mg) }\end{array}$ & $\begin{array}{l}\text { Level of } \\
\text { evidence }\end{array}$ & $\begin{array}{l}\text { Scientific strength } \\
\text { of evidence }\end{array}$ & $\begin{array}{l}\text { Clinical } \\
\text { effectiveness }\end{array}$ & $\begin{array}{l}\text { Adverse } \\
\text { events }\end{array}$ & $\begin{array}{l}\text { No. of } \\
\text { cases }\end{array}$ & References \\
\hline Topiramate oral & 75 & C & $0 /+$ & ++ & Mild & 2 & [333] \\
\hline Topiramate oral & 50 & $\mathrm{C}$ & $0 /+$ & +++ & - & 1 & {$[334]$} \\
\hline Carbamazepine oral & 200 & $\mathrm{C}$ & $0 /+$ & ++ & - & 1 & {$[335]$} \\
\hline Carbamazepine oral & 400 & $\mathrm{C}$ & $0 /+$ & +++ & - & 1 & {$[336]$} \\
\hline Carbamazepine oral & $600-1,000$ & $\mathrm{C}$ & $0 /+$ & $?$ & - & 5 & {$[337-340]$} \\
\hline Carbamazepine oral & 2,000 & $\mathrm{C}$ & $0 /+$ & $?$ & - & 1 & [341] \\
\hline Gabapentin oral & $800-2,700$ & $\mathrm{C}$ & $0 /+$ & +++ & - & 3 & {$[342-344]$} \\
\hline Lamotrigine oral & $100-200$ & $\mathrm{C}$ & $0 /+$ & ++ & - & 12 & {$[345-350]$} \\
\hline Lamotrigine oral & $300-400$ & $\mathrm{C}$ & $0 /+$ & +++ & - & 2 & {$[351,352]$} \\
\hline Verapamil & 480 & $\mathrm{C}$ & $0 /+$ & $?$ & - & 1 & [353] \\
\hline Topiramate oral & 200 & $\mathrm{C}$ & $0 /+$ & +++ & - & 1 & [354] \\
\hline Methylprednisolone oral & $\leq 1 / \mathrm{kg}$ & $\mathrm{C}$ & $0 /+$ & +++ & - & 3 & [355] \\
\hline Oxcarbazepine and gabapentin oral & $600 / 400$ & $\mathrm{C}$ & $0 /+$ & ++ & Mild & 1 & {$[356]$} \\
\hline Lidocaine i.v. & $1.3 / \mathrm{kg} / \mathrm{h}$ & $\mathrm{C}$ & $0 /+$ & +++ & - & 1 & {$[357]$} \\
\hline
\end{tabular}

${ }^{a}$ The scientific strength of evidence has been indicated as 0 (inefficacy)/+ because there is no comparison with placebo or one active agent but sometimes the efficacy of the tested drug has been demonstrated

Another first-choice treatment is ASA $1,000 \mathrm{mg}$ with or without metoclopramide [360]. Metamizole has been shown to be significantly more effective than placebo. Its potential side effects should be taken into account including severe hypotension, agranulocytosis and allergic reactions [361].

Positive data are available for dihydroergotamine $2 \mathrm{mg}$ nasal spray or suppository but the drug is not available in Italy and is less effective than sumatriptan and phenotiazine [71].

Subcutaneous, intranasal and rectal sumatriptan should be available in the ED and it may be particularly useful in migraine patients with nausea and/or vomiting [362-364].
Some evidence on the efficacy of $1 \mathrm{mg}$ of magnesium sulphate by intravenous route in the treatment of migraine attacks in the ED needs to be confirmed [365].

In the presence of nausea and vomiting $10 \mathrm{mg}$ metoclopramide by intramuscular route can be useful, even if occasional adverse events with this drug should be considered including sedation, akathisia, acute dystonic crises and other extrapyramidal symptoms such as stiff neck and oculogyric crises [84].

Among the other antiemetics, ondansetron $4-8 \mathrm{mg}$ by intravenous route may be used.

Prochlorperazine has been shown to be more effective than placebo, metoclopramide and other agents in the 
symptomatic treatment of migraine attacks in the ED [366, 367]. In association with diphenhydramine, prochlorperazine has been shown to be more effective than sumatriptan and sodium valproate i.v. [363, 368]. Its most frequent adverse event is sedation.

Meperidine, an opioid analgesic, although effective, may cause frequent adverse events such as sedation, disorientation, akathisia, gastrointestinal disturbances [369]. Furthermore, it can induce addiction and dependence and therefore it is not recommended by the group of experts.

Benzodiazepines (especially diazepam 5-10 mg, administered by i.v.) are useful in case of concomitant anxiety.

In the status migrainosus and in the treatment of attack recurrence, dexamethasone $10 \mathrm{mg}$ followed by a subsequent dose of $4 \mathrm{mg}$ every $6 \mathrm{~h}$ can be used, even if there are no consistent data on its efficacy in these two conditions [104, 107, 370-373].

\section{Tension-type headache}

The group of experts suggests the use of NSAIDs, i.m. or i.v., to obtain a more significant and rapid relief of pain in the rare cases in which tension-type headache patients present to the ED.

Oral benzodiazepines can also be useful in the case of attacks of great intensity, particularly in patients with concomitant anxiety.

Metoclopramide i.v. has demonstrated a modest analgesic efficacy at the dosage of $10 \mathrm{mg}$ [374].

The efficacy of chlorpromazine i.v., at the dosage of $10 \mathrm{mg}$, in tension-type headache patients presenting to the ED has also been demonstrated [375]. The most frequent adverse event is sedation, occasionally extrapyramidal symptoms or akathisia may occur.

\section{Cluster headache}

Cluster headache attack, given its short duration, is rarely treated in the ED. However, $\mathrm{CH}$ patients with frequent daily attacks can refer to the ED. In these cases indications for an adequate prophylaxis therapy should be provided and patients should be addressed to a Headache Center, possibly in the same hospital, to set up the most suitable preventive treatment.

\section{Headache management in pregnancy and lactation}

\section{Migraine}

No studies are available on the use of both symptomatic and prophylactic drugs in pregnant women. There are also few data on the risk related to their use during pregnancy, delivery and breast-feeding. Available recommendations come from the Regulatory Agencies of the single countries [376, 377].

It is worth noting the potential teratogenic risk of methysergide, other ergot alkaloids and metoclopramide, the use of which is unadvisable during pregnancy and breast-feeding.

There are conflicting data on the potential risk of foetal malformations, although rare, for amitriptyline. In the case of its use during pregnancy, amitriptyline should be suspended, at least 7 days before delivery to reduce the likelihood of a neonatal withdrawal syndrome which is characterized by respiratory distress and trouble feeding. Amitriptyline should be avoided during lactation [378].

According to the group of experts, the majority of symptomatic and prophylactic drugs are not recommended during pregnancy $[379,380]$. For symptomatic treatment, the first-choice drug is paracetamol, particularly during the first trimester of pregnancy. NSAIDs use, if needed, should be limited to second and third trimester of pregnancy [381]. Use of triptans is unadvisable during pregnancy. Data from pregnancy registries show a higher premature delivery frequency and lower weights for newborns in comparison with the average (sumatriptan), but no severe adverse events or complications during delivery (sumatriptan, rizatriptan) [54, 382-392].

In the case of nausea or vomiting during attacks, domperidone is the best choice drug. Antiemetics and sedative phenotiazinic drugs' use is not recommended [393, 394].

Prophylactic drugs should not be used, or at least only rarely, or at least used only rarely, during pregnancy, with particular regard to antiepileptics due to their teratogenic potential [395-397]. The only exceptions are magnesium and beta-blockers (propranolol, metoprolol in the second and third trimesters of pregnancy) for which there is no evidence of teratogenicity (level of recommendation II for both). Beta-blockers could have toxic effects on the newborn and may be responsible for intrauterine growth retardation, hypoglycemia, bradycardia and respiratory depression [398]. They are not recommended in women who present with migraine with aura during pregnancy; they can be used, on the contrary, during lactation. In unresponsive cases, dexamethasone or prednisone may be used [399].

Tension-type headache

There are no studies on TTH during pregnancy. Paracetamol should be preferred for the attack treatment. If preventive treatment is needed, non-pharmacological therapy option should be preferred. 


\section{Cluster headache}

Pregnant women suffering from $\mathrm{CH}[400,401]$ should be informed on the treatment benefits and risks and on the drug potential teratogenic effect. Dosage and number of administrations should be reduced to the minimum. Treatments to be preferred are oxygen, prednisone and verapamil. The use of subcutaneous or intranasal sumatriptan should be limited as much as possible. If verapamil cannot be used, gabapentin should be preferred as prophylactic treatment. During lactation, oxygen and sumatriptan may be used as symptomatic drugs and prednisone/ prednisolone, verapamil and lithium for prophylaxis.

\section{Headache management in the elderly}

In several guidelines for primary headaches specific indications for the management of elderly headache patients are lacking. Furthermore, specific controlled studies are lacking and therefore recommendations are mainly based on opinions of experts.

\section{Migraine}

Among migraine symptomatic drugs, the safest is paracetamol. NSAIDs may also be used, in absence of contraindications. They have however potentially severe adverse events, particularly gastroenteric and renal side effects [399].

Among antiemetics domperidone should be preferred to metoclopramide which, particularly in the elderly, can be responsible for extrapyramidal side effects.

Controlled studies on the use of triptans by patients over 65 years are lacking. From the few data available in the literature, the use of triptans in a general population did not demonstrate a greater frequency of cardio- and cerebrovascular complications in patients over 65 years without vascular risk factors $(1,037)$. In the experts' opinion their use is therefore possible in the presence of low frequency of attacks, after a careful evaluation of cardio- and cerebrovascular risks in the single patient. Conversely, ergot derivatives are contraindicated due to their widespread vasoconstrictive action. Use of combination drugs must be limited due to the risk of abuse. The use of opioid drugs is unadvisable because of the adverse events, such as disorientation, sedation and nausea [400].

First-choice drugs for prophylaxis are beta-blockers, particularly atenolol, metoprolol and bisoprolol because of their good tolerability profile [401]. Their contraindications are chronic obstructive pulmonary disease, bradycardia or ventricular hyperkinetic arrhythmias and depression. Beta- blockers must be used with caution in presence of diabetes. The use of flunarizine should be limited because of its potential side effects with particular regard to extrapyramidal disturbance and parkinsonism.

In relation to the high prevalence of depression in the elderly, antidepressants represent a good therapeutic option [402]. Although effective, tricyclic antidepressants (amitriptyline, nortriptyline) are not free from adverse events, which may be even severe, particularly in the elderly. They include sedation, cognitive disturbances, cardiac rhythm disturbances (tachycardia, hyperkinetic arrhythmias), postural hypotension, acute glaucoma and urinary retention, particularly in patients with prostatic hypertrophy [403].

SSRI and SNRI are better tolerated but they have not shown a significant efficacy for migraine prophylaxis in randomized controlled studies. Their usefulness must be evaluated in individual cases.

The use of antiepileptics should be limited to migraine with a high frequency of attacks and in the case of comorbidity of migraine with epilepsy. Topiramate and sodium valproate should be preferred based on the greater availability of data showing efficacy, but they are not free from adverse events. In particular, topiramate may induce cognitive disturbances and sedation and, rarely, is responsible for visual disturbances (acute myopia onset, glaucoma) and nephrolithiasis. Topiramate use is contraindicated in the last two disturbances [403].

Sodium valproate, conversely, may cause tremors, ataxia and hepatotoxicity (particularly in patients with previous hepatic disturbances). Other antiepileptics with lesser evidence of efficacy, but a higher tolerability profile can be alternatively used, such as gabapentin and, in some cases, pregabalin [401].

Given the recent evidence of efficacy of lisinopril and candesartan in migraine prophylaxis, their use can be considered because of the good tolerability profile especially in the presence of hypertension.

\section{Tension-type headache}

There are no studies regarding the treatment of tensiontype headache in elderly patients. Paracetamol and NSAIDs are recommended for symptomatic treatment, keeping in mind the considerations already reported for migraine.

Given the frequent comorbidity with depressive disturbances, antidepressants are the first-choice drugs among preventive drugs. Mirtazapine, SSRI (fluoxetine, paroxetine, fluvoxamine, sertraline, citalopram and escitalopram) or SNRI (venlafaxine, duloxetine) should be preferred because of their greater tolerability profile in comparison with tricyclics, even if controlled and randomized studies of elderly tension-type headache are lacking.

Drugs with fewer evidence of efficacy are tizanidine and onabotulinumtoxinA for which, in the literature, data are contrasting and, in the majority of cases, negative. 
Non-pharmacological procedures are often the only applicable treatments although there is no evidence of their efficacy in geriatric patients. It should be emphasized that the psychiatric approach, if needed, is particularly difficult in elderly patient.

\section{Cluster headache}

Sumatriptan s.c. is not recommended because of the limitation in its use by patients over 65 years of age and for the possible occurrence of angina and hypertensive crises. The first-choice drug is oxygen $100 \%$, by inhalation using a mask, at the rate of $7 \mathrm{l} / \mathrm{min}$ for $15 \mathrm{~min}$. For preventive treatment the best drug for geriatric patients is verapamil which is well tolerated by patients up to a dosage of $480 \mathrm{mg} /$ day. Side effects for which its suspension is recommended are rare (bradycardia, hypotension, constipation, peripheral edemas). It can be useful to associate melatonine with verapamil, at an evening dosage of 6-10 mg [402, 403]. In the case of an unsatisfactory response to verapamil, the second choice drug is prednisone at the dosage of $50 \mathrm{mg}$, in association with a proton-pump inhibitor. Its use should be limited to a short period (7-14 days). The use of lithium must be restricted to cases refractory to the other prophylactic treatments given the low tolerability in the elderly. The periodic plasma monitoring of lithium levels is needed and values should be maintained within the therapeutic range $(0.4-1.2 \mathrm{mEq} / \mathrm{l})$.

There are no data regarding the use of sodium valproate and topiramate by $\mathrm{CH}$ elderly patients in the unresponsive chronic forms.

As far as the non-pharmacological therapies are concerned, there are no data relative to the application in the elderly of new procedures such as the hypothalamic deep brain stimulation and greater occipital nerve stimulation.

With regard to the treatment of the other primary headaches in the elderly, such as hypnic headache and paroxysmal headache, one can refer to the papers recently published by our subgroups of experts on other primary headaches (2-5).

\section{Non-pharmacological therapy of primary headaches}

Just as for the pharmacological therapy the non-pharmacological therapy includes a symptomatic and a preventive treatment. The non-pharmacological techniques can be a valid alternative or complementary treatment. They are particularly indicated in the case of pregnancy, breast feeding, multiple therapies for comorbid diseases, poor tolerability of drugs, childhood and elderly.

Acute attack treatment

Most of the evidence for the techniques used in controlling headache attacks is purely anecdotic because RCTs are lacking. A study on 400 primary headache (including migraine, TTH and $\mathrm{CH}$ ) patients showed the scarce and momentary efficacy of self-administered manoeuvres on various regions of the head (compression, application of cold or heat, massage). In spite of this, $46 \%$ of the subjects used the manoeuvres constantly, at each attack [404].

In migraine a study compared the efficacy of sumatriptan with acupuncture showing a similar efficacy of the two drugs but it should be pointed out that it is difficult to apply acupuncture at the moment of attack [405].

Transcranial magnetic stimulation (TMS) determined a reduction or the remission of pain in $69 \%$ of migraine with aura patients versus $48 \%$ in the group treated with sham technique (level of recommendation II) [406]. Some evidence is available for the therapeutic blockade of greater occipital and supraorbital nerves in migraine patients [407].

\section{Preventive treatment}

Biofeedback is the non-pharmacological technique of first choice for migraine prophylaxis (level of recommendation I) [408]. The effect of biofeedback is slower but more lasting when compared with drug therapy. The association of biofeedback and pharmacological therapy induces a more marked effect [409]. Conflicting results deriving from the comparison with sham-acupuncture were obtained for acupuncture (level of recommendation II). However, in a recent study, its efficacy was found to be similar to that of flunarizine [410]. Acupuncture is contraindicated in the presence of coagulation deficits, cardiac pacemaker, cardiac arrhythmias and epilepsy. The expertise of the operator is fundamental. Needles have to be sterilized to avoid infections. Other nonpharmacological therapies, including relaxing techniques, sleep therapies, spinal manipulations, stretching, mobilization, physiotherapy and TMS, were rated at the level of recommendation III for migraine preventive therapy prophylaxis on the base of the available scientific evidence.

Further studies with homogeneous methods are needed to definitively demonstrate the efficacy of TENS, physical activity, anaesthetic blockade of the greater occipital and supraorbital nerves, diet restriction and orthodontic/gnathologic techniques (all of these were rated at level of recommendation IV). Several retrospective studies and three prospective studies (one of these was double-blind placebo-controlled) monitoring the post operative course after patent foramen ovale closure for cardiovascular indications showed improvement of concomitant migraine (level of recommendation III) [411, 412]. Promising results come from the surgical deafferentation of muscle trigger points in frontal, temporal and parietal regions (level of recommendation IV).

Basing upon the current scientific evidence biofeedback and acupuncture are the first-choice non pharmacologic 
therapies for the prophylaxis of tension-type headache. Biofeedback shows a slower but more lasting therapeutic effect than amitriptyline [409]. This technique induces a greater efficacy when it is associated with other non pharmacologic or pharmacologic options (level of recommendation I) [413]. Acupuncture was found to be more effective than drug preventive therapy and sham acupuncture and as effective as other therapies (physiotherapy, relaxation programs and massage + relaxation program) in a Cochrane review of 11 studies [414]. For contraindications and limits of this technique, see above.

Many other non pharmacological treatments are useful in the prevention of TTH, although further well-conducted studies are needed to support their efficacy. They include cognitive-behavioural therapy (as effective as amitriptyline but slower) [415], short-term psychodynamic psychotherapy (determining a lower rate of relapse in analgesic overuse than placebo after weaning) [416], osteopathic, chiropractic and massage protocols (contraindicated in the case of fractures, bone lesions and osteoporosis) [417, 418], Physiotherapy/Physical Exercise (several techniques showed to be effective but the results are not comparable because non homogeneous methods have been used in different studies) $[419,420]$ and orthodontic/gnathological techniques (an intraoral removable device induced an improvement similar to amitriptyline's one) [421]. All the aforementioned non pharmacologic techniques have been rated at the level of recommendation III. Moreover, the transcutaneous electrical nerve stimulation (TENS) is largely used in clinical practice to alleviate chronic pain but no evidence is up to now available to demonstrate its efficacy in TTH (level of Recommendation IV) [422].

Deep brain stimulation with stimulator implantation in the posterior hypothalamus represents the most innovative

Table 16 Symptomatic non-pharmacological treatments for migraine

\begin{tabular}{|c|c|c|c|c|c|c|}
\hline Treatment & $\begin{array}{l}\text { Level of } \\
\text { evidence }\end{array}$ & $\begin{array}{l}\text { Scientific strength } \\
\text { of evidence }\end{array}$ & $\begin{array}{l}\text { Clinical } \\
\text { effectiveness }\end{array}$ & $\begin{array}{l}\text { Adverse } \\
\text { events }\end{array}$ & $\begin{array}{l}\text { Level of } \\
\text { recommendation }\end{array}$ & References \\
\hline Pain relieving manoeuvres & - & - & 0 & - & IV & [404] \\
\hline Acupuncture & - & - & + & - & IV & {$[405]$} \\
\hline TMS & $\mathrm{B}$ & ++ & + & - & II & {$[406,427,428]$} \\
\hline Mechanical compression & - & - & 0 & - & IV & [429] \\
\hline GON blockade & $\mathrm{C}$ & ++ & + & - & III & {$[430]$} \\
\hline
\end{tabular}

$T M S$ transcranial magnetic stimulation, GON greater occipital nerve

Table 17 Preventive non-pharmacological treatments for migraine

\begin{tabular}{|c|c|c|c|c|c|c|}
\hline Treatment & $\begin{array}{l}\text { Level of } \\
\text { evidence }\end{array}$ & $\begin{array}{l}\text { Scientific } \\
\text { strength } \\
\text { of evidence }\end{array}$ & $\begin{array}{l}\text { Clinical } \\
\text { effectiveness }\end{array}$ & $\begin{array}{l}\text { Adverse } \\
\text { events }\end{array}$ & $\begin{array}{l}\text { Level of } \\
\text { recommendation }\end{array}$ & References \\
\hline Biofeedback & A & ++ & ++ & - & I & {$[408,409,431,432]$} \\
\hline Relaxation & $\mathrm{C}$ & $0 /+$ & + & - & III & {$[433,434]$} \\
\hline Cognitive-behavioural treatment & - & - & + & - & IV & {$[435-437]$} \\
\hline Sleep & $\mathrm{C}$ & ++ & + & - & III & {$[429,438]$} \\
\hline Chiropractic osteopathy & $\mathrm{C}$ & $0 /+$ & + & - & III & {$[419,422,439-441]$} \\
\hline Physiotherapy & $\mathrm{C}$ & + & + & - & III & {$[442-444]$} \\
\hline Acupuncture & A & ++ & + & Rare & II & {$[445]$} \\
\hline Transcutaneous electrical nerve stimulation (TENS) & - & - & $?$ & - & IV & [442] \\
\hline Transcranial magnetic stimulation (TMS) & $\mathrm{C}$ & + & + & Rare & III & {$[428,446]$} \\
\hline Physical activity & - & - & $?$ & - & IV & [447] \\
\hline Anaesthetic blockade & $\mathrm{C}$ & $?$ & $?$ & Rare & IV & [407] \\
\hline Diet & - & - & $?$ & - & IV & [448] \\
\hline Orthodontic and gnathological techniques & $\mathrm{C}$ & + & + & - & IV & {$[422,449]$} \\
\hline PFO Closure & $\mathrm{C}$ & ++ & $?$ & Rare, severe & III & {$[411,412]$} \\
\hline Occipital nerve stimulation & $\mathrm{C}$ & - & $?$ & Rare & & {$[450]$} \\
\hline Trigger points deafferentation & - & - & ? & - & IV & [451] \\
\hline
\end{tabular}

PFO patent foramen ovale closure 
Table 18 Symptomatic non-pharmacological treatments for tension-type headache

\begin{tabular}{lllllll}
\hline Treatment & $\begin{array}{l}\text { Level of } \\
\text { evidence }\end{array}$ & $\begin{array}{l}\text { Scientific strength } \\
\text { of evidence }\end{array}$ & $\begin{array}{l}\text { Clinical } \\
\text { effectiveness }\end{array}$ & $\begin{array}{l}\text { Adverse } \\
\text { events }\end{array}$ & $\begin{array}{l}\text { Level of } \\
\text { recommendation }\end{array}$ \\
\hline Pain relieving manoeuvres & - & - & 0 & - & IV & [404] \\
\hline
\end{tabular}

Table 19 Preventive non-pharmacological treatments for tension-type headache

\begin{tabular}{|c|c|c|c|c|c|c|}
\hline Treatment & $\begin{array}{l}\text { Level of } \\
\text { evidence }\end{array}$ & $\begin{array}{l}\text { Scientific strength } \\
\text { of evidence }\end{array}$ & $\begin{array}{l}\text { Clinical } \\
\text { effectiveness }\end{array}$ & $\begin{array}{l}\text { Adverse } \\
\text { events }\end{array}$ & $\begin{array}{l}\text { Level of } \\
\text { recommendation }\end{array}$ & References \\
\hline Biofeedback & A & ++ & ++ & - & I & {$[408,413,431]$} \\
\hline Cognitive-behavioural treatment & - & - & + & - & IV & {$[416,435,437,452]$} \\
\hline Strategic short-term psychotherapy & - & - & + & - & IV & [417] \\
\hline Chiropractic osteopathy & $\mathrm{C}$ & + & + & - & III & {$[418,419]$} \\
\hline Physiotherapy & $\mathrm{C}$ & + & + & - & III & {$[419,427,453-458]$} \\
\hline Acupuncture & A & ++ & + & Rare & II & {$[452]$} \\
\hline Transcutaneous electrical nerve stimulation (TENS) & - & - & $?$ & - & IV & {$[422]$} \\
\hline Physical activity & - & - & $?$ & - & IV & [421] \\
\hline Pranotherapy & - & - & $?$ & - & IV & [459] \\
\hline Orthodontic and gnathological techniques & $\mathrm{C}$ & + & + & - & IV & {$[414,422,449,460]$} \\
\hline
\end{tabular}

Table 20 Symptomatic non-pharmacological treatments for cluster headache

\begin{tabular}{lllllll}
\hline Treatment & $\begin{array}{l}\text { Level of } \\
\text { evidence }\end{array}$ & $\begin{array}{l}\text { Scientific strength } \\
\text { of evidence }\end{array}$ & $\begin{array}{l}\text { Clinical } \\
\text { effectiveness }\end{array}$ & $\begin{array}{l}\text { Adverse } \\
\text { events }\end{array}$ & $\begin{array}{l}\text { Level of } \\
\text { recommendation }\end{array}$ \\
\hline Pain relieving manoeuvres & - & - & 0 & - & IV & Reference \\
\hline
\end{tabular}

Table 21 Preventive non-pharmacological treatments for cluster headache

\begin{tabular}{|c|c|c|c|c|c|c|}
\hline Treatment & $\begin{array}{l}\text { Level of } \\
\text { evidence }\end{array}$ & $\begin{array}{l}\text { Scientific strength } \\
\text { of evidence }\end{array}$ & $\begin{array}{l}\text { Clinical } \\
\text { effectiveness }\end{array}$ & $\begin{array}{l}\text { Adverse } \\
\text { events }\end{array}$ & $\begin{array}{l}\text { Level of } \\
\text { recommendation }\end{array}$ & References \\
\hline Anesthetic blockade & - & - & $?$ & Rare & IV & {$[461]$} \\
\hline Lesion of trigeminal nucleus & $\mathrm{C}$ & + & $?$ & Rare, severe & IV & [462-467] \\
\hline Occipital nerve stimulation & $\mathrm{C}$ & - & $?$ & Rare & IV & {$[468,469]$} \\
\hline Hypotalamic deep brain stimulation & $\mathrm{B}$ & ++ & +++ & Rare, very severe & $\begin{array}{l}\text { II (only for chronic } \\
\text { refractory } \mathrm{CH} \text { ) }\end{array}$ & {$[423,470,471]$} \\
\hline
\end{tabular}

surgical technique for aborting chronic refractory cluster headache. Pain relief has been obtained in $83 \%$ of 16 cluster headache patients followed up for 5 years, with $61 \%$ of patients completely free from pain [423]. The efficacy of this approach has been confirmed in nine cluster headache patients followed up for 2 years in $71 \%$ of cases [424]. In a recent double-blind, prospective, crossover study versus sham stimulation involving 11 cluster headache patients a reduction of attacks $>50 \%$ was observed in six patients [425]. This technique is not free from risks: a case of death for cerebral haemorrhage was reported in a case series of seven cluster headache patients who underwent hypothalamic deep brain stimulation [426]. It should be reserved only to chronic cluster headache patients, totally resistant to all therapeutic strategies (level of recommendation II).

Levels of recommendation

Levels of evidence, scientific strength of evidence and clinical effectiveness for symptomatic and preventive nonpharmacological treatments are reported in Tables 16 and 17 for migraine, Tables 18 and 19 for tension-type headache and Tables 20 and Table 21 for cluster headache.

Conflict of interest None. 
Open Access This article is distributed under the terms of the Creative Commons Attribution License which permits any use, distribution, and reproduction in any medium, provided the original author(s) and the source are credited.

\section{Members of the Ad Hoc Committee}

\author{
Marta Allena \\ Vincenzo Amenta \\ Giuseppe Capo \\ Stefano Caproni \\ Claudio Antonio Caputi \\ Cinzia Cavestro \\ Biagio Ciccone \\ Cecilia Condello \\ Fernando Conte \\ Ilenia Corbelli \\ Alfredo Costa \\ Alfio D'Agati \\ Giovanni D'Antonio \\ Filippo Dainese \\ Giorgio Dalla Volta \\ Emilio De Caro \\ Francesco De Cesaris \\ Milena De Marinis \\ Flavio Devetag \\ Graziella Di Meo \\ Franco Di Palma \\ Girolamo Di Trapani \\ Vincenzo Firetto \\ Enrico Ferrante \\ Andrea Giorgetti \\ Sara Gori \\ Enrico Grappiolo \\ Filippo Lanaia \\ Giovanni Battista La Pegna \\ Carlo Lisotto \\ Ferdinando Maggioni \\ Federico Mainardi \\ Annamaria Miccoli \\ Franco Mongini \\ Cesare Morandi \\ Gianni Moro \\ Marco Mucchiut \\ Antonio Palmieri \\ Patrizia Panicucci \\ Giuliano Relja \\ Paolo Rossi \\ Eugenia Rota \\ Francesco Salvadori \\ Mariantonietta Savarese
}

Vittorio Sciruicchio

Lucia Testa

Marco Trucco

\section{Lay Members}

Angela Piperni

Barbara Radaelli

Gianfranco Tazzioli

\section{References}

1. Ad Hoc Committee for the Diagnostic and Therapeutic Guidelines of Migraine and Cluster Headache (2001) Diagnostic and therapeutic guidelines for migraine and cluster headache. Italian Society for the Study of headaches (SISC). J Headache Pain 2(Suppl. 1):105-190

2. Ferrante E, Rossi P, Tassorelli C, Lisotto C, Nappi G (2010) Focus on therapy of primary stabbing headache. J Headache Pain 11(2):157-160 (epub 2010 Jan 30; review)

3. Allena M, Rossi P, Tassorelli C, Ferrante E, Lisotto C, Nappi G (2010) Focus on therapy of the Chapter IV headaches provoked by exertional factors: primary cough headache, primary exertional headache and primary headache associated with sexual activity. J Headache Pain 11(6):525-530 (epub 2010 Oct 2; review)

4. Lisotto C, Rossi P, Tassorelli C, Ferrante E, Nappi G (2010) Focus on therapy of hypnic headache. J Headache Pain 11(4):349-354 (epub 2010 Jun 29; review)

5. Rossi P, Tassorelli C, Allena M, Ferrante E, Lisotto C, Nappi G (2010) Focus on therapy: hemicrania continua and new daily persistent headache. J Headache Pain 11(3):259-265 (epub 2010 Feb 26; review. PubMed PMID: 20186563)

6. Torelli P, Jensen R (2010) Headache diaries and calendars. Handb Clin Neurol 97:137-146

7. Lipton RB, Stewart WF, Stone AM, Láinez MJ, Sawyer JP, Disability in Strategies of Care Study Group (2000) Stratified care vs step care strategies for migraine: the Disability in Strategies of Care (DISC) Study: 4. A randomized trial. JAMA 284(20):2599-2605

8. Ferrari MD, Roon KI, Lipton RB, Goadsby PJ (2001) Oral triptans (serotonin 5-HT $\mathrm{HB}_{1 \mathrm{~B} / 1 \mathrm{D}}$ agonists) in acute migraine treatment: a meta-analysis of 53 trials. Lancet 358:1668-1675

9. Pascual J, Mateos V, Roig C, Sanchez-Del-Rio M, Jiménez D (2007) Marketed oral triptans in the acute treatment of migraine: a systematic review on efficacy and tolerability. Headache 47:1152-1168

10. Tfelt-Hansen P (1998) Efficacy and adverse events of subcutaneous, oral, and intranasal sumatriptan used for migraine treatment: a systematic review based on number needed to treat. Cephalalgia 18(8):532-538

11. Derry CJ, Derry S, Moore RA (2012) Sumatriptan (oral route of administration) for acute migraine attacks in adults. Cochrane Database Syst Rev 2:CD008615

12. Derry CJ, Derry S, Moore RA (2012) Sumatriptan (rectal route of administration) for acute migraine attacks in adults. Cochrane Database Syst Rev 2:CD009664

13. Tfelt-Hansen $P(2000)$ Sumatriptan nasal spray in the acute treatment of migraine: a review of clinical studies. Cephalalgia 20(2):137

14. Chen LC, Ashcroft DM (2008) Meta-analysis of the efficacy and safety of zolmitriptan in the acute treatment of migraine. Headache 48(2):236-247 
15. Oldman AD, Smith LA, McQuay HJ, Moore RA (2001) Rizatriptan for acute migraine. Cochrane Database Syst Rev (3):CD003221

16. Ferrari MD, Loder E, McCarroll KA, Lines CR (2001) Metaanalysis of rizatriptan efficacy in randomized controlled clinical trials. Cephalalgia 21(2):129-136

17. Mathew NT (2005) Efficacy and tolerability of almotriptan in controlled clinical trials. Eur Neurol 53(Suppl 1):29-33 (epub 2005 May 3; review)

18. Smith LA, Oldman AD, McQuay HJ, Moore RA (2001) Eletriptan for acute migraine. Cochrane Database Syst Rev (3):CD003224

19. Elkind AH, MacGregor EA (2008) Frovatriptan for the acute treatment of migraine and prevention of predictable menstrual migraine. Expert Rev Neurother 8(5):723-736

20. Göbel H, Heinze A, Stolze H, Heinze-Kuhn K, Lindner V (1999) Open-labeled long-term study of the efficacy, safety, and tolerability of subcutaneous sumatriptan in acute migraine treatment. Cephalalgia 19(7):676-683 (discussion 626)

21. Pringsheim T, Davenport WJ, Dodick D (2008) Acute treatment and prevention of menstrually related migraine headache: evidence-based review. Neurology 70(17):1555-1563

22. Mett A, Tfelt-Hansen P (2008) Acute migraine therapy: recent evidence from randomized comparative trials. Curr Opin Neurol 21(3):331-337

23. Dowson AJ, Tepper SJ, Dahlöf C (2005) Patients' preference for triptans and other medications as a tool for assessing the efficacy of acute treatments for migraine. J Headache Pain 6(3):112-120 (epub 2005 May 13)

24. Cutrer FM, Goadsby PJ, Ferrari MD, Lipton RB, Dodick DW, McCrory D, Williams P (2004) Priorities for triptan treatment attributes and the implications for selecting an oral triptan for acute migraine: a study of US primary care physicians (the TRIPSTAR Project). Clin Ther 26(9):1533-1545

25. Buzzi MG (2008) Pathways to the best fit of triptans for migraine patients. Cephalalgia 28(Suppl 2):21-27

26. Belvís R, Pagonabarraga J, Kulisevsky J (2008) Individual triptan selection in migraine attack therapy. Recent Pat CNS Drug Discov 4(1):70-81

27. Blau JN (1992) Sumatriptan and recurrence of migraine. Lancet 340(8827): 1110

28. Cortelli P, Allais G, Tullo V, Benedetto C, Zava D, Omboni S, Bussone G (2011) Frovatriptan versus other triptans in the acute treatment of migraine: pooled analysis of three double-blind, randomized, cross-over, multicenter, Italian studies. Neurol Sci 32(Suppl 1):S95-S98

29. Láinez M (2004) Clinical benefits of early triptan therapy for migraine. Cephalalgia 24(Suppl 2):24-30 (review)

30. Goadsby PJ (2008) The 'Act when Mild' (AwM) study: a step forward in our understanding of early treatment in acute migraine. Cephalalgia 28(Suppl 2):36-41 (review)

31. Valade D (2009) Early treatment of acute migraine: new evidence of benefits. Cephalalgia 29(Suppl 3):15-21

32. Dodick DW (2005) Triptan nonresponder studies: implications for clinical practice. Headache 45(2):156-162

33. Färkkilä M, Olesen J, Dahlöf C, Stovner LJ, ter Bruggen JP, Rasmussen S, Muirhead N, Sikes C (2003) Eletriptan for the treatment of migraine in patients with previous poor response or tolerance to oral sumatriptan. Cephalalgia 23(6):463-471

34. Diener HC, Gendolla A, Gebert I, Beneke M (2005) Almotriptan in migraine patients who respond poorly to oral sumatriptan: a double-blind, randomized trial. Headache 45(7):874-882

35. Diener HC (2005) Efficacy of almotriptan $12.5 \mathrm{mg}$ in achieving migraine-related composite endpoints: a double-blind, randomized, placebo-controlled study in patients controlled study in patients with previous poor response to sumatriptan $50 \mathrm{mg}$. Curr Med Res Opin 21(10):1603-1610
36. Dahlöf CG (2006) Infrequent or non-response to oral sumatriptan does not predict response to other triptans-review of four trials. Cephalalgia 26(2):98-106 (review)

37. Goldstein J, Tiseo PT, Albert KS, Li C, Sikes CR (2006) Eletriptan in migraine patients reporting unsatisfactory response to rizatriptan. Headache 46(7):1142-1150

38. Jakubowski M, Levy D, Goor-Aryeh I, Collins B, Bajwa Z, Burstein R (2005) Terminating migraine with allodynia and ongoing central sensitization using parenteral administration of COX1/COX2 inhibitors. Headache 45(7):850-861

39. Ferrari MD (2001) Sumatriptan by injection. Cephalalgia 21(Suppl 1):6-8

40. Cady R, Schreiber C (2006) Sumatriptan: update and review. Expert Opin Pharmacother 7(11):1503-1514

41. Dahlöf C (1999) Sumatriptan nasal spray in the acute treatment of migraine: a review of clinical studies. Cephalalgia 19(9):769778

42. Ahrens SP, Farmer MV, Williams DL, Willoughby E, Jiang K, Block GA, Visser WH (1999) Efficacy and safety of rizatriptan wafer for the acute treatment of migraine. Rizatriptan Wafer Protocol 049 Study Group. Cephalalgia 19(5):525-530

43. Spierings EL, Rapoport AM, Dodick DW, Charlesworth B (2004) Acute treatment of migraine with zolmitriptan $5 \mathrm{mg}$ orally disintegrating tablet. CNS Drugs 18(15):1133-1141

44. The Multinational Oral Sumatriptan and Cafergot Comparative Study Group (1991) A randomized, double-blind comparison of sumatriptan and Cafergot in the acute treatment of migraine. Eur Neurol 31(5):314-322

45. Diener HC, Jansen JP, Reches A, Pascual J, Pitei D, Steiner TJ, Eletriptan and Cafergot Comparative Study Group (2002) Efficacy, tolerability and safety of oral eletriptan and ergotamine plus caffeine (Cafergot) in the acute treatment of migraine: a multicentre, randomised, double-blind, placebo-controlled comparison. Eur Neurol 47(2):99-107

46. Láinez MJ, Galván J, Heras J, Vila C (2007) Crossover, doubleblind clinical trial comparing almotriptan and ergotamine plus caffeine for acute migraine therapy. Eur J Neurol 14(3):269-275

47. Christie S, Göbel H, Mateos V, Allen C, Vrijens F, Shivaprakash M, Rizatriptan-Ergotamine/Caffeine Preference Study Group (2003) Crossover comparison of efficacy and preference for rizatriptan $10 \mathrm{mg}$ versus ergotamine/caffeine in migraine. Eur Neurol 49(1):20-29

48. Bigal ME, Lipton RB (2008) Excessive acute migraine medication use and migraine progression. Neurology 71(22):18211828 (review)

49. Cleves C, Tepper SJ (2008) Sumatriptan/naproxen sodium combination for the treatment of migraine. Expert Rev Neurother 8(9):1289-1297 (review)

50. Lipton RB, Dodick DW, Adelman JU, Kaniecki RG, Lener SE, White JD, Nelsen AC (2009) Consistency of response to sumatriptan/naproxen sodium in a placebo-controlled, crossover study. Cephalalgia 29(8):826-836 (epub 2009 Feb 12)

51. Krymchantowski AV, Bigal ME (2004) Rizatriptan versus rizatriptan plus rofecoxib versus rizatriptan plus tolfenamic acid in the acute treatment of migraine. BMC Neurol 4:10

52. Freitag F, Diamond M, Diamond S, Janssen I, Rodgers A, Skobieranda F (2008) Efficacy and tolerability of coadministration of rizatriptan and acetaminophen vs rizatriptan or acetaminophen alone for acute migraine treatment. Headache 48(6):921-930

53. Whyte CA, Tepper SJ (2009) Adverse effects of medications commonly used in the treatment of migraine. Expert Rev Neurother 9(9):1379-1391 (review)

54. Duong S, Bozzo P, Nordeng H, Einarson A (2010) Safety of triptans for migraine headaches during pregnancy and breastfeeding. Can Fam Physician 56(6):537-539 
55. Callenbach PM, Pels LP, Mulder PG, Linssen WH, Gooskens RH, van der Zwan JL, Brouwer OF, SUM30042 Trial Group (2007) Sumatriptan nasal spray in the acute treatment of migraine in adolescents and children. Eur J Paediatr Neurol 11(6):325-330 (epub 2007 Apr 10)

56. Lewis DW, Winner P, Hershey AD, Wasiewski WW, Adolescent Migraine Steering Committee (2007) Efficacy of zolmitriptan nasal spray in adolescent migraine. Pediatrics 120(2) :390-396

57. Robbins MS, Lipton RB (2010) Management of headache in the elderly. Drugs Aging 27(5):377-398. doi:10.2165/11315980000000000-00000

58. Eadie MJ (2001) Clinically significant drug interactions with agents specific for migraine attacks. CNS Drugs 15(2):105-118

59. Pfaffenrath V, Scherzer S (1995) Analgesics and NSAIDs in the treatment of the acute migraine attack. Cephalalgia 15(Suppl 15):14-20 (review)

60. Limmroth V (2001) Analgesics. Curr Med Res Opin 17(Suppl 1):s13-s16 (review)

61. Derry S, Moore RA, McQuay HJ (2010) Paracetamol (acetaminophen) with or without an antiemetic for acute migraine headaches in adults. Cochrane Database Syst Rev 11:CD008040

62. Kirthi V, Derry S, Moore RA, McQuay HJ (2010) Aspirin with or without an antiemetic for acute migraine headaches in adults. Cochrane Database Syst Rev 4:CD008041 (review)

63. Rabbie R, Derry S, Moore RA, McQuay HJ (2010) Ibuprofen with or without an antiemetic for acute migraine headaches in adults. Cochrane Database Syst Rev 10:CD008039

64. Derry S, Rabbie R, Moore RA (2012) Diclofenac with or without an antiemetic for acute migraine headaches in adults. Cochrane Database Syst Rev 2:CD008783

65. Suthisisang CC, Poolsup N, Suksomboon N, Lertpipopmetha V, Tepwitukgid B (2010) Meta-analysis of the efficacy and safety of naproxen sodium in the acute treatment of migraine. Headache 50(5):808-818 (epub 2010 Mar 5)

66. Shrestha M, Singh R, Moreden J, Hayes JE (1996) Ketorolac vs chlorpromazine in the treatment of acute migraine without aura. A prospective, randomized, double-blind trial. Arch Intern Med 156(15):1725-1728

67. Seim MB, March JA, Dunn KA (1998) Intravenous ketorolac vs intravenous prochlorperazine for the treatment of migraine headaches. Acad Emerg Med 5(6):573-576

68. Meredith JT, Wait S, Brewer KL (2003) A prospective doubleblind study of nasal sumatriptan versus IV ketorolac in migraine. Am J Emerg Med 21(3):173-175

69. Tfelt-Hansen PC, Koehler PJ (2008) History of the use of ergotamine and dihydroergotamine in migraine from 1906 and onward. Cephalalgia 28(8):877-886 (epub 2008 May 5)

70. Tfelt-Hansen P, Saxena PR, Dahlöf C, Pascual J, Láinez M, Henry P, Diener H, Schoenen J, Ferrari MD, Goadsby PJ (2000) Ergotamine in the acute treatment of migraine: a review and European consensus. Brain 123(Pt 1):9-18 (review)

71. Saper JR, Silberstein S (2006) Pharmacology of dihydroergotamine and evidence for efficacy and safety in migraine. Headache 46(Suppl 4):S171-S181

72. Azzopardi TD, Brooks NA (2008) Oral metoclopramide as an adjunct to analgesics for the outpatient treatment of acute migraine. Ann Pharmacother 42(3):397-402 (epub 2008 Feb 19)

73. Lipton RB (1997) Ergotamine tartrate and dihydroergotamine mesylate: safety profiles. Headache 37(Suppl 1):S33-S41

74. Raymond GV (1995) Teratogen update: ergot and ergotamine. Teratology 51(5):344-347

75. Straube A, Aicher B, Fiebich BL, Haag G (2011) Combined analgesics in (headache) pain therapy: shotgun approach or precise multi-target therapeutics? BMC Neurol 11:43. doi: 10.1186/1471-2377-11-43 (published online 2011 March 31)
76. Anneken K, Evers S, Husstedt IW (2010) Efficacy of fixed combinations of acetylsalicyclic acid, acetaminophen and caffeine in the treatment of idiopathic headache: a review. Eur $\mathbf{J}$ Neurol 17(4):534-e25 (review)

77. Di Monda V, Nicolodi M, Aloisio A, Del Bianco P, Fonzari M, Grazioli I, Uslenghi C, Vecchiet L, Sicuteri F (2003) Efficacy of a fixed combination of indomethacin, prochlorperazine, and caffeine versus sumatriptan in acute treatment of multiple migraine attacks: a multicenter, randomized, crossover trial. Headache 43(8):835-844

78. Sandrini G, Cerbo R, Del Bene E, Ferrari A, Genco S, Grazioli I, Martelletti P, Nappi G, Pinessi L, Sarchielli P, Tamburro P, Uslenghi C, Zanchin G (2007) Efficacy of dosing and re-dosing of two oral fixed combinations of indomethacin, prochlorperazine and caffeine compared with oral sumatriptan in the acute treatment of multiple migraine attacks: a double-blind, doubledummy, randomised, parallel group, multicentre study. Int $\mathrm{J}$ Clin Pract 61(8):1256-1269

79. Bigal ME, Serrano D, Buse D, Scher A, Stewart WF, Lipton RB (2008) Acute migraine medications and evolution from episodic to chronic migraine: a longitudinal population-based study. Headache 48(8): 1157-1168

80. Feinstein AR, Heinemann LA, Dalessio D, Fox JM, Goldstein J, Haag G, Ladewig D, O'Brien CP (2000) Do caffeine-containing analgesics promote dependence? A review and evaluation. Clin Pharmacol Ther 68(5):457-467

81. Ferrari A, Savino G, Gallesi D, Pinetti D, Bertolini A, Sances G, Coccia CP, Pasciullo G, Leone S, Loi M, Sternieri E (2006) Effect of overuse of the antimigraine combination of indomethacin, prochlorperazine and caffeine (IPC) on the disposition of its components in chronic headache patients. Pharmacol Res 54(2):142-149 (epub 2006 Apr 7)

82. Becker WL (1999) Migraine-associated symptoms: clinical significance and management. Can J Clin Pharmacol 6(Suppl A):15A-19A (review)

83. Schulman EA, Dermott KF (2003) Sumatriptan plus metoclopramide in triptan-nonresponsive migraineurs. Headache 43(7):729-733

84. Schwarzberg MN (1994) Application of metoclopramide specificity in migraine attacks therapy. Headache 34(7):439-441

85. Kelly AM, Walcynski T, Gunn B (2009) The relative efficacy of phenothiazines for the treatment of acute migraine: a metaanalysis. Headache 49(9):1324-1332 (epub 2009 Jun 2)

86. Colman I, Brown MD, Innes GD, Grafstein E, Roberts TE, Rowe BH (2004) Parenteral metoclopramide for acute migraine: meta-analysis of randomised controlled trials. BMJ 329(7479): 1369-1373 (epub 2004 Nov 18)

87. Waelkens J (1984) Dopamine blockade with domperidone: bridge between prophylactic and abortive treatment of migraine? A dosefinding study. Cephalalgia 4(2):85-90

88. Waelkens J (1982) Domperidone in the prevention of complete classical migraine. Br Med J (Clin Res Ed) 284(6320):944

89. Gill SK, Einarson A (2007) The safety of drugs for the treatment of nausea and vomiting of pregnancy. Expert Opin Drug Saf 6(6):685-694

90. Somerville BW (1976) Treatment of migraine attacks with an analgesic combination (Mersyndol). Med J Aust 1(23):865-866

91. Boureau F, Joubert JM, Lasserre V, Prum B, Delecoeuillerie G (1994) Double-blind comparison of an acetaminophen $400 \mathrm{mg}$ codeine $25 \mathrm{mg}$ combination versus aspirin $1000 \mathrm{mg}$ and placebo in acute migraine attack. Cephalalgia 14(2):156-161

92. Hakkarainen H, Gustafsson B, Stockman O (1978) A comparative trail of ergotamine tartrate, acetyl salicylic acid and a dextropropoxyphene compound in acute migraine attacks. Headache 18(1):35-39 (no abstract available)

93. Melanson SW, Morse JW, Pronchik DJ, Heller MB (1997) Transnasal butorphanol in the emergency department management of migraine headache. Am J Emerg Med 15(1):57-61 
94. Hoffert MJ, Couch JR, Diamond S, Elkind AH, Goldstein J, Kohlerman NJ 3rd, Saper JR, Solomon S (1995) Transnasal butorphanol in the treatment of acute migraine. Headache 35(2):65-69

95. Davis CP, Torre PR, Williams C, Gray C, Barrett K, Krucke G, Peake D, Bass B Jr (1995) Ketorolac versus meperidine-pluspromethazine treatment of migraine headache: evaluations by patients. Am J Emerg Med 13(2):146-150

96. Silberstein SD, Freitag FG, Rozen TD, Kudrow DB, Hewitt DJ, Jordan DM, Fisher AC, Rosenthal NR, CAPSS-223 Investigators (2005) Tramadol/acetaminophen for the treatment of acute migraine pain: findings of a randomized, placebo-controlled trial. Headache 45(10):1317-1327

97. Engindeniz Z, Demircan C, Karli N, Armagan E, Bulut M, Aydin T, Zarifoglu M (2005) Intramuscular tramadol vs. diclofenac sodium for the treatment of acute migraine attacks in emergency department: a prospective, randomised, double-blind study. J Headache Pain 6(3):143-148 (epub 2005 May 13)

98. Alemdar M, Pekdemir M, Selekler HM (2007) Single-dose intravenous tramadol for acute migraine pain in adults: a singleblind, prospective, randomized, placebo-controlled clinical trial. Clin Ther 29(7):1441-1447

99. Bigal ME, Lipton RB (2009) Excessive opioid use and the development of chronic migraine. Pain 142(3):179-182 (epub 2009 Feb 15)

100. Silberstein SD, McCrory DC (2001) Butalbital in the treatment of headache: history, pharmacology, and efficacy. Headache 41(10):953-967

101. Rapoport AM, Bigal ME, Tepper SJ, Sheftell FD (2004) Intranasal medications for the treatment of migraine and cluster headache. CNS Drugs 18(10):671-685 (review)

102. Maizels M, Scott B, Cohen W, Chen W (1996) Intranasal lidocaine for treatment of migraine: a randomized, double-blind, controlled trial. JAMA 276(4):319-321

103. Blanda M, Rench T, Gerson LW, Weigand JV (2001) Intranasal lidocaine for the treatment of migraine headache: a randomized, controlled trial. Acad Emerg Med 8(4):337-342

104. Colman I, Friedman BW, Brown MD, Innes GD, Grafstein E, Roberts TE, Rowe BH (2008) Parenteral dexamethasone for acute severe migraine headache: meta-analysis of randomised controlled trials for preventing recurrence. BMJ 336(7657): 1359-1361 (epub 2008 Jun 9; review)

105. Singh A, Alter HJ, Zaia B (2008) Does the addition of dexamethasone to standard therapy for acute migraine headache decrease the incidence of recurrent headache for patients treated in the emergency department? A meta-analysis and systematic review of the literature. Acad Emerg Med 15(12):1223-1233 (epub 2008 Oct 25; review. Erratum in: Acad Emerg Med. 2009 May;16(5):435)

106. Fiesseler FW, Shih R, Szucs P, Silverman ME, Eskin B, Clement M, Saxena R, Allegra J, Riggs RL, Majlesi N (2011) Steroids for migraine headaches: a randomized double-blind, two-armed, placebo-controlled trial. J Emerg Med 40(4):463-468

107. Friedman BW, Greenwald P, Bania TC, Esses D, Hochberg M, Solorzano C, Corbo J, Chu J, Chew E, Cheung P, Fearon S, Paternoster J, Baccellieri A, Clark S, Bijur PE, Lipton RB, Gallagher EJ (2007) Randomized trial of IV dexamethasone for acute migraine in the emergency department. Neurology 69(22):2038-2044 (epub 2007 Oct 17)

108. Kelly AM, Kerr D, Clooney M (2008) Impact of oral dexamethasone versus placebo after ED treatment of migraine with phenothiazines on the rate of recurrent headache: a randomised controlled trial. Emerg Med J 25(1):26-29

109. Prakash S, Shah ND (2009) Migrainous vertigo responsive to intravenous methylprednisolone: case reports. Headache 49(8):1235-1239 (epub 2009 Jun 22)
110. Robbins MS, Wang D, DeOrchis VS (2010) Methylprednisolone for status migrainous vertigo and cephalic status migrainosus. Headache 50(2):328

111. Bigal M, Sheftell F, Tepper S, Tepper D, Ho TW, Rapoport A (2008) A randomized double-blind study comparing rizatriptan, dexamethasone, and the combination of both in the acute treatment of menstrually related migraine. Headache 48(9): $1286-1293$

112. Frazee LA, Foraker KC (2008) Use of intravenous valproic acid for acute migraine. Ann Pharmacother 42(3):403-407 (epub 2008 Feb 26)

113. Hoffmann J, Goadsby PJ (2012) New agents for acute treatment of migraine: CGRP receptor antagonists, iNOS inhibitors. Curr Treat Options Neurol 14(1):50-59

114. Ramadan NM (2007) Current trends in migraine prophylaxis. Headache 47(Suppl 1):S52-S57

115. Silberstein SD (2009) Preventive migraine treatment. Neurol Clin 27:429-443

116. Limmroth V, Michel MC (2001) The prevention of migraine: a critical review with special emphasis on beta-adrenoceptor blockers. Br J Clin Pharmacol 52(3):237-243

117. Evans RW, Rizzoli P, Loder E, Bana D (2008) Beta-blockers for migraine. Headache 48(3):455-460

118. Linde K, Rossnagel K (2004) Propranolol for migraine prophylaxis. Cochrane Database Syst Rev (2):CD003225 (review)

119. Schellenberg R, Lichtenthal A, Wöhling H, Graf C, Brixius K (2008) Nebivolol and metoprolol for treating migraine: an advance on beta-blocker treatment? Headache 48(1):118-125

120. Johannsson V, Nilsson LR, Widelius T, Jäverfalk T, Hellman P, Akesson JA, Olerud B, Gustafsson CL, Raak A, Sandahl G et al (1987) Atenolol in migraine prophylaxis a double-blind crossover multicentre study. Headache 27(7):372-374

121. Forssman B, Lindblad CJ, Zbornikova V (1983) Atenolol for migraine prophylaxis. Headache 23(4):188-190

122. Ryan RE Sr, Ryan RE Jr, Sudilovsky A (1982) Nadolol and placebo comparison study in the prophylactic treatment of migraine. Panminerva Med 24(2):89-94

123. Freitag FG, Diamond S (1984) Nadolol and placebo comparison study in the prophylactic treatment of migraine. J Am Osteopath Assoc 84(4):343-347

124. van de Ven LL, Franke CL, Koehler PJ (1997) Prophylactic treatment of migraine with bisoprolol: a placebo-controlled study. Cephalalgia 17(5):596-599

125. Pfaffenrath V, Rehm M (1998) Migraine in pregnancy: what are the safest treatment options? Drug Saf 19(5):383-388

126. Ludin HP (1991) The place of calcium antagonists in the prophylactic treatment of migraine. J Cardiovasc Pharmacol 18(Suppl 8):S17-S19 (review)

127. Centonze V, Magrone D, Vino M, Caporaletti P, Attolini E, Campanale G, Albano O (1990) Flunarizine in migraine prophylaxis: efficacy and tolerability of $5 \mathrm{mg}$ and $10 \mathrm{mg}$ dose levels. Cephalalgia 10(1):17-24

128. Diener HC, Matias-Guiu J, Hartung E, Pfaffenrath V, Ludin HP, Nappi G, De Beukelaar F (2002) Efficacy and tolerability in migraine prophylaxis of flunarizine in reduced doses: a comparison with propranolol $160 \mathrm{mg}$ daily. Cephalalgia 22(3):209221 (erratum in: Cephalalgia. $2002 \mathrm{Jul} ; 22(6): 488)$

129. Togha M, Ashrafian H, Tajik P (2006) Open-label trial of cinnarizine in migraine prophylaxis. Headache 46(3):498-502

130. Togha M, Rahmat Jirde M, Nilavari K, Ashrafian H, Razeghi S, Kohan L (2008) Cinnarizine in refractory migraine prophylaxis: efficacy and tolerability. A comparison with sodium valproate. J Headache Pain 9(2):77-82 (epub 2008 Feb 20. Erratum in: J Headache Pain. 2008 Aug;9(4):257)

131. Krebs R (1983) Adverse reactions with calcium antagonists. Hypertension 5(4 Pt 2):II125-II129 
132. Daniel JR, Mauro VF (1995) Extrapyramidal symptoms associated with calcium-channel blockers. Ann Pharmacother 29(1):73-75 (review)

133. Punay NC, Couch JR (2003) Antidepressants in the treatment of migraine headache. Curr Pain Headache Rep 7(1):51-54

134. Koch HJ, Jürgens TP (2009) Antidepressants in long-term migraine prevention. Drugs 69(1):1-19. doi:10.2165/00003495200969010-00001 (review)

135. Jackson JL, Shimeall W, Sessums L, Dezee KJ, Becher D, Diemer M, Berbano E, O’Malley PG (2010) Tricyclic antidepressants and headaches: systematic review and meta-analysis. BMJ 341:c5222. doi:10.1136/bmj.c5222 (review)

136. Bulut S, Berilgen MS, Baran A, Tekatas A, Atmaca M, Mungen B (2004) Venlafaxine versus amitriptyline in the prophylactic treatment of migraine: randomized, double-blind, crossover study. Clin Neurol Neurosurg 107(1):44-48

137. Tarlaci S (2009) Escitalopram and venlafaxine for the prophylaxis of migraine headache without mood disorders. Clin Neuropharmacol 32(5):254-258

138. Ozyalcin SN, Talu GK, Kiziltan E, Yucel B, Ertas M, Disci R (2005) The efficacy and safety of venlafaxine in the prophylaxis of migraine. Headache 45(2):144-152

139. Moja PL, Cusi C, Sterzi RR, Canepari C (2005) Selective serotonin re-uptake inhibitors (SSRIs) for preventing migraine and tension-type headaches. Cochrane Database Syst Rev 20(3):CD002919 (review)

140. Hays P (1997) Paroxetine prevents migraines. J Clin Psychiatry 58(1):30-31

141. Park HJ, Lee ST, Shim JY, Kim B, Hwang SH, Kim SH, Park JE, Park JH, Jung SH, Ahn JY, Chu K, Kim M (2006) The effect of paroxetine on the reduction of migraine frequency is independent of its anxiolytic effect. J Clin Neurol 2(4):246-251 (epub 2006 Dec 20)

142. Bánk J (1994) A comparative study of amitriptyline and fluvoxamine in migraine prophylaxis. Headache 34(8):476-478

143. Munera PA, Goldstein A (2001) Migraine and sertraline. J Am Acad Child Adolesc Psychiatry 40(10):1125-1126

144. Steiner TJ, Ahmed F, Findley LJ, MacGregor EA, Wilkinson M (1998) S-fluoxetine in the prophylaxis of migraine: a phase II double-blind randomized placebo-controlled study. Cephalalgia 18(5):283-286

145. d'Amato CC, Pizza V, Marmolo T, Giordano E, Alfano V, Nasta A (1999) Fluoxetine for migraine prophylaxis: a double-blind trial. Headache 39(10):716-719

146. Mulleners WM, Chronicle EP (2008) Anticonvulsants in migraine prophylaxis: a Cochrane review. Cephalalgia 28(6):585-597 (review)

147. Vikelis M, Rapoport AM (2010) Role of antiepileptic drugs as preventive agents for migraine. CNS Drugs 24(1):21-33. doi: 10.2165/11310970-000000000-00000 (review)

148. Lovell BV, Marmura MJ (2010) Valproate semisodium ER for migraine and cluster headache prophylaxis. Expert Opin Drug Metab Toxicol 6(4):495-504

149. Rothrock JF (1997) Successful treatment of persistent migraine aura with divalproex sodium. Neurology 48(1):261-262

150. Erdemoglu AK, Ozbakir S (2000) Valproic acid in prophylaxis of refractory migraine. Acta Neurol Scand 102(6):354-358

151. Silberstein SD, Collins SD (1999) Safety of divalproex sodium in migraine prophylaxis: an open-label, long-term study. Longterm Safety of Depakote in Headache Prophylaxis Study Group. Headache 39(9):633-643

152. Edwards KR, Potter DL, Wu SC, Kamin M, Hulihan J (2003) Topiramate in the preventive treatment of episodic migraine: a combined analysis from pilot, double-blind, placebo-controlled trials. CNS Spectr 8(6):428-432

153. Bussone G, Diener HC, Pfeil J, Schwalen S (2005) Topiramate $100 \mathrm{mg} /$ day in migraine prevention: a pooled analysis of double- blind randomised controlled trials. Int $\mathrm{J}$ Clin Pract 59(8): 961-968

154. Mathew NT, Rapoport A, Saper J, Magnus L, Klapper J, Ramadan N, Stacey B, Tepper S (2001) Efficacy of gabapentin in migraine prophylaxis. Headache 41(2):119-128

155. D'Andrea G, Granella F, Cadaldini M, Manzoni GC (1999) Effectiveness of lamotrigine in the prophylaxis of migraine with aura: an open pilot study. Cephalalgia 19(1):64-66

156. Lampl C, Buzath A, Klinger D, Neumann K (1999) Lamotrigine in the prophylactic treatment of migraine aura-a pilot study. Cephalalgia 19(1):58-63

157. Pascual J, Caminero AB, Mateos V, Roig C, Leira R, GarcíaMoncó C, Laínez MJ (2004) Preventing disturbing migraine aura with lamotrigine: an open study. Headache 44(10):10241028

158. Steiner TJ, Findley LJ, Yuen AW (1997) Lamotrigine versus placebo in the prophylaxis of migraine with and without aura. Cephalalgia 17(2):109-112

159. Tomson T, Battino D (2005) Teratogenicity of antiepileptic drugs: state of the art. Curr Opin Neurol 18(2):135-140 (review)

160. Perucca E, Meador KJ (2005) Adverse effects of antiepileptic drugs. Acta Neurol Scand Suppl 181:30-35

161. Mylecharane EJ (1991) 5-HT2 receptor antagonists and migraine therapy. J Neurol 238(Suppl 1):S45-S52 (review)

162. Behan PO, Connelly K (1986) Prophylaxis of migraine: a comparison between naproxen sodium and pizotifen. Headache 26(5):237-239

163. Vilming S, Standnes B, Hedman C (1985) Metoprolol and pizotifen in the prophylactic treatment of classical and common migraine. A double-blind investigation. Cephalalgia 5(1):17-23

164. Cerbo R, Casacchia M, Formisano R, Feliciani M, Cusimano G, Buzzi MG, Agnoli A (1986) Flunarizine-pizotifen single-dose double-blind cross-over trial in migraine prophylaxis. Cephalalgia $6(1): 15-18$

165. Rascol A, Montastruc JL, Rascol O (1986) Flunarizine versus pizotifen: a double-blind study in the prophylaxis of migraine. Headache 26(2):83-85

166. Young WB, Rozen TD (2005) Preventive treatment of migraine: effect on weight. Cephalalgia 25(1):1-11

167. Gales BJ, Bailey EK, Reed AN, Gales MA (2010) Angiotensinconverting enzyme inhibitors and angiotensin receptor blockers for the prevention of migraines. Ann Pharmacother 44(2):360-366 (epub 2010 Jan 19; review)

168. Stovner LJ (2007) Migraine prophylaxis with drugs influencing the renin-angiotensin system. Eur J Neurol 14(7):713-714

169. Schuh-Hofer S, Flach U, Meisel A, Israel H, Reuter U, Arnold G (2007) Efficacy of lisinopril in migraine prophylaxis - an open label study. Eur J Neurol 14(6):701-703

170. Schrader H, Stovner LJ, Helde G, Sand T, Bovim G (2001) Prophylactic treatment of migraine with angiotensin converting enzyme inhibitor (lisinopril): randomised, placebo controlled, crossover study. BMJ 322(7277):19-22

171. Tronvik E, Stovner LJ, Helde G, Sand T, Bovim G (2003) Prophylactic treatment of migraine with an with an angiotensin II receptor blocker: a randomized controlled trial. JAMA 289(1):65-69

172. Pradalier A, Lantéri-Minet M, Géraud G, Allain H, Lucas C, Delgado A (2004) The PROMISE study: PROphylaxis of MIgraine with SEglor (dihydroergotamine mesilate) in French primary care. CNS Drugs 18(15):1149-1163

173. Schürks M (2009) Dihydroergotamine: role in the treatment of migraine. Expert Opin Drug Metab Toxicol 5(9):1141-1148 (review)

174. Schoenen J, Jacquy J, Lenaerts M (1998) Effectiveness of highdose riboflavin in migraine prophylaxis. A randomized controlled trial. Neurology 50(2):466-470 
175. Agosti R, Duke RK, Chrubasik JE, Chrubasik S (2006) Effectiveness of Petasites hybridus preparations in the prophylaxis of migraine: a systematic review. Phytomedicine 13(9-10):743-746 (epub 2006 Sep 20)

176. Pittler MH, Ernst E (2000) Feverfew for preventing migraine. Cochrane Database Syst Rev 2004(1):CD002286 (update of: Cochrane Database Syst Rev (3):CD002286)

177. Sándor PS, Di Clemente L, Coppola G, Saenger U, Fumal A, Magis D, Seidel L, Agosti RM, Schoenen J (2005) Efficacy of coenzyme Q10 in migraine prophylaxis: a randomized controlled trial. Neurology 64(4):713-715

178. Magis D, Ambrosini A, Sándor P, Jacquy J, Laloux P, Schoenen $\mathrm{J}$ (2007) A randomized double-blind placebo-controlled trial of thioctic acid in migraine prophylaxis. Headache 47(1):52-57

179. Meyer C, Isler HR, Evers S, Grotemeyer KH, Taneri Z, Soyka D, Göbel H, Fischer M (1996) Magnesium in the prophylaxis of migraine - a double-blind placebo-controlled study. Cephalalgia 16(6):436-440

180. Peikert A, Wilimzig C, Köhne-Volland R (1996) Prophylaxis of migraine with oral magnesium: results from a prospective, multi-center, placebo-controlled and double-blind randomized study. Cephalalgia 16(4):257-263

181. Shuhendler AJ, Lee S, Siu M, Ondovcik S, Lam K, Alabdullatif A, Zhang X, Machado M, Einarson TR (2009) Efficacy of botulinum toxin type A for the prophylaxis of episodic migraine headaches: a meta-analysis of randomized, double-blind, placebo-controlled trials. Pharmacotherapy 29(7):784-791

182. Sullivan E, Bushnell C (2010) Management of menstrual migraine: a review of current abortive and prophylactic therapies. Curr Pain Headache Rep 14(5):376-384

183. MacGregor EA, Brandes JL, Silberstein S, Jeka S, Czapinski P, Shaw B, Pawsey S (2009) Safety and tolerability of short-term preventive frovatriptan: a combined analysis. Headache 49(9): $1298-1314$

184. Silberstein SD, Berner T, Tobin J, Xiang Q, Campbell JC (2009) Scheduled short-term prevention with frovatriptan for migraine occurring exclusively in association with menstruation. Headache 49(9):1283-1297 (epub 2009 Sep 14)

185. Tuchman MM, Hee A, Emeribe U, Silberstein S (2008) Oral zolmitriptan in the short-term prevention of menstrual migraine: a randomized, placebo-controlled study. CNS Drugs 22(10): $877-886$

186. Sances G, Martignoni E, Fioroni L, Blandini F, Facchinetti F, Nappi G (1990) Naproxen sodium in menstrual migraine prophylaxis: a double-blind placebo controlled study. Headache 30(11):705-709

187. de Lignières BB, Vincens M, Mauvais-Jarvis P, Mas JL, Touboul PJ, Bousser MG (1986) Prevention of menstrual migraine by percutaneous oestradiol. Br Med J (Clin Res Ed) 293(6561): 1540

188. Calhoun AH, Hutchinson S (2009) Hormonal therapies for menstrual migraine. Curr Pain Headache Rep 13(5):381-385 (review)

189. Diener HC, Dodick DW, Goadsby PJ, Bigal ME, Bussone G, Silberstein SD, Mathew N, Ascher S, Morein J, Hulihan JF, Biondi DM, Greenberg SJ (2009) Utility of topiramate for the treatment of patients with chronic migraine in the presence or absence of acute medication overuse. Cephalalgia 29(10):10211027 (epub 2009 Apr 23; review)

190. Silberstein S, Lipton R, Dodick D, Freitag F, Mathew N, Brandes J, Bigal M, Ascher S, Morein J, Wright P, Greenberg S, Hulihan J (2009) Topiramate treatment of chronic migraine: a randomized, placebo-controlled trial of quality of life and other efficacy measures. Headache 49(8):1153-1162

191. Ruiz L, Ferrandi D (2009) Topiramate in migraine progression. J Headache Pain 10(6):419-422 (epub 2009 Oct 17; review)
192. Dodick DW, Turkel CC, DeGryse RE, Aurora SK, Silberstein SD, Lipton RB, Diener HC, Brin MF, PREEMPT Chronic Migraine Study Group (2010) OnabotulinumtoxinA for treatment of chronic migraine: pooled results from the double-blind, randomized, placebo-controlled phases of the PREEMPT clinical program. Headache 50(6):921-936 (epub 2010 May 7)

193. Sandrini G, Perrotta A, Tassorelli C, Torelli P, Brighina F, Sances G, Nappi G (2011) Botulinum toxin type-A in the prophylactic treatment of medication-overuse headache: a multicenter, double-blind, randomized, placebo-controlled, parallel group study. J Headache Pain 12(4):427-433 (epub 2011 Apr 16)

194. Cady RK, Schreiber CP, Porter JA, Blumenfeld AM, Farmer KU (2011) A multi-center double-blind pilot comparison of onabotulinumtoxinA and topiramate for the prophylactic treatment of chronic migraine. Headache 51(1):21-32. doi:10.1111/j.15264610.2010.01796.x

195. Langemark M, Olesen J (1987) Effervescent ASA versus solid ASA in the treatment of tension headache. A double blind, placebo controlled study. Headache 27(2):90-95

196. Peters BH, Fraim CJ, Masel BE (1983) Comparison of $650 \mathrm{mg}$ aspirin and $1000 \mathrm{mg}$ acetaminophen with each other, and with placebo in moderately severe headache. Am J Med 74:36-42

197. Kubitzeka F, Zieglerb G, Gold MS, Liu JM, Ionescud E (2003) Low-dose diclofenac potassium in the treatment of episodic tension-type headache. Eur J Pain 7:155-162

198. Lange R, Lentz R (1995) Comparison of ketoprofen, ibuprofen and naproxene sodium in the treatment of tension type headache. Drugs Exp Clin Res 21(3):89-96

199. Diamond S (1983) Ibuprofen versus aspirin and placebo in the treatment of muscle contraction headache. Headache 23:206-210

200. Mehlisch DR, Weaver M, Fladung B (1988) Ketoprofen, acetaminophen, and placebo in the treatment of tension headache. Headache 38(8):579-589

201. Martinez-Martin P, Raffaelli E Jr, Titus F, Despuig J, Fragoso YD, Diez-Tejedor E, Liano H, Leira R, Cornet ME, van Toor BSJ, Camara J, Peil H, Vix JM, Ortiz P, and the Co-operative Study Group (2001) Efficacy and safety of metamizol vs. acetylsalicylic acid in patients with moderate episodic tension-type headache: a randomised, double-blind, placebo- and activecontrolled, multicentre study. Cephalalgia 21:604-610

202. Ramacciotti AS, Soares BG, Atallah AN (2007) Dipyrone for acute primary headaches. Cochrane Database Syst Rev 18(2): CD004842

203. Bigal ME, Bordini CA, Speciali JG (2002) Intravenous dipyrone for the acute treatment of episodic tension-type headache: a randomized, placebo-controlled, double-blind study. Braz J Med Biol Res 35(10):1139-1145

204. Prior MJ, Cooper KM, May LG, Bowen DL (2002) Efficacy and safety of acetaminophen and naproxen in the treatment of tension-type headache. A randomized, double-blind, placebo-controlled trial. Cephalalgia 22:740-748

205. Steiner TJ, Lange R, Voelker M (2003) Aspirin in episodic tension-type headache: placebo controlled dose-ranging comparison with paracetamol. Cephalalgia 23:59-66

206. Diamond S, Freitag FG, Balm TK, Berry DA (1997) The use of a combination agent of ibuprofen and caffeine in the treatment of episodic tension-type headache. Cephalalgia 17:466

207. Diamond S, Balm TK, Freitag FG (2000) Ibuprofen plus caffeine in the treatment of tension-type headache. Clin Pharmacol Ther 68:312-319

208. Migliardi JR, Armellino JJ, Friedman M, Gillings BD, Beaver WT (1994) Caffeine as an analgesic adjuvant in tension headache. Clin Pharmacol Ther 56:576-586

209. Pini LA, Del Bene E, Zanchin G, Sarchielli P, Di Trapani G, Prudenzano MP, LaPegna G, Savi L, Di Loreto G, Dionisio P, 
Granella F (2008) Tolerability and efficacy of a combination of paracetamol and caffeine in the treatment of tension-type headache: a randomised, double-blind, double-dummy, crossover study versus placebo and naproxen sodium. J Headache Pain 9(6):367-373

210. Diener HC, Pfanferath V, Pageler L, Peil H, Aicher B (2005) The fixed combination of asa, paracetamol and caffeine is more effective than single substance and dual combination for the treatment of headache: a multicentre, randomized, double blind, single dose, placebo controlled parallel group study. Cephalalgia 25:766-787

211. Friedman AP, Di Serio FJ (1987) Symptomatic treatment of chronically recurring tension headache: a placebo-controlled, multicenter investigation of Fioricet and acetaminophen with codeine. Clin Ther 10(1):69-81

212. Silberstein SD, McCrory DC (2001) Butalbital in the treatment of headache: history, pharmacology and efficacy. Cephalalgia 41:953-957

213. Cicek M, Karcioglu O, Parlak I, Ozturk V, Duman O, Serinken M, Guryay M (2004) Prospective, randomised, double blind, controlled comparison of metoclopramide and pethidine in the emergency treatment of acute primary vascular and tension type headache episodes. Emerg Med J 21:323-326

214. Bigal ME, Bordini CA, Speciali JG (2002) Intravenous chlorpromazine in the acute treatment of episodic tension-type headache. Arq Neuropsiquiatr 60(3-A):537-541

215. Gobel H, Schmidt G, Soyka D (1994) Effect of peppermint and eucalyptus oil preparations on neurophysiological and experimental algesimetric headache parameters. Cephalalgia 14:228-234

216. Gobel H, Fresenius J, Heinze A, Dworschak M, Soyka D (1996) Effectiveness of oleum menthae piperitae and paracetamol in therapy of headache of the tension type [German]. Nervenarzt 67:672-681

217. Schattner P, Randerson D. (1996) Tiger Balm as a treatment of tension headache. A clinical trial in general practice. Aust Fam Physician 25(2):216, 218, 220

218. Wöber C, Holzhammer J, Zeitlhofer J, Wessely P, WöberBingöl C (2006) Trigger factors of migraine and tension-type headache: experience and knowledge of the patients. J Headache Pain 7(4):188-195 (epub 2006 Aug 11)

219. Gobel H, Hamouz V, Hansen C, Heiningen K, Hirsch S, Lindner V, Heuss D, Soyka D (1994) Amitriptyline in therapy of chronic tension headache. Nervenarzt 65(10):670-679

220. Mitsikostas DD, Gatzonis S, Thomas A, Ilias A (1997) Buspirone vs amitriptyline in the treatment of chronic tension-type headache. Acta Neurol Scand 96(4):247-251

221. Langemark M, Loldrup D, Bech P, Olesen J (1990) Clomipramine and Mianserin in the treatment of chronic tension headache. A double blind, controlled study. Headache 30:118-121

222. Walker Z, Walker RW, Robertson MM, Stansfeld S (1998) Antidepressant treatment of chronic tension-type headache: a comparison between fluoxetine and desipramine. Headache 38(7):523-528

223. Tomkins GE, Jackson JL, O'Malley PG, Balden E, Santoro JE (2001) Treatment of chronic headache with antidepressants: a meta-analysis. Am J Med 11:54-63

224. Moja PL, Cusi C, Sterzi RR, Canepari C (2006) Selective serotonin re-uptake inhibitors (SSRIs) for preventing migraine and tension-type headaches (Review) II. Copyright (C) The Cochrane Collaboration. Wiley, NY

225. Bendtsen L, Jensen R (2004) Mirtazapine is effective in the prophylactic treatment of chronic tension-type headache. Neurology 62:1706-1711

226. Martín-Araguz A, Bustamante-Martínez C, de Pedro-Pijoán JM (2003) Treatment of chronic tension type headache with mirtazapine and amitriptyline. Rev Neurol 37(2):101-105
227. Adelman LC, Adelman JU, Von Seggern R, Mannix LK (2000) Venlafaxine extended release (XR) for the prophylaxis of migraine and tension-type headache: a retrospective study in a clinical setting. Headache 40(7):572-580

228. Zissis NP, Harmoussi S, Vlaikidis N, Mitsikostas D, Thomaidis T, Georgiadis G, Karageorgiou K (2007) A randomized, doubleblind, placebo-controlled study of venlafaxine XR in outpatients with tension-type headache. Cephalalgia 27:315-324

229. Manna V, Bolino F, Di Cicco L (1994) Chronic tension-type headache, mood depression and serotonin: therapeutic effects of fluvoxamine and mianserine. Headache 34:44-49

230. Fogelholm R, Murros K (1985) Maprotiline in chronic tension headache: a double-blind crossover study. Headache 25:273-275

231. Saper JR, Lake AE, Tepper SJ (2001) Nefazodone for chronic daily headache prophylaxis: an open-label study. Headache 41(5):465-474

232. Nappi G, Sandrini G, Granella F, Ruiz L, Cerutti G, Facchinetti F, Blandini F, Manzoni GC (1990) A new 5-HT2 antagonist (ritanserin) in the treatment of chronic headache with depression. A double-blind study vs amitriptyline. Headache 30(7):439-444

233. Ansink BJ, Hartman JW, Smakman JG (1992) Ritanserin is not effective in tension headache. Headache 32(6):314

234. Langemark M, Olesen J (1994) Sulpiride and paroxetine in the treatment of chronic tension-type headache. An explanatory double-blind trial. Headache 34(1):20

235. Fogelholm R, Murros K (1992) Tizanidine in chronic tensiontype headache: a placebo controlled double-blind cross-over study. Headache 32:509-513

236. Saper JR, Lake AE, Cantrell DT, Winner PK, White JR (2002) Chronic Daily Headache prophylaxis with tizanidine. A doubleblind, placebo-controlled, multicentric outcome study. Headache 42:470-482

237. Lance JW, Anthony M (1972) Cyclobenzaprine in the treatment of chronic tension headache. Med J Aust 2(25):1409-1411

238. Paiva T, Nunes JS, Moreira A, Santos J, Texeira J, Barbosa A (1982) Effects of frontalis EMG biofeedback and diazepam in the treatment of tension headache. Headache 22(5):216-220

239. Weber MB (1973) The treatment of muscle contraction headache with diazepam. Curr Ther Res 15:210-216

240. Shukla R, Nag D, Ahuja RC (1996) Alprazolam in chronic tension type headache. J Assoc Physicians India 44(9):641-644

241. Lampl C, Marecek S, May A, Bendtsen L (2006) A prospective, open-label, long-term, study of the efficacy and tolerability of topiramate in the prophylaxis of chronic tension-type headache. Cephalalgia 26:1203-1208

242. Ribeiro CA (2000) L-5-Hydroxytryptophan in the prophylaxis of chronic tension-type headache: a double-blind, randomized, placebo-controlled study. For the Portuguese Head Society. Headache 40(6):451-456

243. Rozen D, Sharma J (2006) Treatment of tension-type headache with botox: a review of the literature. Mt Sinai J Med 73(1):493-498 (review)

244. Schulte-Mattler WJ, Leinisch E (2008) Evidence based medicine on the use of botulinum toxin for headache disorders. J Neural Transm 115(4):647-651

245. Halker R, Vargas B, Dodick DW (2010) Cluster headache: diagnosis and treatment. Semin Neurol 30(2):175-185 (epub 2010 Mar 29)

246. Goadsby PJ, Cittadini E, Burns B, Cohen AS (2008) Trigeminal autonomic cephalalgias: diagnostic and therapeutic developments. Curr Opin Neurol 21(3):323-330

247. May A (2006) Update on the diagnosis and management of trigemino-autonomic headaches. J Neurol 253(12):1525-1532

248. The Sumatriptan Cluster Headache Study Group (1991) Treatment of acute cluster headache with sumatriptan. N Engl J Med 325:322-326 
249. Ekbom K, Monstad I, Prusinski A, Cole JA, Pilgrim AJ, Noronha D (1993) Subcutaneous sumatriptan in the acute treatment of cluster headache: a dose comparison study. Acta Neurol Scand 88:63-69

250. Gregor N, Schlesiger C, Akova-Öztürk E, Kraemer C, Husstedt I-W, Evers S (2005) Treatment of cluster headache attacks with less than $6 \mathrm{mg}$ subcutaneous sumatriptan. Headache 45:10691072

251. Ekbom K, Krabbe A, Micelli G, Prusinski A, cole JA, Pilgrim AJ, Noronha J, for the Sumatriptan Cluster Headache Long-term Study Group (1995) Cluster headache attacks treated for up three months with subcutaneous sumatriptan $(6 \mathrm{mg})$. Cephalalgia 15:230-236

252. Göbel H, Lindner A, Heinze A, Ribbat M, Deuschl G (1998) Acute therapy for cluster headache with sumatriptan: findings of a one-year long-term study. Neurology 51:908-911

253. Van Vliet JA, Bahra A, Martin V, Ramadan N, Aurora SK, Mathew NT, Ferrari MD, Goadsby PJ (2003) Intranasal sumatriptan in cluster headache. Randomized placebo-controlled double-blind study. Neurology 60:630-633

254. Law S, Derry S, Moore RA (2010) Triptans for acute cluster headache. Cochrane Database Syst Rev (4):CD008042

255. Bahra A, Gawel MJ, Hardebo J-E, Millson D, Breen SA, Goadsby PJ (2000) Oral zolmitriptan is effective in the acute treatment of cluster headache. Neurology 54:1832-1839

256. Cittadini E, May A, Straube A, Evers S, Bussone G, Goadsby PJ (2006) Effectiveness of intranasal zolmitriptan in acute cluster headache. A randomized, placebo-controlled, double-blind crossover study. Arch Neurol 63:1537-1542

257. Rapoport AM, Mathew NT, Silberstein SD, Dodick D, Tepper SJ, Sheftell FD, Bigal ME (2007) Zolmitriptan nasal spray in the acute treatment of cluster headache: a double-blind study. Neurology 69:821-826

258. Hedlund C, Rapoport AM, Dodick DW, Goadsby PJ (2009) Zolmitriptan nasal spray in the acute treatment of cluster headache: a meta-analysis of two studies. Headache 49(9):13151323

259. Fogan L (1985) Treatment of cluster headache. A double-blind comparison of oxygen $\mathrm{v}$ air inhalation. Arch Neurol 42:362-363

260. Cohen AS, Burns B, Goadsby PJ (2009) High-flow oxygen for treatment of cluster headache. JAMA 302:2451-2457

261. Rozen TD (2004) High oxygen flow rates for cluster headache. Neurology 63:593

262. Horton BT, Ryan R, Reynolds JR (1948) Clinical observations on the use of E.C. 110, a new agent for the treatment of headache. Mayo Clin Proc 23:105-108

263. Magee KR, Westerberg MR, DeJong RM (1952) Treatment of headache with ergotamine-caffeine suppositories. Neurology 2:477-480

264. Speed WG (1960) Ergotamine tartrate inhalation: a new approach to the management of recurrent vascular headaches. Am J Med Sci 240:327-331

265. Graham JR, Malvea BP, Gramm HF (1960) Aerosol ergotamine tartrate for migraine and Horton's syndrome. N Engl J Med 263:802-804

266. Andersson PG, Jespersen LT (1986) Dihydroergotamine nasal spray in the treatment of attacks of cluster headaches. Cephalalgia 6:51-54

267. Kittrelle JP, Grouse DS, Seybold ME (1985) Cluster headache. Local anesthetic abortive agents. Arch Neurol 42:496-498

268. Robbins L (1995) Intranasal lidocaine for cluster headache. Headache 35:83-84

269. Costa A, Pucci E, Antonaci F, Sances G, Granella F, Broich G, Nappi G (2000) The effect of intranasal cocaina and lidocaine on nitroglycerin-induced attacks in cluster headache. Cephalalgia 20:85-91
270. Barre' F (1982) Cocaine as an abortive agent in cluster headache. Headache 22:69-73

271. Sicuteri F, Geppetti P, Marabini S, Lembeck F (1984) Pain relief by somatostatin in attacks of cluster headache. Pain 18(4): 359-365

272. Matharu MS, Levy MJ, Meeran K, Goadsby PJ (2004) Subcutaneous octreotide in cluster headache: randomized placebocontrolled double-blind crossover study. Ann Neurol 56:488494

273. Francis GJ, Becker WJ, Pringsheim TM (2010) Acute and preventive pharmacologic treatment of cluster headache. Neurology 75(5):463-473

274. Leone M, D'Amico D, Frediani F, Moschiano F, Grazzi L, Attanasio A, Bussone G (2000) Verapamil in the prophylaxis of episodic cluster headache: a double-blind study versus placebo. Neurology 54:1382-1385

275. Gabai IJ, Spierings ELH (1989) Prophylactic treatment of cluster headache with verapamil. Headache 29:167-168

276. Bussone G, Leone M, Peccarisi C, Micieli G, Granella F, Magri M, Manzoni GC, Nappi G (1990) Double blind comparison of lithium and verapamil in cluster headache prophylaxis. Headache 30:411-417

277. Blau JN, Engel HO (2004) Individualizing treatment with verapamil for cluster headache patients. Headache 44:1013-1018

278. Loder E (2006) Cluster headache and the heart. Curr Pain Headache Rep 10(2):142-146

279. Cohen AS, Matharu MS, Goadsby PJ (2007) Electrocardiographic abnormalities in patients with cluster headache on verapamil therapy. Neurology 69(7):668-675

280. Ekbom K (1981) Lithium for cluster headache: review of the literature and preliminary results of long-term treatment. Headache 21:132-139

281. Steiner TJ, Hering R, Couturier EGM, Davies PTG, Whitmarsh TE (1997) Double-blind placebo-controlled trial of lithium in episodic cluster headache. Cephalalgia 17:673-675

282. Geddes JR, Burgess S, Hawton K, Jamison K, Goodwin GM (2004) Long-term lithium therapy for bipolar disorder: systematic review and meta-analysis of randomized controlled trials. Am J Psychiatry 161:217-222

283. Couch JR, Ziegler DK (1978) Prednisone therapy for cluster headache. Headache 18:219-221

284. Mir P, Alberca R, Navarro A, Montes E, Martínez E, Franco E, Cayuela A, Lozano P (2003) Prophylactic treatment of episodic cluster headache with intravenous bolus of metilprednisolone. Neurol Sci 24:318-321

285. Antonaci F, Costa A, Candeloro E, Sjaastad O, Nappi G (2005) Single high dose steroid treatment in episodic cluster headache. Cephalalgia 25:290-295

286. Curran DA, Hinterberger H, Lance JW (1967) Methysergide. Res Clin Stud Headache 1:74-122

287. Lovshin LL (1963) Treatment on histaminic cephalalgia with Methysergide (UML-491) (based on 159 cases). Dis Nerv Syst 24:120-124

288. Graham J, Suby H, Le Compte P, Sadowsky N (1966) Fibrotic disorders associated with methysergide therapy for headache. New Engl J Med 270:67-72

289. Ekbom K (1969) Prophylactic treatment of cluster headache with a new serotonin antagonist, BC 105. Acta Neurol Scandinav 45:601-610

290. Raffaelli E, Martins OJ, dos Santos P, Dágua Filho A (1983) Lisuride in cluster headache. Headache 23:117-121

291. Hering R, Kuritzky A (1989) Sodium valproate in the treatment of cluster headache: an open clinical trial. Cephalalgia 9:195-198

292. El Amrani M, Massiou H, Bousser MG (2002) A negative trial of sodium valproate in cluster headache: methodological issues. Cephalalgia 22:205-208 
293. Wheeler SD, Carrazana EJ (1999) Topiramate-treated cluster headache. Neurology 53:234-236

294. Láinez MJA, Pascual J, Pascual AM, Santonja JM, Ponz A, Salvador A (2003) Topiramate in the prophylactic treatment of cluster headache. Headache 43:784-789

295. Leone M, Dodick D, Rigamonti A, D’Amico D, Grazzi L, Mea E, Bussone G (2003) Topiramate in cluster headache prophylaxis: an open trial. Cephalalgia 23:1001-1002

296. Ahmed F (2000) Chronic cluster headache responding to gabapentin: a case report. Cephalalgia 20:252-253

297. Leandri M, Luzzani M, Cruccu G, Gottlieb A (2001) Drugresistant cluster headache responding to gabapentin: a pilot study. Cephalalgia 21:744-746

298. Schuh-Hofer S, Israel H, Neeb L, Reuter U, Arnold G (2007) The use of gabapentin in chronic cluster headache patients refractory to first-line therapy. Eur J Neurol 14:694-696

299. Vukovic V, Lovrencic-Huzjan A, Budišic M, Demarin V (2009) Gabapentin in the prophylaxis of cluster headache: an observational open label study. Acta Clin Croat 48:311-314

300. Symonds C (1956) A particular variety of headache. Brain 79:217-232

301. Mather PJ, Silberstein SD, Schulman EA, Mc Fadden Hopkins M (1991) The treatment of cluster headache with repetitive intravenous dihydroergotamine. Headache 31:525-532

302. Magnoux E, Zlotnik G (2004) Outpatient intravenous dihydroergotamine for refractory cluster headache. Headache 44:249-255

303. Diamond S, Freitag FG, Prager J, Gandhi S (1986) Treatment of intractable cluster. Headache 26:42-46

304. Siow HC, Pozo-Rosich P, Silberstein SD (2004) Frovatriptan for the treatment of cluster headaches. Cephalalgia 24:1045-1048

305. Zebenholzer K, Wöber C, Vigl M, Wessely P (2004) Eletriptan for the short-term prophylaxis of cluster headache. Headache 44:361-364

306. Monstad I, Krabbe A, Micieli G, Prusinski A, Cole J, Pilgrim A, Shevlin P (1995) Preemptive oral treatment with sumatriptan during a cluster period. Headache 35:607-613

307. Sicuteri F, Fusco BM, Marabini S, Camapagnolo V, Maggi CA, Geppetti P, Fanciullacci M (1989) Beneficial effect of capsaicin application to the nasal mucosa in cluster headache. Clin J Pain 5:49-53

308. Fusco BM, Marabini S, Maggi CA, Fiore G, Geppeti P (1994) Preventive effect of repeated nasal applications of capsaicin in cluster headache. Pain 59:321-325

309. Chazot G, Claustrat B, Brun J, Sassolas G, Schott B (1984) A chronobiological study on melatonin, cortisol, growth hormone and prolactin secretion in cluster headache. Cephalalgia 4:213-220

310. Leone M, D'Amico D, Moschiano F, Fraschini F, Bussone G (1996) Melatonin versus placebo in the prophylaxis of cluster headache: a double-blind pilot study with parallel groups. Cephalalgia 16:494-496

311. Pringsheim T, Magnoux E, Dobson CF, Hamel E, Aubé M (2002) Melatonin as adjunctive therapy in the prophylaxis of cluster headache: a pilot study. Headache 42:787-792

312. Sjaastad O, Vincent M (2010) Indomethacin responsive headache syndromes: chronic paroxysmal hemicrania and hemicrania continua. How they were discovered and what we have learned since. Funct Neurol 25(1):49-55

313. Pareja JA, Caminero AB, Franco E, Casado JL, Pascual J, Sánchez del Río M (2001) Dose, efficacy and tolerability of long-term indomethacin treatment of chronic paroxysmal hemicrania and hemicrania continua. Cephalalgia 21(9):906-910

314. May A, Leone M, Afra J, Linde M, Sándor PS, Evers S, Goadsby PJ, EFNS Task Force (2006) EFNS guidelines on the treatment of cluster headache and other trigeminal-autonomic cephalalgias. Eur J Neurol 13:1066

315. Porta-Etessam J, Cuadrado M, Rodríguez-Gómez O, GarcíaPtacek S, Valencia C (2010) Are Cox-2 drugs the second line option in indomethacin responsive headaches? J Headache Pain 11(5):405-407

316. Sjaastad O, Antonaci F (1995) A piroxicam derivative partly effective in chronic paroxysmal hemicrania and hemicrania continua. Headache 35(9):549-550

317. Lisotto C, Maggioni F, Mainardi F, Zanchin G (2003) Rofecoxib for the treatment of chronic paroxysaml emicrania. Cephalagia 23(4):318-320

318. Siow HC (2004) Seasonal episodic paroxysmal hemicrania responding to cyclooxygenase- 2 inhibitors. Cephalalgia 24(5):414-415

319. Mathew NT, Kailasam J, Fischer A (2000) Responsiveness to celecoxib in chronic paroxysmal hemicrania. Neurology 55(2):316

320. Evers S, Husstedt IW (1996) Alternatives in drug treatment of chronic paroxysmal hemicrania. Headache 36(7):429-432

321. Bussone G, Rapoport A (2010) Acute and preventive treatment of cluster headache and other trigeminal autonomic cephalgias. Handb Clin Neurol 97:431-442

322. Caminero AB, Pareja JA, Dobato JL (1998) Chronic paroxysmal hemicrania-tic syndrome. Cephalalgia 18(3):159-161

323. Martinez-Salio A, Porta-Etessam J, Perez-Martinez D, Balseiro J, Gutierrez-Rivas E (2000) Case reports: chronic paroxysmal hemicrania-tic syndrome. Headache 40(8):682-685

324. Evans RW, Olesen J (2000) Remitting chronic paroxysmal hemicrania or episodic paroxysmal hemicrania? Headache 40(10):858-859

325. Hannerz J (1993) Trigeminal neuralgia with chronic paroxysmal hemicrania: the CPH-tic syndrome. Cephalalgia 13(5):361-364

326. Goadsby PJ, Edvinsson L (1996) Neuropeptide changes in a case of chronic paroxysmal hemicrania-evidence for trigeminoparasympathetic activation. Cephalalgia 16(6):448-450

327. Mateo I, Pascual J (1999) Coexistence of chronic paroxysmal hemicrania and benign cough headache. Headache 39(6):437438

328. Boes CJ, Swanson JW, Dodick DW (1998) Chronic paroxysmal hemicrania presenting as otalgia with a sensation of external acoustic meatus obstruction: two cases and a pathophysiologic hypothesis. Headache 38(10):787-791

329. Pareja J, Pareja J (1992) Chronic paroxysmal hemicrania coexisting with migraine. Differential response to pharmacological treatment. Headache 32(2):77-78

330. Tehindrazanarivelo AD, Visy JM, Bousser MG (1992) Ipsilateral cluster headache and chronic paroxysmal hemicrania: two case reports. Cephalalgia 12(5):318-320

331. Spierings EL (1992) Episodic and chronic paroxysmal hemicrania. Clin J Pain 8(1):44-48

332. Boes CJ, Matharu MS, Goadsby PJ (2003) The paroxysmal hemicrania-tic syndrome. Cephalalgia 23(1):24-28

333. Rossi P, Cesarino F, Faroni J, Malpezzi MG, Sandrini G, Nappi G (2003) SUNCT syndrome successfully treated with topiramate: case reports. Cephalalgia 23(10):998-1000

334. Matharu MS, Boes CJ, Goadsby PJ (2002) SUNCT syndrome: prolonged attacks, refractoriness and response to topiramate. Neurology 58(8):1307

335. Calvo JF, Bruera OC, de Lourdes Figuerola M, Gestro D, Tinetti N, Leston JA (2004) SUNCT syndrome: clinical and 12-year follow-up case report. Cephalalgia 24(10):900-902

336. Putzki N, Nirkko A, Diener HC (2005) Trigeminal autonomic cephalalgias: a case of post-traumatic SUNCT syndrome? Cephalalgia 25(5):395-397 
337. Pareja JA, Sjaastad O (1994) SUNCT syndrome in the female. Headache 34(4):217-220

338. Raimondi E, Gardella L (1998) SUNCT syndrome. Two cases in Argentina. Headache 38(5):369-371

339. Becser N, Berky M (1995) SUNCT syndrome: a Hungarian case. Headache 35(3):158-160

340. Selekler HM, Efendi H, Alemdar M (2005) Short-lasting unilateral neuralgiform headache with severe lacrimation and mild conjunctival injection. Cephalalgia 25(4):317-320

341. Schwaag S, Frese A, Husstedt IW, Evers S (2003) SUNCT syndrome: the first German case series. Cephalalgia 23(5):398400

342. Porta-Etessam J, Benito-Leon J, Martinez-Salio A, Berbel A (2002) Gabapentin in the treatment of SUNCT syndrome. Headache 42(6):523-524

343. Graff-Radford SB (2000) SUNCT syndrome responsive to gabapentin (Neurontin). Cephalalgia 20(5):515-517

344. Hunt CH, Dodick DW, Bosch EP (2002) SUNCT responsive to gabapentin. Headache 42(6):525-526

345. Gutierrez-Garcia JM (2002) SUNCT syndrome responsive to lamotrigine. Headache 42(8):823-825

346. Leone M, Rigamonti A, Usai S, Damico D, Grazzi L, Bussone G (2000) Two new SUNCT cases responsive to lamotrigine. Cephalalgia 20(9):845-847

347. D'Andrea G, Granella F, Ghiotto N, Nappi G (2001) Lamotrigine in the treatment of SUNCT syndrome. Neurology 57(9): 1723-1725

348. Chakravarty A, Mukherjee A (2003) SUNCT syndrome responsive to lamotrigine: documentation of the first Indian case. Cephalalgia 23(6):474-475

349. D'Andrea G, Granella F, Cadaldini M (1999) Possible usefulness of lamotrigine in the treatment of SUNCT syndrome. Neurology 53(7):1609

350. Vikelis M, Xifaras M, Mitsikostas DD (2005) SUNCT syndrome in the elderly. Cephalalgia 25(11):1091-1092

351. Piovesan EJ, Siow C, Kowacs PA, Werneck LC (2003) Influence of lamotrigine over the SUNCT syndrome: one patient follow-up for two years. Arq Neuropsiquiatr 61(3A):691-694

352. Malik K, Rizvi S, Vaillancourt PD (2002) The SUNCT syndrome: successfully treated with lamotrigine. Pain Med 3(2):167-168

353. Narbone MC, Gangemi S, Abbate M (2005) A case of SUNCT syndrome responsive to verapamil. Cephalalgia 25(6):476-478

354. Kuhn J, Vosskaemper M, Bewermeyer H (2005) SUNCT syndrome: a possible bilateral case responding to topiramate. Neurology 64(12):2159

355. Trauninger A, Alkonyi B, Kovács N, Komoly S, Pfund Z (2010) Methylprednisolone therapy for short-term prevention of SUNCT syndrome. Cephalalgia 30(6):735-739

356. Marziniak M, Breyer R, Evers S (2009) SUNCT syndrome successfully treated with the combination of oxcarbazepine and gabapentin. Pain Med 10(8):1497-1500

357. Arroyo AM, Durán XR, Beldarrain MG, Pinedo A, GarcíaMoncó JC (2010) Response to intravenous lidocaine in a patient with SUNCT syndrome. Cephalalgia 30(1):110-112

358. Friedman D, Feldon S, Holloway R, Fisher S (2009) Utilization, diagnosis, treatment and cost of migraine treatment in the emergency department. Headache 49(8):1163-1173

359. Davis CP, Torre PR, Schafer NC, Dave B, Bass B Jr (1993) Ketorolac as a rapid and effective treatment of migraine headache: evaluations by patients. Am J Emerg Med 11(6):573-575

360. Diener HC, Lampl C, Reimnitz P, Voelker M (2006) Aspirin in the treatment of acute migraine attacks. Expert Rev Neurother 6(4):563-573 (review)

361. Bigal ME, Bordini CA, Tepper SJ, Speciali JG (2002) Intravenous dipyrone in the acute treatment of migraine without aura and migraine with aura: a randomized, double blind, placebo controlled study. Headache 42:862-871

362. Akpunonu BE, Mutgi AB, Federman DJ, Volinsky FG, Brickman K, Davis RL, Gilbert C, Asgharnejad M (1995) Subcutaneous sumatriptan for treatment of acute migraine in patients admitted to the emergency department: a multicenter study. Ann Emerg Med 25(4):464-469

363. Kostic MA, Gutierrez FJ, Rieg TS, Moore TS, Gendron RT (2010) A prospective, randomized trial of intravenous prochlorperazine versus subcutaneous sumatriptan in acute migraine therapy in the emergency department. Ann Emerg Med 56(1):1-6 (epub 2010 Jan 4)

364. Mellick LB, Mellick GA (2004) Treatment of primary headache in the emergency department. Headache 44(8):840-841

365. Mauskop A, Altura BT, Cracco RQ et al (1996) Intravenous magnesium sulfate rapidly alleviates headaches of various types. Headache 36(3):1541-1560

366. Coppola M, Yealy DM, Leibold RA (1995) Randomized, placebo-controlled evaluation of prochlorperazine versus metoclopramide for emergency department treatment of migraine headache. Ann Emerg Med 26(5):541-546

367. Friedman BW, Esses D, Solorzano C, Dua N, Greenwald P, Radulescu R, Chang E, Hochberg M, Campbell C, Aghera A, Valentin T, Paternoster J, Bijur P, Lipton RB, Gallagher EJ (2008) A randomized controlled trial of prochlorperazine versus metoclopramide for treatment of acute migraine. Ann Emerg Med 52(4):399-406 (epub 2007 Nov 19)

368. Tanen DA, Miller S, French T, Riffenburgh RH (2003) Intravenous sodium valproate versus prochlorperazine for the emergency department treatment of acute migraine headaches: a prospective, randomized, double-blind trial. Ann Emerg Med 41(6):847-853

369. Friedman BW, Kapoor A, Friedman MS, Hochberg ML, Rowe $\mathrm{BH}$ (2008) The relative efficacy of meperidine for the treatment of acute migraine: a meta-analysis of randomized controlled trials. Ann Emerg Med 52(6):705-713 (epub 2008 Jul 16)

370. Baden EY, Hunter CJ (2006) Intravenous dexamethasone to prevent the recurrence of benign headache after discharge from the emergency department: a randomized, double-blind, placebo-controlled clinical trial. CJEM 8:393-400

371. Innes GD, Macphail I, Dillon EC, Metcalfe C, Gao M (1999) Dexamethasone prevents relapse after emergency department treatment of acute migraine: a randomized clinical trial. CJEM $1: 26-33$

372. Donaldson D, Sundermann R, Jackson R, Bastani A (2008) Intravenous dexamethasone vs placebo as adjunctive therapy to reduce the recurrence rate of acute migraine headaches: a multicenter, double-blinded, placebo-controlled randomized clinical trial. Am J Emerg Med 26:124-130

373. Rowe BH, Colman I, Edmonds ML, Blitz S, Walker A, Wiens S (2008) Randomized controlled trial of intravenous dexamethasone to prevent relapse in acute migraine headache. Headache 48(3):333-340 (epub 2007 Nov 28)

374. Cicek M, Karcioglu O, Parlak I, Ozturk V, Duman O, Serinken M, Guryay M (2004) Prospective, randomised, double blind, controlled comparison of metoclopramide and pethidine in the emergency treatment of acute primary vascular and tension type headache episodes. Emerg Med J 21(3):323-326

375. Bigal ME, Bordini CA, Speciali JG (2002) Intravenous chlorpromazine in the acute treatment of episodic tension-type headache: a randomized, placebo controlled, double-blind study. Arq Neuropsiquiatr 60(3-A):537-541

376. Loder E (2007) Migraine in pregnancy. Semin Neurol 27(5):425-433 (review)

377. MacGregor EA (2007) Migraine in pregnancy and lactation: a clinical review. J Fam Plann Reprod Health Care 33(2):83-93 (review) 
378. Allais G, Gabellari IC, Borgogno P, De Lorenzo C, Benedetto C (2010) The risks of women with migraine during pregnancy. Neurol Sci 31(Suppl 1):S59-S61 (review)

379. Contag SA, Bushnell C (2010) Contemporary management of migrainous disorders in pregnancy. Curr Opin Obstet Gynecol 22(6):437-445

380. Cassina M, Di Gianantonio E, Toldo I, Battistella PA, Clementi M (2010) Migraine therapy during pregnancy and lactation. Expert Opin Drug Saf 9(6):937-948

381. Brandes JL (2008) Headache related to pregnancy: management of migraine and migraine headache in pregnancy. Curr Treat Options Neurol 10(1):12-19

382. Evans RW, Diamond ML (2000) Is sumatriptan use safe during pregnancy? Headache 40(10):856-857

383. Olesen C, Steffensen FH, Sorensen HT, Nielsen GL, Olsen J (2000) Pregnancy outcome following prescription for sumatriptan. Headache 40:20-24

384. Källen B, Lygner PE (2001) Delivery outcome in women who used drugs for migraine during pregnancy with special reference to sumatriptan. Headache 41:351-356

385. Fox AW, Chambers CD, Anderson PO, Diamond ML, Spierings EL (2002) Evidence-based assessment of pregnancy outcome after sumatriptan exposure. Headache 42:8-15

386. Loder E (2003) Safety of sumatriptan in pregnancy: a review of the data so far. CNS Drugs 17:1-7

387. Fox AW (2004) Revised estimates for probability of successful outcome of pregnancy after sumatriptan exposure. Headache 44(3):293-294

388. Evans EW, Lorber KC (2008) Use of 5-HT1 agonists in pregnancy. Ann Pharmacother 42:543-549

389. Cunnington M, Ephross S, Churchill P (2009) The safety of sumatriptan and naratriptan in pregnancy: what have we learned? Headache 49(10):1414-1422 (epub 2009 Oct 5)

390. Blair EM, Nelson KB (2011) Migraine and preterm birth. J Perinatol 31(6):434-439

391. Nezvalová-Henriksen K, Spigset O, Nordeng H (2010) Triptan exposure during pregnancy and the risk of major congenital malformations and adverse pregnancy outcomes: results from the Norwegian Mother and Child Cohort Study. Headache 50(4):563-575 (epub 2010 Jan 28)

392. Kurth T, Hernandez-Diaz S (2010) Commentary: triptan use during pregnancy: a safe choice? Headache 50(4):576-578

393. Marcus DA (2008) Managing headache during pregnancy and lactation. Expert Rev Neurother 8(3):385-395 (review)

394. Fox AW, Diamond ML, Spierings EL (2005) Migraine during pregnancy: options for therapy. CNS Drugs 19(6):465-481

395. Diav-Citrin O, Shechtman S, Bar-Oz B, Cantrell D, Arnon J, Ornoy A (2008) Pregnancy outcome after in utero exposure to valproate: evidence of dose relationship in teratogenic effect. CNS Drugs 22(4):325-334

396. Hill DS, Wlodarczyk BJ, Palacios AM, Finnell RH (2010) Teratogenic effects of antiepileptic drugs. Expert Rev Neurother 10(6):943-959 (review)

397. Hunt SJ, Morrow JI (2005) Safety of antiepileptic drugs during pregnancy. Expert Opin Drug Saf 4(5):869-877 (review)

398. Lucas S (2009) Medication use in the treatment of migraine during pregnancy and lactation. Curr Pain Headache Rep 13(5):392-398 (review)

399. Gladstone JP, Eross EJ, Dodick DW (2004) Migraine in special populations. Treatment strategies for children and adolescents, pregnant women, and the elderly. Postgrad Med 115(4):39-44, 47-50 (review)

400. Jürgens TP, Schaefer C, May A (2009) Treatment of cluster headache in pregnancy and lactation. Cephalalgia 29(4):391400 (epub 2009 Jan 19)
401. Giraud P, Chauvet S (2009) Cluster headache during pregnancy: case report and literature review. Headache 49(1):136-139

402. Sarchielli P, Mancini ML, Calabresi P (2006) Practical considerations for the treatment of elderly patients with migraine. Drugs Aging 23(2):131-155

403. Martin VT, Goldstein JA (2005) Evaluating the safety and tolerability profile of acute treatments for migraine. Am J Med 118(Suppl 1):36S-44S

404. Zanchin G, Maggioni F, Granella F, Rossi P, Falco L, Manzoni GC (2001) Self-administered pain-relieving manoeuvres in primary headaches. Cephalalgia 21(7):718-726

405. Melchart D, Thormaehlen J, Hager S, Liao J, Linde K, Weidenhammer W (2003) Acupuncture versus placebo versus sumatriptan for early treatment of migraine attacks: a randomized controlled trial. J Intern Med 253(2):181-188

406. Lipton RB, Dodick DW, Silberstein SD, Saper JL, Aurora SK, Pearlman SH, Fischell RE, Ruppel PL, Goadsby PJ (2010) Single-pulse transcranial magnetic stimulation for acute treatment of migraine with aura: a randomized, double-blind, parallel-group, sham-controlled trial. Lancet Neurol 9:373-380

407. Caputi CA, Firetto V (1997) Therapeutic blockade of greater occipital and supraorbital nerves in migraine patients. Headache 37:174-179

408. Nestoriuc Y, Martin A (2007) Efficacy of biofeedback for migraine: a meta-analysis. Pain 128(1-2):111-127 (epub 2006 Nov)

409. Mullally WJ, Hall K, Goldstein R (2009) Efficacy of biofeedback in the treatment of migraine and tension type headaches. Pain Physician 12(6):1005-1011

410. Wang LP, Zhang XZ, Guo J, Liu HL, Zhang Y, Liu CZ, Yi JH, Wang LP, Zhao JP, Li SS (2011) Efficacy of acupuncture for migraine prophylaxis: a single-blinded, double-dummy, randomized controlled trial. Pain 152(8):1864-1871 (epub 2011 May 26)

411. Rigatelli G, Dell'Avvocata F, Ronco F, Cardaioli P, Giordan M, Braggion G, Aggio S, Chinaglia M, Rigatelli G, Chen JP (2010) Primary transcatheter patent foramen ovale closure is effective in improving migraine in patients with high-risk anatomic and functional characteristics for paradoxical embolism. JACC Cardiovasc Interv 3(3):282-287

412. Dowson A, Mullen MJ, Peatfield R, Muir K, Khan AA, Wells C, Lipscombe SL, Rees T, De Giovanni JV, Morrison WL, HildickSmith D, Elrington G, Hillis WS, Malik IS, Rickards A (2008) Migraine Intervention With STARFlex Technology (MIST) trial: a prospective, multicenter, double-blind, sham-controlled trial to evaluate the effectiveness of patent foramen ovale closure with STARFlex septal repair implant to resolve refractory migraine headache. Circulation 117(11):1397-1404 (epub 2008 Mar 3)

413. Nestoriuc Y, Rief W, Martin A (2008) Meta-analysis of biofeedback for tension-type headache: efficacy, specificity, and treatment moderators. J Consult Clin Psychol 76(3):379-396

414. De Tommaso M, Shevel E, Pecoraro C, Sardaro M, Divenere D, Di Fruscolo O, Lamberti P, Livrea P (2006) Intra-oral orthosis vs amitriptyline in chronic tension-type headache: a clinical and laser evoked potentials study. Head Face Med 2:15

415. Holroyd KA, O’Donnel FJ, Stensland M, Lipchick GL, Cordingley GE, Carlson BW (2001) Management of chronic tensiontype headache with tricyclic antidepressant medication, stress management therapy, and their combination. JAMA 285(17): 2208-2214

416. Altieri M, Di Giambattista R, Di Clemente L (2009) Combined pharmacological and short-term psychodynamic psychotherapy for probable medication overuse headache: a pilot study. Cephalalgia 29:293-299 
417. Anderson E, Seniscal C (2006) A comparison of selected osteopathic treatment and relaxation for tension-type headaches. Headache 46(8):1273-1280

418. Ernst E (2004) Manual therapies for pain control: chiropractic and massage. Clin J Pain 20(1):8-12 (review)

419. Fernandez-de-las-Penas C, Alonso-Blanco C, San-Roman J, Miangollara-Page JC (2006) Methodological quality of randomized controlled trials of spinal manipulation and mobilization in TTH, migraine, and cervicogenic headache. J Orthop Sports Phys Ther 36(3):160-169

420. Söderberg E, Carlsson J, Stener-Victorin E (2006) Chronic tension-type headache treated with acupuncture, physical training and relaxation training. Between-group differences. Cephalalgia 26(11):1320-1329

421. Shankland WE (2002) Nociceptive trigeminal inhibition-tension suppression system: amethod of preventing migraine and tension headaches. Compend Contin Educ Dent 23:105-108

422. Bronfort G, Nilsson N, Haas M, EvansR, Goldsmith CH, Assendelft WJ, Bouter LM (2004) Non-invasive physical treatments for chronic/recurrent headache. Cochrane Database Syst Rev (3):CD001878 (review)

423. Leone M, Franzini A, Broggi G, Bussone G (2006) Hypothalamic stimulation for intractable cluster headache: long-term experience. Neurology 67(1):150-152

424. Franzini A, Leone M, Messina G, Cordella R, Marras C, Bussone G, Broggi G (2008) Neuromodulation in treatment of refractory headaches. Neurol Sci 29(Suppl 1):S65-S68

425. Fontaine D, Lazorthes Y, Mertens P, Blond S, Géraud G, Fabre N, Navez M, Lucas C, Dubois F, Gonfrier S, Paquis P, LantériMinet M (2010) Safety and efficacy of deep brain stimulation in refractory cluster headache: a randomized placebo-controlled double-blind trial followed by a 1-year open extension. J Headache Pain 11(1):23-31 (comment in J Headache Pain 11(1):2122, 2010)

426. Bartsch T, Paemeleire K, Goadsby PJ (2009) Neurostimulation approaches to primary headache disorders. Curr Opin Neurol 22:262-268

427. Castien RF, van der Windt DA, Grooten A, Dekker J (2011) Effectiveness of manual therapy for chronic tension-type headache: a pragmatic, randomised, clinical trial. Cephalalgia 31(2):133-143 (epub 2010 Jul 20)

428. Lipton RB, Pearlman SH (2010) Transcranial magnetic stimulation in the treatment of migraine. Neurotherapeutics 7:204-212

429. Calhoun AH, Ford S (2007) Behavioral sleep modification may revert transformed migraine to episodic migraine. Headache 47:1178-1183

430. Pieterse H, Kuster JA, Van Bortel LM (2007) Is the Migraid device an asset in the non-pharmacologic treatment of migraine? Acta Neurol Belg 107(2):40-46

431. Mongini F, Ciccone G, Rota E, Ferrero L, Ugolini A, Evangelista A, Ceccarelli M, Galassi C (2008) Effectiveness of an educational and physical programme in reducing headache, neck and shoulder pain: a workplace controlled trial. Cephalalgia 28(5):541-552

432. Stokes DA, Lappin MS (2010) Neurofeedback and biofeedback with 37 migraineur: a clinical outcome study. Behav Brain Funct 2:6-9

433. John PJ, Sharma N, Sharma CM, Kankane A (2007) Effectiveness of yoga therapy in the treatment of migraine without aura: a randomized controlled trial. Headache 47(5):654-661

434. Nickel A, Hillecke T, Argstatter H, Volker, Bolay Y (2005) Outcome research in music therapy. A step on the long road to an evidence 7-based treatment. Ann N Y Acad Sci 1060:283-293

435. Andrasik F (2007) What does the evidence show? Efficacy of behavioural treatments for recurrent headaches in adults. Neurol Sci 28(suppl 2):570-577
436. Grazzi L, Andrasik F, D’Amico D, Leone M, Usai S, Kass SJ, Bussone G (2002) Behavioral and pharmacologic treatment of transformed migraine with analgesic overuse: outcome at 3 years. Headache 42(6):483-490

437. Symvoulakis EK, Clark LV, Dowson AJ, Jones R, Ridsdale L (2007) Headache: a "suitable case" for behavioural treatment in primary care? Br J Gen Pract 57:231-237

438. Rains JC, Poceta S (2006) Headache and sleep disorders: review and clinical implications for headache management. Headache 46:1344-1363

439. Maher C (2001) A randomized controlled trial of chiropractic spinal manipulative therapy for migraines. J Manip Phisiol Ther 24(2):143-144

440. Nelson CF, Bronfort G, Evans R, Boline P, Goldsmith C, Anderson AV (1998) The efficacy of spinal manipulation, amitriptyline and the combination of both therapies for the prophylaxis of migraine headache. J Manip Physiol Ther 21(8):511-519

441. Sandor PS, Afra J (2005) Nonpharmacological treatment of migraine. Curr Pain Headache Rep 9(3):202-205

442. Bronfort G, Haas M, Evans R, Leininger B, Triano J (2010) Effectiveness of manual therapies: the UK evidence report. Chiropr Osteopat 18:3

443. Lawler SP, Cameron LD (2006) A randomized, controlled trial of massage therapy as a treatment for migraine. Ann Behav Med 32(1):50-59

444. Marcus DA, Scharff L, Mercer S, Turk DC (1998) Nonpharmacological treatment for migraine: incremental utility of physical therapy with relaxation and thermal biofeedback. Cephalalgia 18(5):266-272 (discussion 242)

445. Diener HC, Kronfeld K, Boewing G, Lungenhausen M, Maier C, Molsberger A, Tegenthoff M, Trampisch HJ, Zenz M, Meinert R (2006) Efficacy of acupuncture for the prophylaxis of migraine: a multicentre randomised controlled clinical trial. Lancet Neurol 5(4):310-316

446. Teepker M, Hötzel J, Timmesfeld N, Reis J, Mylius V, Haag A, Oertel WH, Rosenow F, Schepelmann K (2010) Low-frequency rTMS of the vertex in the prophylactic treatment of migraine. Cephalalgia 30(2):137-144

447. Lockett DM, Campbell JF (1992) The effects of aerobic exercise on migraine. Headache 32(1):50-54 (erratum in: Headache Apr;32(4):187)

448. Alpay K, Ertas M, Orhan EK, Ustay DK, Lieners C, Baykan B (2010) Diet restriction in migraine, based on IgG against foods: a clinical double-blind, randomised, cross-over trial. Cephalalgia 30(7):829-837

449. Shevel E (2005) Craniomandibular muscles, intraoral orthoses and migraine. Expert Rev Neurother 5(3):371-377

450. Oh MY, Ortega J, Bellotte JB, Whiting DM, Alo K (2004) Peripheral nerve stimulation for the treatment of occipital neuralgia and transformed migraine using a $\mathrm{C} 1-2-3$ subcutaneous paddle style electrode. A technical report. Neuromodulation 7:103-112

451. Guyuron B, Kriegler JS, Davis J, Amini S (2011) Five-year outcome of surgical treatment of migraine headaches. Plast Reconstr Surg 127(2):603-608

452. Granato A, Chiodo Grandi F, Stokelj D, Musho S, Pizzolato G (2010) Acupunture in tension-type headache. Neuroepidemiology 35:160-162

453. Biondi DM (2005) Physical treatments for headache: a structured review. Headache 45(6):738-746 (review)

454. Castien RF, van der Windt DA, Dekker J, Mutsaers B, Grooten A (2009) Effectiveness of manual therapy compared to usual care by the general practitioner for chronic tension-type headache: design of a randomised clinical trial. BMC Musculoskelet Disord 10:21 
455. Grunnet-Nilsson N, Bove G (2000) Therapeutic manipulation of episodic TTH. A randomized, controlled clinical trial. Ugeskr laeger 162(2):174-177

456. Lenssinck ML, Damen L, Verhagen AP, Berger MY, Passchier J, Koes BW (2004) The effectiveness of physiotherapy and manipulation in patients with tension-type headache: a systematic review. Pain 112(3):381-388 (review)

457. Torelli P, Jensen R, Olesen J (2004) Physiotherapy for tensiontype headache: a controlled study. Cephalalgia 24(1):29-36

458. van Ettekoven H, Lucas C (2006) Efficacy of physiotherapy including a craniocervical training program for TTH; a randomized clinical trial. Cephalalgia 26(8):983-991

459. Keller E, Bzdek VM (1986) Effects of therapeutic touch on tension headache pain. Nurs Res 35(2):101-106

460. Ekberg E, Vallon D, Nilner M (2002) Treatment outcome of headache after occlusal appliance therapy in a randomised controlled trial among patients with temporomandibular disorders of mainly arthrogenous origin. Swed Dent J 26(3):115-124

461. Ambrosini A, Vandenheede M, Rossi P et al (2005) Suboccipital injection with a mixture of rapid-and long-acting steroids in cluster headache: a double- blind placebo-controlled study. Pain 118:92-96

462. Donnet A, Tamura M, Valide D, Regis J (2006) Trigeminal nerve radiosurgical treatment in intractable chronic cluster headache: unexpected high toxicity. Neurosurgery 59(6):1252-1257

463. Kano H, Kondziolka D, Mathieu D, Stafford SL, Flannery TJ, Niranjan A, Pollock BE, Kaufmann AM, Flickinger JC, Lunsford LD (2011) Stereotactic radiosurgery for intractable cluster headache: an initial report from the North American Gamma Knife Consortium. J Neurosurg 114(6):1736-1743 (epub 2010 Apr 30)

464. Jarrar RG, Black DF, Dodick DW, Davis DH (2003) Outcome of trigeminal nerve section in the treatment of chronic cluster headache. Neurology 60(8):1360-1362

465. McClelland S 3rd, Tendulkar RD, Barnett GH, Neyman G, Suh JH (2006) Long-term results of radiosurgery for refractory cluster headache. Neurosurgery 59(6):1258-1262

466. McClelland S 3rd, Barnett GH, Neyman G, Suh JH (2007) Repeat trigeminal nerve radiosurgery for refractory cluster headache fails to provide long-term pain relief. Headache 47(2):298-300

467. Taha JM, Tew JM Jr (1995) Long-term results of radiofrequency rhizotomy in the treatment of cluster headache. Headache 35(4): 193-196

468. Magis D, Allena M, Bolla M, Pasqua VD, Remacle JM, Schoenen J (2007) Occipital nerve stimulation for drug-resistant chronic cluster headache. A prospective pilot study. Lancet Neurol 6:314-321

469. Burns B, Watkins L, Goadsby PJ (2009) Treatment of intractable chronic cluster headache by occipital nerve stimulation in 14 patients. Neurology 72:341-345

470. Leone M, Franzini A, Cecchini AP, Brogli G, Bussone G (2010) Hypothalamic deep brain stimulation in the treatment of chronic cluster headache. Ther Adv Neurol Disord 3(3):187-195

471. Leone M (2006) Deep brain stimolation in headache. Lancet Neurol 5:873-877 